\title{
AN EXPLORATION OF LANGUAGE AND NURSING PRACTICE TO IMPROVE COMMUNICATION IN THE CONTEXT OF EAR SYRINGING
}

by

Elsa June Lally

A Thesis submitted to the Victoria University of Wellington in partial fulfillment of the requirements for the degree of Master of Arts (Applied) in Nursing 



\begin{abstract}
Action research is a critical reflective process that involves spirals of cycles if of planning, acting, reflecting/evaluating and replanning the next cycle. This action research inquiry explores communication and nursing practice in an effort to improve practice and enhance patient care. Implications of this study indicate that action research is a method that works, and it is a satisfying way of challenging and changing nursing practice.
\end{abstract}

Using ear syringing as a procedure, in the general practice setting and at two separate surgeries, another Practice Nurse and I co-researched this study during working hours.

12 people consented to participate in the research that involved the audiotaping of each ear syringing interaction. Following each transcription of the recording, my coresearcher and I read our own and then each other's transcripts, and listened to the recordings. We then met to discuss and reflect on our findings and to plan the next cycle.

Throughout the process, my co researcher and I found a number of areas of practice we could change or enhance. Changes included the use of technical language such as "contraindications" and "auditory meatus", the side effects of syringing, improvements in communicating situations where ear syringing is not recommended and the options available, and post procedure information. These changes became a significant challenge and areas for improvement when both my co-researcher and I forgot the changes, thus repeating previous errors and omissions. This factor highlighted the need to practise any changes prior to interactions, and to have a cue card on hand to facilitate recollection and to cement improvements into practice.

Although time constraints limited this inquiry to three cycles, at the final meeting we agreed to continue the reflective process we had begun to explore our practice. 


\section{Acknowledgements}

My first acknowledgement must be to my supervisor, Kathy Nelson, who has been unstinting in her generous support, advice, and feedback that has enabled me to complete this degree. I acknowledge and thank the lecturers and staff of the School of Nursing and Midwifery at Victoria University of Wellington. It was a pleasure to meet so many inspirational people.

I am very grateful for the support and energy of my co-researcher, Diane Auld, whose insight, understanding and humour helped make the research process an interesting and informative one. I offer thanks to the patients who participated in this study and continued to express interest in how my study was progressing. Thank you to my friend and work-mate, Colleen Trewavas, who graciously took over transcribing the audiotaped interactions when the previous transcriber was unable to continue. The support of my employer, Dr Alan Brookes and Diane's Employers, Drs David Low and Andy Dawson, was instrumental in my being able to pursue my inquiry, as was the assistance given to me by Jonathon Port, whose suggestions and practical help with formatting was instrumental in finalising this thesis.

I acknowledge the love and support of my family. My husband, David, listened to my anxieties and stresses and affirmed my ability to achieve my goal of a Masters degree and my children, Sandra, Renee and Chris gave valuable feedback and encouragement, as well as shoulders to lean on. I thank my sister, Helen, for her encouragement and sustenance and my niece, Emma, for her generous solace, advice and moral support and her unstinting sharing of her Dunedin flat in the early stages of my study.

Finally, but not least, I thank my Masters colleagues who journeyed with me over the years. These nurses affirm my belief that the health and wellbeing of the people is in expert and caring hands and it has been a privilege to have met such motivated and enlightened individuals. 
$\begin{array}{ll}\text { Table of Contents } & \text { Page }\end{array}$

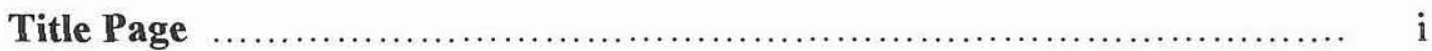

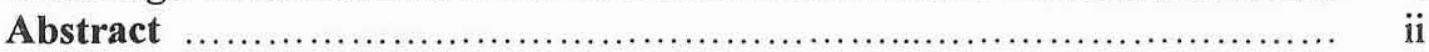

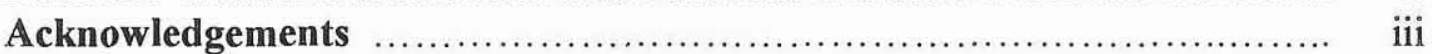

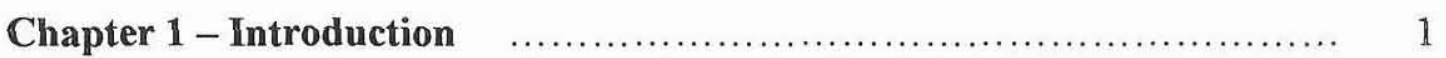

1.1 An introduction to practice nursing and reflection $\ldots \ldots \ldots \ldots \ldots \ldots \ldots \ldots . . \ldots \ldots$

1.2 The need to work with reflection to improve practice $\ldots \ldots \ldots \ldots \ldots \ldots \ldots . . . \ldots \ldots$

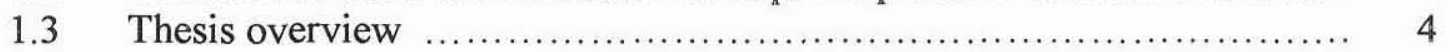

Chapter 2 - Practice nursing or practising nursing $\ldots \ldots \ldots \ldots \ldots \ldots \ldots \ldots, 7$

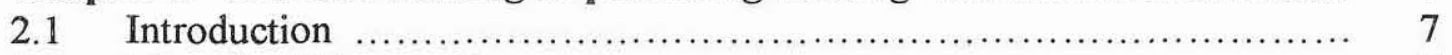

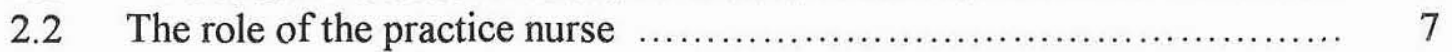

2.2.1 Practice murse education ........................................... 10

2.3 Accountability frameworks governing the work of the practice nurse .... 12

2.3.1 Legislation ...................................................... 12

2.3.2 Accountability .................................................. 12

2.3.3 Minimising risk ................................................. 14

2.3.4 Medical misadventure ......................................... 15

2.3.5 Informed choice and consent .................................... 15

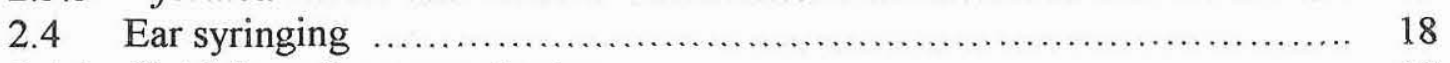

2.4.1 Guidelines for ear syringing ................................... 18

2.4.2 Indications for ear syringing ................................... 19

2.4.3 Contraindications to ear syringing .............................. 19

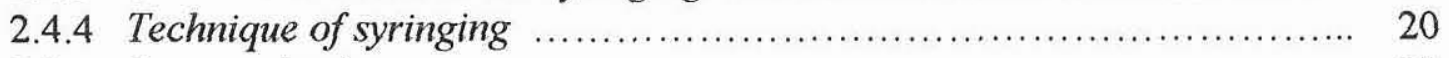

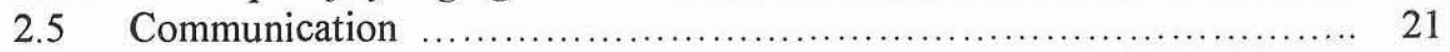

2.5.1 Language ...................................................... 21

2.5.2 Language as power ............................................ 23

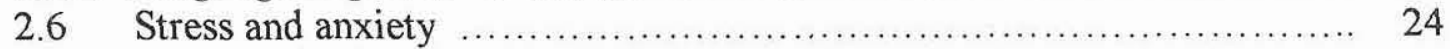

2.6.1 Relationship between communication and stress ..................... 24

2.7 Conclusion .................................................... 26

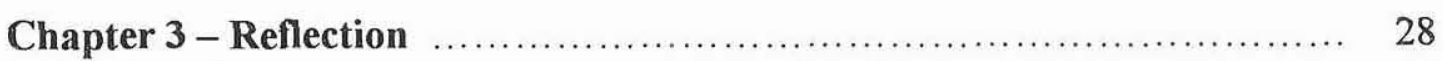

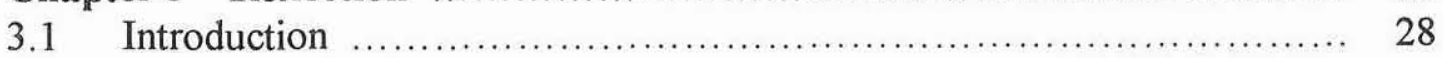

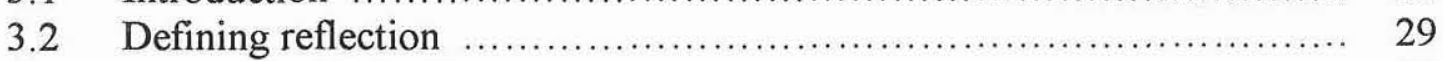

3.2.1 Influence of John Dewey ....................................... 29

3.2.2 Influence of Donald Schön ..................................... 31

3.3 Elements and levels of reflective practice.......................... 33

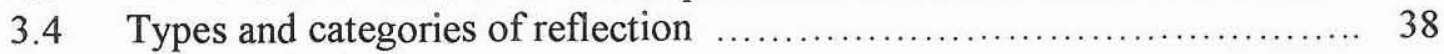

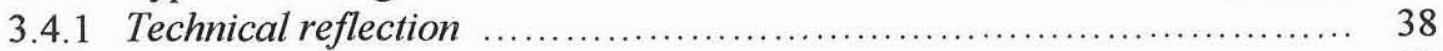

3.4 .2 Practical reflection............................................... 39

3.4.3 Emancipatory reflection ....................................... 39

3.5 Political constraints of the work environment........................ 41

3.6 Values, strengths and weaknesses of reflection ....................... 42

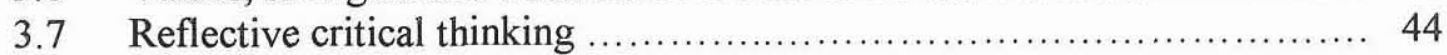

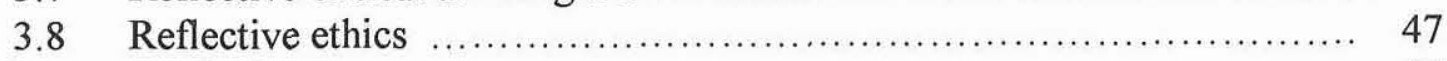

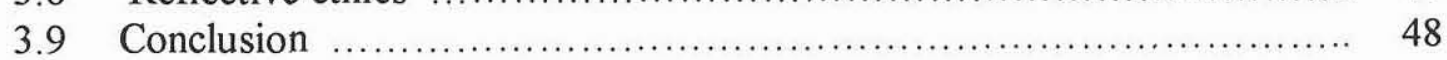




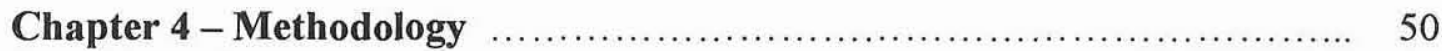

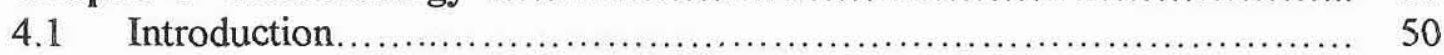

4.1.1 Reasons for choosing action research ............................ 51

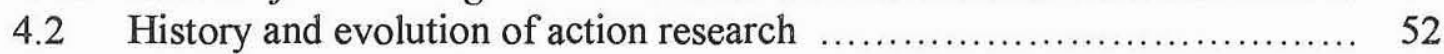

4.2 .1 Critical social origins ........................................ 52

4.2.2 Kurt Lewin's influence .......................................... 53

4.2 .3 Expansion into education ...................................... 54

4.2.4 Action research and nursing ....................................... 55

$4.3 \quad$ Action research .................................................. 55

4.3.1 Insight into action research ...................................... 55

$4.4 \quad$ Approaches to action research .................................... 57

4.4.1 Collaborative approaches to action research ....................... 57

4.4 .2 Outsider, insider models ........................................ 58

4.4.3 Double act model .................................................. 59

4.5 Action research typologies .................................... 60

4.5.1 Participatory action research (PAR) and participatory research (PR) .... 60

4.5.2 PAR and action research ........................................... 60

4.5 .3 Praxis research ................................................. 61

4.5.4 Generative action research .................................... 61

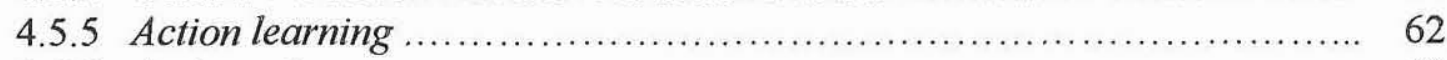

4.5.6 Action science ................................................ 63

4.5.7 My comparison of participatory and action research inquiries ........... 64

4.5.8 Making sense of this knowledge .................................. 65

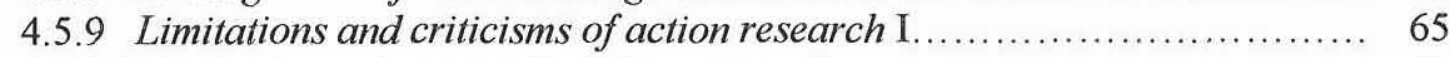

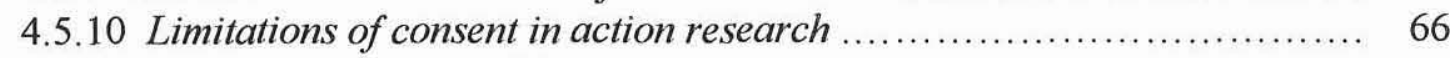

4.5.11 Limitations of ownership ...................................... 67

4.5.12 Considerations of my research limitations .......................... 67

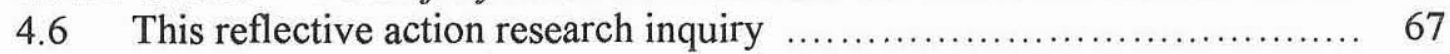

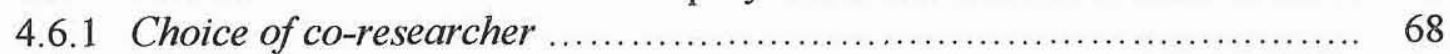

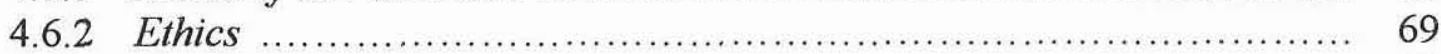

4.6.3 The research process ............................................ 70

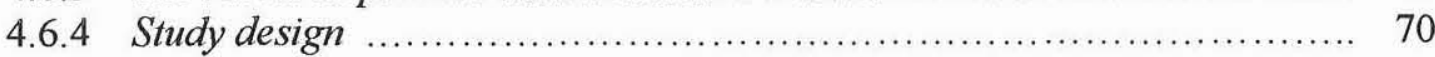

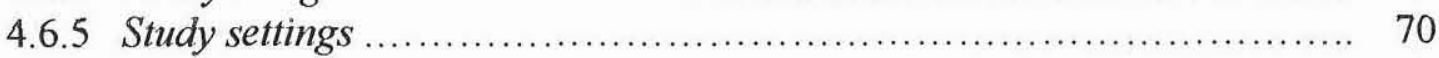

4.6.6 Recruitment of patients ......................................... 71

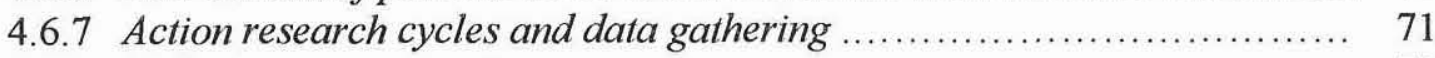

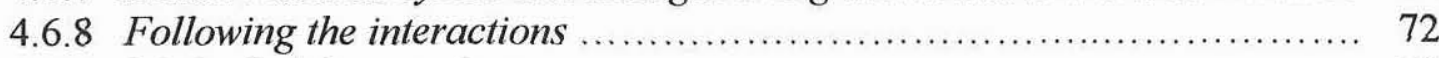

4.6.9 Method of data analysis ........................................ 73

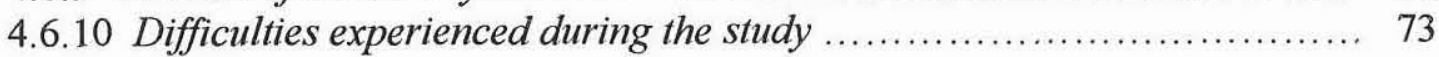

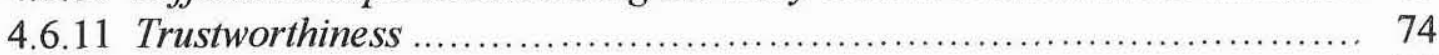

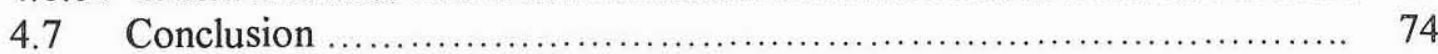

Chapter 5 - Ear syringing across the three cycles..................... 76

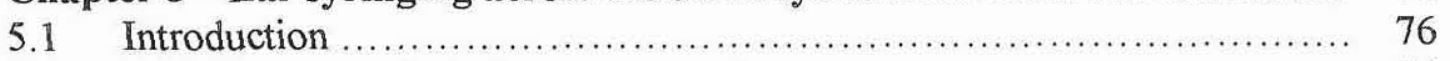

5.2 What we accomplished in our research ............................ 76

5.2 .1 Changes ...................................................... 77

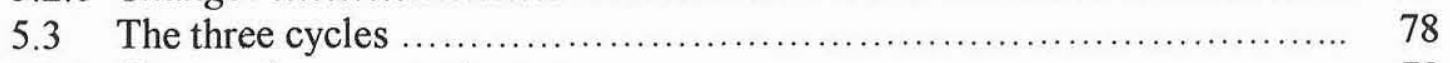

5.3 .1 First cycle: reconnaissance ...................................... 78

5.3 .2 Second cycle ................................................. 81

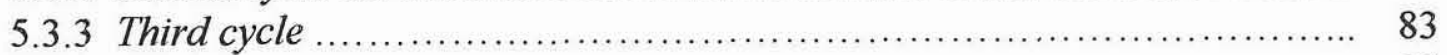

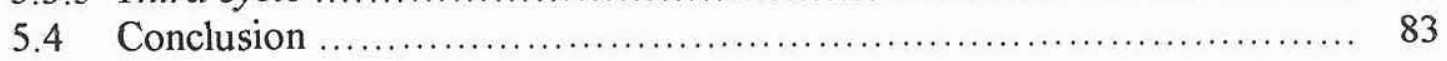


Chapter 6 - Process and inquiry into Communication and

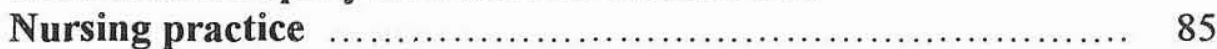

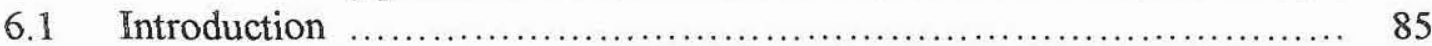

6.2 What I found about the research process $\ldots \ldots \ldots \ldots \ldots \ldots \ldots \ldots \ldots . \ldots 5$

6.2 .1 Recruitment of co-researcher and participants........................ 86

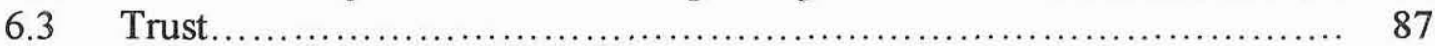

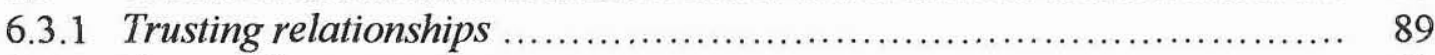

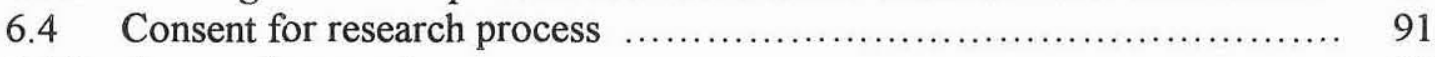

6.4.1 Assumed consent .............................................. 92

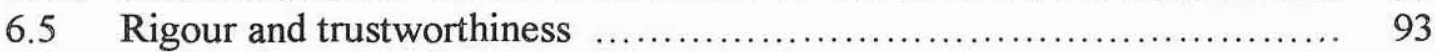

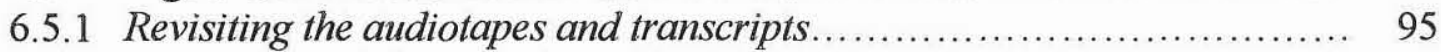

6.6 Doing research in the real world f................................. 95

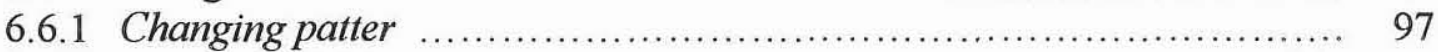

6.6.2 Getting it right .................................................. 99

6.6.3 Ownership of research .......................................... 100

6.7 Communication ...................................................... 100

6.7.1 Verbal and non-verbal communication pertaining to ear syringing ........ 101

6.8 Conclusion ..................................................... 102

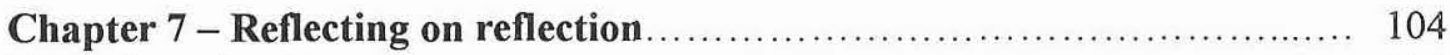

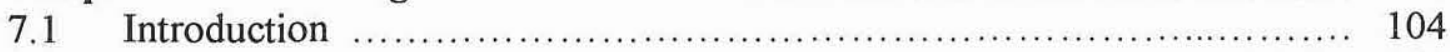

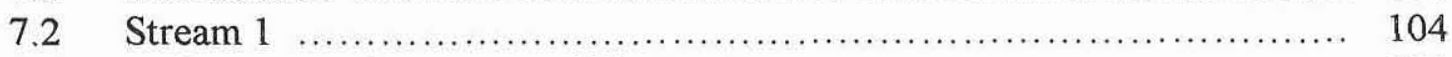

7.2.1 Reflection on the process of the inquiry............................ 104

7.2.2 Reflection on meetings, audiotapes and transcripts ................... 105

7.2 .3 Reflection on patter ............................................ 106

7.2 .4 Reflection on trust ............................................. 107

7.2.5 Reflection on practice nurse education ................................. 108

7.3 What the findings meant in relation to the literature .................... 109

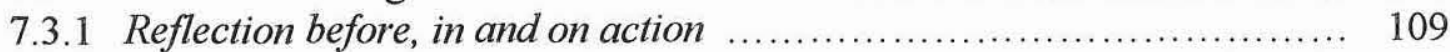

7.3.2 Formal versus informal reflection .................................. 110

7.3.3 Reflection on Taylor's (2000) work ................................... 111

7.3.4 Reflection on my practice, communication and consent ............... 112

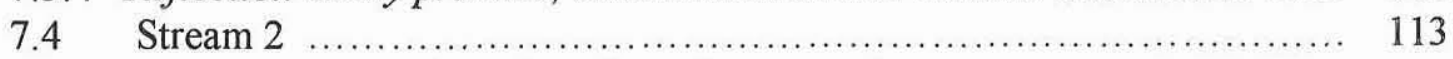

7.4.1 Reflection on my learning about the research process ................. 113

7.5 Conclusion.................................................. 115

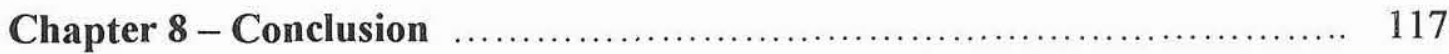

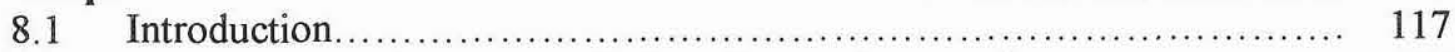

8.2 Conclusions and recommendations for nursing practice............... 117

8.2.1 Changes to the ear syringing process .............................. 117

8.2 .3 Changes take time................................................ 118

8.2.4 Other areas that could look at nursing practice .......................... 119

8.3 Conclusions and recommendations for nurses' use of reflection ......... 119

8.3.1 One co-researcher was enough.................................... 119

8.3 .2 Formal and informal reflection.................................. 120

8.3 .3 Recommendations for practice nursing ........................... 121

8.4 Conclusions and recommendations regarding action research and nursing 122

8.4.1 Methodology for nursing ....................................... 122

8.4.2 Number of participants and cycles................................. 122

8.4 .3 Continuing cycles............................................... 123 
8.4.4 General considerations............................................ 124

8.5 Limitations of this study............................................ 125

8.6 Celebration of the inquiry and its people............................ 126

Appendices

Appendix 1. Employer's consent form ................................... 134

Appendix 2. Regional Ethics Committee approval ......................... 136

Appendix 3. Guidelines for ear syringing .............................. 137

Appendix 4. Patient information sheet …................................ 139

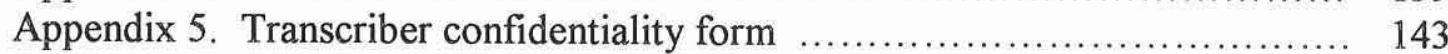

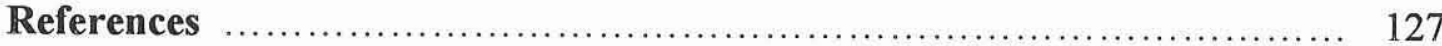

List of Tables

Table 1. Ghaye and Lilliman's 12 principles of reflective practice.

List of Figures

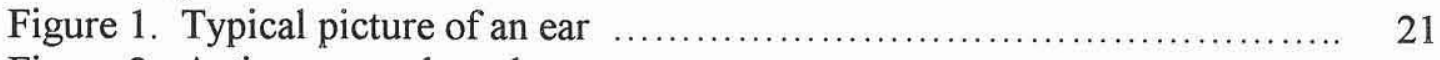

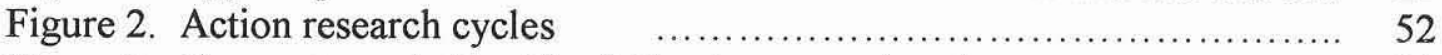

Figure 3. Cue card created by Elsa following second cycle................... 99 


\section{Chapter 1 - Introduction}

\section{1 - An introduction to practice nursing and reflection}

Because of my abiding interest in finding ways of fostering my practice to provide better patient care, the question of my research became one of intense thought and reflection. It was this contemplation that indicated the need to work with reflection to improve practice. Therefore the research question is "In the general practice setting, and using action research methodology, what do my co-researcher and I need to do to improve our communication and practice?"

This introductory chapter describes the area of my inquiry exploring communication and nursing practice to improve nursing practice in the context of ear syringing, and why I chose it for this research. I outline the chapters that make up this thesis and the reason that I find reflection and improving practice meaningful and valuable to me. Following discussions with colleagues, I perceived that patient interactions during the ear syringing procedure would be an appropriate and accessible means of assessing the need for changes to improve our communication.

Although I recognise that developments to nursing practice can follow many paths such as formal education, self-directed learning, courses, conferences and seminars, the medium I chose to explore how I could achieve my personal and research aim of improving practice was through reflection and reflective practice. An investigation of the qualitative research literature brought me to the conclusion that an action research methodology with its focus on change and improvement would be an appropriate vehicle for this inquiry.

Practice nurses (PNs), of which I am one, are Registered Nurses who are employed most often in the private sector by general practitioners (GPs), although other organisations such as union health centres engage PNs. I have been in one surgery with the same employer for 14 years, and in that time I have experienced many changes in the range of activities that I have been able to undertake, as well as opportunities to extend my scope of practice. A PN's work is varied and interesting and covers most aspects of primary 
health care, including, but not limited to, childhood immunisations, lifestyle advice, wellhealth checks, wound care, diabetes and asthma education, and screening.

Effective communication by listening as well as talking, and making a human connection early in any consultation process has beneficial consequences in how the consultation proceeds. The professional knowledge and skill of PNs is an important health care resource, and as I strive to provide expert care to people within the practice population, I need to continually review and reflect on my practice, and to make changes when required. In addition, I endeavour to frame the patients' interactions with me, as a health professional and as a person, to be as comfortable and free from stress and anxiety as is possible given the circumstances and environment. Advancing my expertise in primary health care ensures that I continue to apply best practice methods and ensure that those in my care receive the nursing care to which they are entitled.

In general practice, one of the regular activities of PNs is ear syringing. This procedure is used to remove wax that is blocking the ear canal and causing deafness and distress. While it is not the preferred task of many nurses, I have always found it a very satisfying one because of its (usually) swift and positive outcome. For example, some people arrive at the surgery distressed and deafened from wax obstructing the ear canal, and leave having their hearing restored. Other people, who already wear hearing aids, have improved hearing once the wax is no longer blocking the aid. However, while ear syringing is a simple procedure to perform once trained, like all such tasks in nursing practice, it can cause some patients to feel stressed and anxious. This is especially so if it is the first time patients have had their ears syringed, they have had an experience of ear syringing that has not been satisfactorily performed, the outcome has not met patient expectations, or the nurse has been too busy or distracted to listen to patients responsively.

While ear syringing is common in general practice, there are contraindications to the procedure such as previous ear surgery, as well as a risk of perforating the ear drum if it has been weakened in any way. For those reasons, PNs need to understand their responsibilities and accountabilities that are laid down by their governing body, the Nursing Council of New Zealand, that regulates nursing practice, and its Code of Conduct for Nurses and Midwives (1995). In addition, the New Zealand Nurses 
Organisation's Standards for Nursing Practice (2001) and Practice Nurse Standards (2001) and Code of Ethics (1995) guide nursing practice. Other organisations' standards and responsibilities that nurses need to have cognisance of are The Health and Disability Commissioner Act (1994) and the Accident Rehabilitation and Compensation and Insurance Act (1992), commonly called "ACC". While these organisations have their particular fields of interest, they all have the protection of society as a common goal. It is important that nurses use mediums such as reflection to assist their practice and uphold their commitment to society that ensures that nursing care is of the highest standard. People expect nurses to update their knowledge and skill and for this new information and competencies to be reflected in enhancement of the nurse/patient partnership. As nursing is about caring for people to the best of our knowledge and abilities and within our scope of practice, it is important that we continually ask questions about our practice and explore potential answers.

\section{2 - The need to work with reflection to improve practice}

Reflecting on my practice has been instrumental in helping me in the quest to evolve and make improvements to my practice. Because everyone thinks in numerous and diverse ways and depths, thoughtful reflection can be carried out before the task is undertaken, while the task is being carried out and following its completion. Reflection does not need to rely on anyone else to make it happen, and it can be held over to a more convenient time if necessary or desirable. For me, reflection and reflective practice are fascinating and effective ways to enhance my skill and knowledge, and in addition, I can pass on my new knowledge to benefit others through PN education session, newsletters and informal conversations with colleagues. Nevertheless, I believed that it was important for me to explore a more structured approach such as research to continue learning. It was a consequence of these observations and the desire to work with reflection to improve practice that led me to the research question. As the question is practice-based, and because ear syringing is a familiar task to most PNs, I chose to work collaboratively with a supportive and enthusiastic colleague from another surgery as a co-researcher in an action research inquiry.

This action research inquiry was undertaken in the nurses' own workplaces and during normal working hours and to pre-empt any possible misunderstanding, I asked my coresearcher to read the information sheet. Because this was action-based research with a 
co-researcher, my colleague consented by her participation. In addition, each of us required our employer's consent (see Appendix 1) who were provided with information sheets explaining the inquiry and consent forms to read and sign. The study received ethics approval from the regional ethics committee.

Our role of listening and reflecting that included observations of our practice, would affirm our experience and ourselves. As I did not wish to place "vulnerable" people in a possibly unsafe position as active participants in a research project, I took care to find a process where I could examine my practice, and to find a tool that could be applied to numerous nurse/patient interactions. To demonstrate how improvements in communication could benefit patients, action research's spirals of planning, acting, reflecting/monitoring and replanning methodology was the ideal choice, and ear syringing the consummate procedure. My co-researcher and I believed that if our communication with people was improved, we would all benefit from the experience, with patients feeling confident that we were using best practice methods, and that we cared about them.

\section{3 - Thesis overview}

This research is presented in eight chapters, with each chapter exploring aspects and perspectives of the inquiry. Although I undertook this research with a co-researcher, there are occasions that I have included my own thoughts and private reflections. Although it might become confusing to readers, in describing what occurred, as well as demonstrating a point of view of writing about action research and reflective practice, I have, at times, used 'we' or 'our', as well as 'I' and 'my', in my explanations

Chapter 1 of this thesis is this introductory Chapter, Chapter 2 explores the background to the inquiry looking at the role of practice nurses and their responsibilities and accountabilities, informed choice and consent and nurses' education. The procedure of ear syringing is explained as well as how language can influence the stress and anxiety patients might experience when arriving at the surgery for procedures such as ear syringing.

As reflection is a major part of the inquiry, Chapter 3 explores the different types, approaches and thoughts about reflection and reflective practice in nursing. I have used 
Beverley Taylor's (2000) work on reflective practice as a foundation because it resonates with my own attitude to reflection. I explore Schön's (1983) reflection-in-action and reflection-on-action as well as Greenwood's (1993) reflection-before-action elements of reflection. In addition, I discuss how different types of reflection are embodied in our research and how critical reflection can influence practice.

Chapter 4 explores the critical social beginnings of action research and its continuing upward spiral of cycles that encourage ongoing reflection, describing the collaborative approaches as well as different types of action research such as participatory action research, praxis research, and generative action research. While action research is my chosen methodology, I recognise that it has its critics and its limitations, and these will be discussed in this chapter. I also describe how I chose my co-researcher and the research process. The study design, the setting for the inquiry, ethics, recruitment, trustworthiness, method of data analysis as well as the difficulties my co-researcher and I experienced during the study.

Because my understanding of research has been based on the conventional way of doing things, I found that the interconnectedness of the analysis and what this means caused me some difficulty in separating the data and process from the reflections. The following three chapters present the analysis of each of the three aspects of the inquiry. Chapter 5 describes and discusses the action research process that involved my co-researcher and I in three cycles of planning acting, observing reflecting and replanning. Our findings of the timing of the cycles, our observations of the interactions between us as co-researchers and what we accomplished over the research period. Chapter 6 discusses issues relating to recruitment, trust, ownership of the research, patter, consent, research in the real world rigour and trustworthiness. Chapter 7 is separated into two streams. Stream 1 discusses the reflection process and how we used it to improve our communication and practice, and what the finding mean in relation to the literature. Stream 2 describes my own Master of Arts (Applied) journey of the research process using sections from my own journaling as illustrations. This journey has demonstrated to me that as this thesis has progressed, my insight, understandings and thought processes associated with reflection and action research have developed and I am encouraged to continue this development. 
The concluding chapter, Chapter 8 , revisits the inquiry process and how it has influenced my co-researcher's and my practice. It gives suggestions of how our findings could be utilised on other areas of practice such as immunisation and cervical screening as well as ideas for further research. Importantly, I consider it adds to the purpose and benefits of reflection. 


\section{Chapter 2-Practice nursing or practising nursing}

\section{1 - Introduction}

"Are you still practising, then?" is a comment associated with the title of practice nurse most practice nurses have heard from patients at one time or another. My answer to this is yes and no. Yes, because experts in any field of endeavour keep practising to remain experts, and no, because the title reflects the nursing care we give is in a general practice. As a part of my striving for excellence, this chapter details the background to my inquiry exploring language and nursing practice to improve communication in the context of ear syringing. I describe my role as a practice nurse (PN) employed by a general practitioner (GP), the legislation that governs my practice and the role of the Nursing Council of New Zealand (NCNZ), the Health and Disability Commission and the Accident Compensation Corporation (ACC). In addition, discussion of my accountability and responsibility to the patient, employer and the NCNZ will show the need for me to balance the tension between these bodies. I describe how PNs learn their role in primary health care and how my co-researcher and myself were trained to syringe ears. This is accompanied by a description of the ear syringing procedure, as well as the dilemmas that PNs experience pertaining to the process of gaining informed consent for the procedure. Included in this section is an explanation of the indications and contraindications for this procedure. As clear, effective communication is critical in minimising possible risk to the patient of damage to the ear by syringing, the nurse, employer and surgery, through medical misadventure claims, ways of minimising these risks are explored. I conclude this chapter with a discussion of stress and anxiety patients might experience when they require such procedures in general practice, and how nursing practice can influence these emotions and therefore the outcome of the interaction.

\section{2 - The role of the practice nurse}

A practice nurse is defined by the College of Practice Nurses NZNO. as:

"A Registered General or Comprehensive Nurse whose main focus is Practice Nursing in the delivery of Practice Nursing Services and, working with a General Practitioner in the Primary Health Care setting and/or the facilitation of educational and professional development of Practice Nurses. The Practice Nurse works as a member of the primary health care team and, with the family doctor, acts as a client's advocate. It is recognised that the 
role and function of the Practice Nurse may vary widely from practice to practice dependent on such factors as practice population, special interests of the doctor and the geographical location. As a member of the primary health care team the Practice Nurse is professionally accountable for all aspects of nursing care delivery." (2001, p. 4)

Because PNs work in close proximity with their GPs and share working space and equipment, the role distinguishes us from other nursing disciplines such as those employed by District Health Boards, private hospitals and private nurse-run positions.

In the general practice setting, PNs can be working with several GPs in a medical centre, or a single employer as I am, and in small practices such as mine, rooms often have multiple functions and purposes. The size and number of the rooms, the availability for procedures such as ear syringing and immunisation, and privacy concerns impact on the work of the nurse and on the way information is communicated. Where I work the physical environment for procedures such as ear syringing and wound care is called "the kitchen" and is separated from the rest of the surgery by a curtain. It is so named because the surgery was once a private dwelling and in the remodeling certain sections retained domestic features such as the kitchen sink and electric stove. This area is also used as a staff room for tea breaks, and cups and food are often still on the bench waiting to be consumed at the same time as a patient is there waiting for treatment. My co-researcher, however, has dedicated rooms for patient treatments and staff-room for tea breaks.

The type of work my PN co-researcher and I carry out in our general practices is very similar. Employed by GPs, we give vaccinations, undertake cervical screening and wellhealth checks, as well as annual diabetes reviews and practice audits. We triage accidents and emergencies, as well as give telephone advice. Our work means that we assist the GP with minor surgery as well as act as a chaperone advocate for patients when required. We take laboratory samples such as blood and urine, and act on referrals from other health professionals as well as referring patients to other health-care agencies. In addition, to these tasks, I carry out electrocardiograms, tympanograms and audiograms, while my co-researcher specialises in travel vaccinations. 
Willis, Congdon and Litt (1998) point out, that a significant amount of PN's work is by referral from the GP, however, for those individuals who require a procedure to be repeated over time such as ear syringing, some GP employers authorise nurses to assess patients and complete the procedure without further GP consultation. This authorisation usually follows an evaluation by the GP of the competency of the PN to carry out such procedures. From discussions I have had with PNs from throughout New Zealand, I have ascertained that in a number of practices including mine, GPs prefer to routinely assess each patient on every occasion prior to ear syringing, and sometimes before and after the procedure is undertaken. Reasons put forward by both nurses and GPs for this latter preference range from the manner in which GPs are funded through the General Medical Services Benefit (GMS) that requires GPs to see patients to be able to claim, (PN's are not able to claim) to ensuring that the patient is well cared for by the GP. The GMS benefit, while it is a benefit for patients who hold a Community Services Card that entitles them to reduced medical fees, or are under the age of 18 years, is claimed by the GP from the Health Funding Authority. There are many instances however, where GPs prefer PNs to have their own consultation list and exact a fee for their service, the GPs only consulting with the patient after referral from the PN.

When analysing the amount and type of work allocated to PNs by GP employers, Willis et al. (1998) found that the relationship between the GP and the PN are relevant factors in the type and amount of work PNs are asked to perform. If the relationship is one of trust and confidence shared between the PN and GP, then the variety and responsibility of the work is greater. Willis et al.'s contention supports my own experience because, over time, as my employer has gained confidence in my knowledge and competence, I have experienced my clinical judgement acknowledged and respected and the range of work and responsibility has been increased. The close association between employee and employer raises pertinent issues concerning responsibility and accountability for PNs and employers.

In many practices it is often a practice nurse who is the first health professional who makes the initial assessment of a patient's concern about blocked ears, while at other times, the referral for ear syringing might come from the GP. Discussion with other PNs confirms my experience that whoever assesses the patient it is usually the PN who carries out the ear syringing procedure. Whatever the context, in my experience most PNs 
"imbue the task with a professional frame of reference" (Christensen, 1995, p. 190) as each contact with a patient becomes a partnership where the nurse and patient work together through the ear syringing experience to reach an acceptable outcome. To be able to make an accurate assessment of a patient's ears, the PN needs to be educated in ear care. According to Christensen, to be professionally responsible and accountable, nurses need education and knowledge to be safe and competent in their nursing discernment and in their practice.

\subsection{1 - Practice Nurse education}

Within the nursing profession, practice nursing has progressed to become a specialist discipline. Practice Nurse Accreditation Certificates and Vaccinators Certificates, while not mandatory, are expected to be held by members of the New Zealand College of Practice Nurses NZNO (hereinafter referred to as CPN). These certificates will be significant in obtaining Competency Based Practising Certificates in the future (Dawbin, 2001). As there is no mandatory training in place, the educational needs of PNs have largely been the responsibility of nurses themselves (Docherty, 1996). My own and my co-researcher's training for much of our role was self-directed and it took place while at work, by following another PN's advice or demonstration, and by asking the GP. For example, I learnt suturing by studying illustrations in a book, a conference demonstration, practising on pieces of material, a pig's skin, and by observing GPs. The technique of ear syringing was learnt from instructions and demonstrations by GPs, attending workshops and reading relevant journals and articles. Nursing and medical journals and newsletters continue to be useful sources of knowledge for me. Whether training is undertaken while at work or at specified education sessions, apart from the mannequins required for cardiopulmonary resuscitation (CPR) practise, new learning such as cervical smear taking and ear syringing, is often followed by using trial and error to become competent.

Many regional Divisions of the CPN, including Nelson, provide new PNs with orientation programmes, written information and personal support and advice. The Otago Division developed Telephone Guidelines (1998) for PNs to refer to when they give telephone advice and triage. Other Divisions such as Nelson, have produced guidelines for PNs (2002) covering practical tasks, including but not limited to, immunisation, ear syringing, Depo Provera injections, cervical smear taking and anaphylaxis. Practice Nurse conferences are also sources for education but cost or family 
commitments prevent many nurses from attending. The committees of most PN Divisions attempt to provide high quality education sessions for nurses, but as funding is often a barrier, it is difficult for a significant number of committees to do this. Sponsorship from drug companies and medical suppliers and diagnostic laboratories, as well as the Independent Practitioner Associations (IPA) help with education needs. Post Graduate study in Primary Health Care in Practice Nursing is being offered by some institutions such as the Christchurch School of Medicine and Health Sciences and the Auckland University of Technology. Masters and Doctoral Degrees are also offered by many Universities.

Historically, a number of Polytechnics and Institutes of Technology have offered PN education courses but many have not continued. In discussion with my colleagues I found that the reasons for discontinuation of the courses range from the course not meeting PN's needs, to insufficient numbers registering for the courses. For example, two Practice Nurse papers from The Open Polytechnic of New Zealand I completed in 1996 received such small enrolment numbers that the papers were discontinued after a few months. Anecdotal evidence from colleagues suggests that a significant number of nurses are reluctant to attempt study after many years away from formal education, while others find the cost prohibitive. Further, I have heard nurses expressing reluctance about approaching their employers for monetary assistance. The IPA in this region reimburses travel costs for nurses whose journey to education sessions is more than 100 kilometres, and in rural areas there is contested funding through the IPA GP rural allowance, to offset costs of education. Significantly, in June 2002 the Ministry of Health announced the availability of Primary Health Care Nursing Post Graduate scholarships. I gained my Bachelor of Nursing in 1997 and will complete my Master of Arts (Applied) in Nursing, in 2003. My study has developed skills and knowledge to help me identify and address issues to improve my nursing practice.

Astonishingly and frustratingly for me, I found that some nurses contend that their life experience and training or demonstrations given by their employing GP is sufficient education to practise safely. Practice nurses have reported instances where GPs have employed untrained and inexperienced PN's so that the GP can teach them in the way he or she wishes them to work and carry out procedures, rather than have trained and 
experienced PN's who might have philosophies and practices that might conflict with those of the employer.

Whatever way PN's obtain their practical learning, an understanding of the law and how it affects patients is essential in any interaction with people. Although ear syringing is a simple and, for me, most often a satisfying procedure because of the prompt result, there are many elements inherent in the process and procedure of ear syringing that the nurse needs to take into account to maintain an acceptable level of care. Legislation governing nursing practice is contained in the Nurses Act (1977), its amendments and regulations, such as the Nurses Regulations and the Nurses and Midwives Code of Conduct (1986). Further, the Code of Health and Disability Services Consumer's Rights (1996), and the Privacy Act (1993) are also relevant to health professionals (Burgess, 1996).

\section{3 - Accountability frameworks governing the work of the practice nurse}

\subsection{1 - Legislation}

The Nursing Council of New Zealand (NCNZ) is the regulatory body for nurses and midwives. Through the Nurses Act (1977) the council is responsible to the people for the standards of entry into the profession, and for maintaining those professional standards (Burgess, 1996). This means that the NCNZ is responsible for the registration of nurses and midwives and has the power to discipline a practitioner whose practice or behaviour does not meet the standard required. The NCNZ maintains the register and roll of nurses and midwives permitted to practice, and issues annual practising certificates. According to Burgess this certificate is to remind practitioners of their responsibilities applicable to the legislation and to their individual professional practice.

\subsection{2- Accountability}

All nurses are accountable for their practice and as such are required to maintain certain standards for nursing practice (NZNO, 2001). Also, as a PN I have a further set of standards specifically relating to practice nursing (NZNO, 2001). The NZNO Social Policy Statement (1994, p. 17) maintains that "accountability cannot be claimed in the absence of responsibility, which in turn derives from authority which is granted by virtue of specialised as well as general knowledge". The PN Standards of Practice state that accountability is deemed to be "the acceptance of rights and responsibility for conduct of behaviour. It is the acceptance of responsibility to self, the profession, the client, 

employers and to society as a whole" (NZNO, 2001, p. 9). According to Burgess (1996) each nurse is responsible for maintaining her or his level of competency and standard of practice. The NCZN (1995) states that a nurse is accountable for her actions, where these actions are within her scope of practice and expertise. For example, if the GP requested me to carry out minor surgery, such as excising a mole, it would be outside my scope of practice, skill and knowledge and as I have not been taught that procedure, I would be at risk of legal action if I were to do it.

Any concern I may have regarding a GP instruction or request that I consider outside my competency or scope of practice is my responsibility, and I need to communicate the concern with my employer. I am also responsible for ensuring that any technique I use is safe, and that I take care of the instruments and chattels I use. I am accountable to my profession by following a professional code of ethics, and by being a member of a professional organisation (NZNO, 2001).

In the context of ear syringing, I am firstly accountable to myself as a member of a professional body, and therefore, I am responsible for keeping myself up-to-date with best practice methods and maintaining nursing care skills. My practice must be safe, legal, effective and responsive to the needs of the patient, and I need to maintain up-todate knowledge to deliver what is considered current best practice. Safeguarding the patient from physical and psychological harm and avoidable risk signifies my accountability to my patient. In addition, it means that my practice must be appropriate and acceptable to the patient who is in my care and that the patient's decisions and choices are respected and accommodated. As a part of this accountability, I am also accountable to my employer and the contract I work under (Burgess, 1996).

While PNs and GPs work closely together, tension can occur when a PN's responsibility to the employer conflicts with her or his responsibility to the patient. For instance, a woman arriving at the surgery for a routine cervical smear refuses to see a male GP and insisting that she consult me, would conflict with my employer's instruction to see each patient before a procedure such as this is undertaken. If I ask the patient to wait until I am able to discuss her request with the doctor, she could be waiting for some considerable time, but if I continue with taking the smear, then later informing the doctor of the patient's wishes, this could result in a reprimand for me. I could decline to take the 
smear unless the patient agrees to see the doctor, but this could be unacceptable to the patient. By acceding to the patient's request, I meet my primary responsibility to the patient, but fall short of meeting my responsibility to my employer. In circumstances such as this, the nurse/patient and nurse/doctor relationship plays a significant role in how the situation is managed. In my experience, where trust has been established between the GP and me as a nurse, discussion to resolve issues such as these is less constrained and has a better outcome for everyone. These workplace constraints often result in feelings of conflict because while I am aware that my first priority is to the patient, I am also required to work within my employer's philosophy and concept of how he requires and desires me to work. This tension within the workplace reinforces the need for me to understand the legislation and accountabilities that have relevance to my practice.

Over the many years of my nursing practice, I have experienced times when my accountability and responsibility for my practice protected patients from harm and shielded me from possible medical misadventure claims. As my research involves ear syringing I will use this procedure to illustrate my point. On one occasion, a GP who had referred an adult patient to me for ear syringing had overlooked asking some relevant questions about ear problems. However, before undertaking the procedure I discovered that in the past, the patient had had operations involving one ear. If I had continued with the procedure as requested by the GP, the patient might have sustained damage to the ear. Advising the GP of the situation, I referred the patient to the Ear Nose and Throat department at the base hospital. In addition to concerns about the welfare of the patient, there was a risk that both the GP and I could face questions from the ACC for medical misadventure, and the Health and Disability Commissioner for incompetent practice. While I have responsibilities for my practice, my employer also has a responsibility, and liability to ensure that I have the necessary knowledge and skill when undertaking any procedure and process that he requests of me (Burgess, 1996).

\subsection{3 - Minimising risk}

At a communication seminar in June 2002 organised by the Cognitive Institute in Australia, the facilitator Michael O'Brien advised participants that the interpersonal skills of the health professional were relevant factors in minimising the risk to the patient and to themselves. He maintained that effective communication is one of the most effective 
risk management tools, and that listening is just as important as talking. Making a human connection early in the consultation process is consequential in how an interview is experienced by the patient. While I acknowledge that perfection is denied me, my own experience of consultations with health professionals reinforces my commitment to act toward patients, as I would like them to act towards me.

As a PN, I have a duty of care to patients and need to be able to communicate effectively to minimise risk by maintaining my knowledge and skill in ear care and taking responsibility to see that the instruments are cleaned and maintained correctly. Careful assessment of the patient and the history relevant to the procedure and the level of anxiety surrounding the procedure are noted and addressed. The level of communication between the patient, the GP, and myself plays an important role in the outcome of the process. Unfortunately, there are occasions when mishaps do occur to patients and a claim is placed with ACC.

\subsection{4 - Medical Misadventure}

In New Zealand, the accident compensation legislation, with its no-fault liability provisions, provides compensation for accidental personal injury, including medical misadventure. 'Medical misadventure' is defined as "personal injury from the care of a registered health professional through 'medical error' or 'medical mishap"'. 'Medical error' is a "failure to observe a standard of care and skill reasonable to be expected in the circumstances, and 'medical mishap' is the "result of adverse consequences of properly given treatment on the basis of the outcome being rare and severe" (Burgess, 1996, p. 30). Clear communication of the risks, benefits and options of the care is a significant factor in reducing the element of risk.

\subsection{5 - Informed choice and consent}

According to Rogers and Niven (1996) the principles of informed choice and consent are "autonomy, responsibility and accountability" (p. 66). As a nurse I have a duty of care to inform patients of issues surrounding any care I give, and any information I supply must be accessible and understandable to the patient. According to the Ministry of Health's Immunisation Handbook (2002), consent based on ethical principles is a fundamental concept for the provision of health care services. This is supported by the Health and

Disability Commissioner Act (1994), The Code of Health and Disability Services 
Consumer's Rights (1996), and the Privacy Act (1993). Burgess (1996) reiterates that the basic principle underlying consent is that "every sane adult has the right to say what shall be done or not done to her or his body" (p. 31).

Avenyard (2002) supports Faden and Beauchamp's (1986, p. 274) definition that asserts that informed consent is the patient's autonomous authorisation, and stresses that this is more than a simple expressed agreement or assent to the proposal by the patient. According to these authors, for patients to consent they need to actively authorise the proposed procedure or process, and to do this they must be able to comprehend the information and give voluntary consent. Acknowledging these principles, nurses must obtain informed consent before undertaking any procedure. Nursing care involves touching people and as such consent is an issue for a significant amount of nurses work. Generally, consent can be oral, written or implied and it must be freely given. However informed consent denotes that the patient has been given sufficient information about the risks, benefits and options of any nursing care procedure or action to be able to make up her or his own mind about treatment. Although an individual should be legally capable of giving consent, parents or caregivers acting on behalf of young children or people unable to speak for themselves can give consent. In certain circumstances, treatment can given without consent when a patient is psychotic or in emergency situations, for example (Burgess, 1996).

The process of presenting the patient with enough information to make an informed choice for procedures such as ear syringing contains a number of aspects that affect me as a PN and I need to be familiar with regulations setting out the rights of the consumer and health care provider's duties such as The Code of Health and Disability Services, Consumers' Rights Regulations (1996). However, there is considerable debate among health-care professionals as to what constitutes sufficient information to make an informed choice. Johnstone (2000) notes that some doctors complain that the informed choice and consent process is flawed or misguided as it is impossible to fully inform patients of all they need to know in order to make intelligent decisions about care.

Over a number of years, colleagues and associates have confirmed my contention that there are a number of nurses who disagree with my interpretation of what informed consent means. These nurses believe that by arriving at the surgery for a specific 
procedure such as ear syringing or vaccination, patients' imply consent even though they may not have been fully informed about the risks or benefits of any given procedure. A lecturer for the Department of Public Health and General Practice at the Christchurch School of Medicine and Health Sciences Cooper has experienced the same phenomenon during her PN Orientation lectures (J. Cooper, personal communication, March 2002). Likewise, Avenyard (2002) asserts that as many nursing care procedures have the potential to threaten patient autonomy, merely arriving at the hospital (or surgery) does not in itself denote consent. Implied consent, according to Burgess (1996), is where a patient indicates without speaking that they will have the medication, injection, or procedure. For example, a person who fills a glass with water, rolls up a sleeve, or prepares him or herself for a procedure could indicate implied consent. Even though a patient might request a procedure such as ear syringing, if he or she does not have sufficient information to enable him or her to make an autonomous decision then consent cannot be said to be given (Habiba, 2000).

Although consent is necessary to protect patient autonomy, Avenyard (2002) contends that it should be a flexible process with sufficient information needed by the patient to make a decision. An example from my practice will illustrate this point. A young mother brings her baby in for routine immunisations, and as I have not met this mother or baby before, I begin the consent process for the immunisation to be given. Interrupting me, the mother insists that she knows that immunisation is important and realises that there are risks, but that she does not want to discuss them and would I please get it (the immunisation) over with as she finds it really difficult to bring her baby in for something that is going to hurt. To insist that this anxious mother to be further informed about the risks and benefits associated with vaccinations something that she did not want to know at this time in my opinion would be infringing on her rights and autonomy. I note in the patient's records if the caregiver has given consent and if further information has been given or if it has been declined.

Nevertheless, in my experience, most people want to know what is going to happen to them and what effect it will have on them, before any procedure is undertaken, and they want to know what side effects any prescribed medication might have. Patients have told me that misunderstanding the risks of the possible side-effects, and the potential benefits of medication has led to them discontinuing their medication as they fear that the doctor's 
prescription will do them harm. This information has been confirmed for me by a local pharmacist who regularly finds that medicines are not collected as prescribed. Cultural beliefs, tradition and economics are also factors that influence an individual's decision whether or not to want information. Some cultures leave the decision-making to family members or the doctors to make the choice for them, thus reducing some of the stress and anxiety they might have experienced had they had full disclosure (Hampton, 2001). In my place of work, people of many cultures, ethnicities and economic strands visit the practice, therefore it is of utmost importance that I am a aware of these factors. Asking the patient or family members how they wish to be informed and who is entitled to speak for them is respectful of their culture and demonstrates careful practice.

When an individual needs his or her ears cleared of wax or debris, a significant part of gaining informed consent is the explanation of the whole process and procedure. While many people have had previous experience of syringing, in my judgment, not everyone is aware of the risks or options of the procedure. This discernment emphasises the point that PN's should not assume that they, other nurses or GPs have gone through the process with the patient as well as they might. There are occasions when circumstances at the time, such as interruptions, affect the flow of the process, and memory of what has been said becomes disjointed. This in turn could result in less than optimal understanding by the patient that could lead to possible harm to the patient.

\section{4 - Ear syringing}

\subsection{1 - Guidelines for ear syringing}

Practice Nurses in the Nelson region are encouraged to follow the guidelines for ear syringing (see Appendix 3). These guidelines are among many developed for practice nurses by members of the Nelson Division of the CPN (2002). The guidelines have the approval of the appropriate specialists and GP employers. Nurses from many parts of New Zealand have requested the guidelines book for their surgeries. The guidelines for ear syringing detail the procedure and the risks and contraindications of the procedure.

While suctioning an ear canal to remove the blockage is the option of choice (Dr. J. Clelland, personal communication, April, 2000), the necessary equipment is unavailable in most surgeries, so people with relevant contraindications to ear syringing such as prior ear surgery are referred to the appropriate person for this option. However, patients in 
this region are required to wait for three weeks or more to be seen by the ear nurse specialist at a hospital some distance away, causing the majority of people to choose the syringing procedure so that their discomfort can be relieved quickly.

\subsection{2 - Indications for ear syringing}

In general practice ear syringing with tepid water is used mainly to remove impacted cerumen (wax) from the ear canal. Other reasons include, removing foreign bodies, and clearing the canal of debris. The instruments for syringing my co-researcher and I use are different. I use an instrument that resembles a cake-icing tool with the water being sucked into it and then squirted into the ear canal. My co-researcher uses an instrument with a long curved nozzle that is held like a handgun and water is expelled through the nozzle by squeezing the trigger. According to Blake, Matthews and Hornibrook (1998) when used correctly, the cake-icing instrument should not cause perforation to a healthy eardrum, but there has been an ACC case where the nozzle was not adequately connected to the syringe and it was forced down the canal, perforating the drum.

\subsection{3 - Contraindications to ear syringing}

Although a number of practices do not have formalised guidelines for ear syringing, some do. In general, these guidelines take the form of either stand-alone guidelines created by and for the individual practice, or guidelines based on PN Division recommendations. The Nelson PN guidelines are an example of the latter and set out nine contraindications to ear syringing. These are as follows:

1. any injury or aversion to ear syringing,

2. previous or current history of middle ear disease or a wet infected ear

3. previous history of ear surgery

4. previous or current history of vertigo

5. Otitis Externa (acute or chronic)

6. perforation of tympanic membrane

7. presence of grommets

8. mastoid cavity

9. dermatitis involving the scalp or ear

(Nelson Division, New Zealand College of Practice Nurses NZNO, 2002) 
Following the investigation into ACC claims involving ear syringing, Blake et al. (1998) list 14 conditions where syringing is contraindicated. In addition to those covered in the practice guidelines, aversion to ear syringing, children under 12 , unco-operative patients, and a past history of radiation therapy that involved the external or middle ear, skull base or mastoid are contraindications.

A study undertaken by Price (1997) for the British Medical Defence Union found that $19 \%$ of medical misadventure claims to that organisation were the result of ear syringing. Of this, $56 \%$ were claims for procedures undertaken by the nurse. Ear syringing is also undertaken by ear, nose and throat specialists, specialist nurses, GPs and PNs. Blake et al. (1998) discovered that, over a 17-month period, the ACC Medical Misadventure Unit accepted 47 claims for error or mishap relating to ear syringing. I note that the total number of claims received was 110 , with 63 declined. Of those accepted, 41 were for mishap and 6 were the result of error. Perforations made up 38 of these claims. Blake et al. found that the most common reason for error or mishap was the failure of the health professional to take an adequate history or to perform a proper examination of the ear prior to the procedure. The ACC Ear Nose and Throat Medical Misadventure Committee report alleges that many injuries or claims could be avoided if practitioners took greater care (Blake et al. 1998).

\subsection{4 - Technique of syringing}

After the pre-procedure process has been accomplished, Blake et al. (1998) recommend straightening the ear canal by drawing the pinna upwards and backwards (a child's pinna is drawn downwards and backwards). Of note is that Maori and Polynesian patients have straighter canals than Europeans, requiring adjustment to the angle of the nozzle. At a temperature of 38 degrees Celsius, one degree above body temperature, water is squirted gently into the ear along the roof of the canal and behind the wax, washing back along the floor of the canal and into the waiting receptacle bringing the wax with it. Since it is the pressure of the water between the wax and the drum that forces the wax to move, a healthy eardrum is essential for an acceptable outcome. Frequent observation of the canal and the patient during the procedure is important because any untoward symptoms can be assessed and treatment reviewed. Following the procedure, the ear may be dried with a dampened paper tissue and/or the patient's head tilted to remove excess water from the canal. Water usually evaporates from the ear canal within two to three hours. 
Figure 1 is a typical picture of the ear, and wax sits usually about the middle of the ear canal, unless pushed further back towards the ear drum.

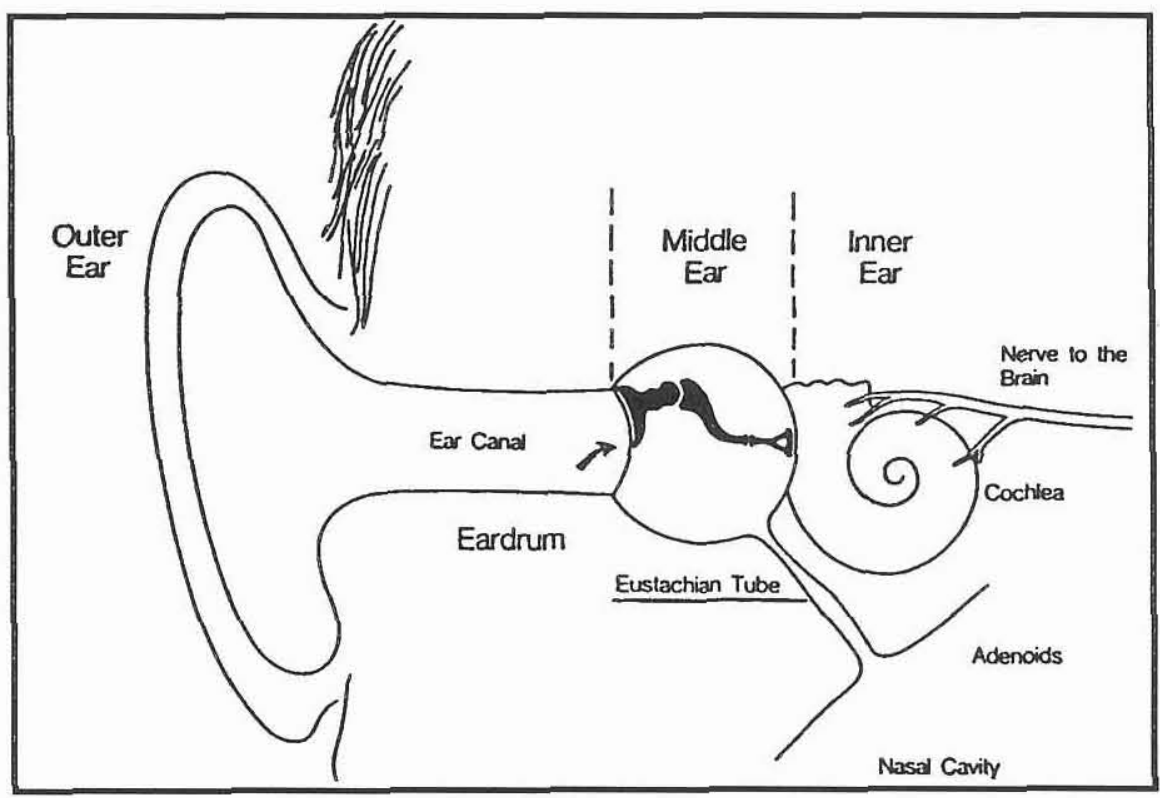

Figure 1. Typical picture of an ear

Feedback from patients supports my observations that the sight of the ear syringing instruments often increases patients' apprehension before and during the procedure, making the process more alarming. For me, insight such as this affirms my professional and personal responsibility to communicate effectively with the patient and/or GP to ensure that, as far as possible, no harm comes to the patient, employer, the surgery, or myself. Because effective communication involves listening, as well as talking and looking, I need to be attuned to the meanings behind the words of patients as well as any non-verbal cues so that I can understand their mindset and adjust my communication style accordingly.

\section{5 - Communication}

\subsection{1 - Language}

Effective communication includes language, and Boutain (1999) describes language as representing reality. It is language that is "primarily understood as the channel through which the material world is described and understood" (p. 1). In addition, it can belong 
to the linguistic world or the non-linguistic world. In practice this means that what I say and what I do or portray, represents my reality. For instance, the words I use as well as my posture, and facial expression represent to the patient a reality of the situation as they perceive it. Non-verbal communication can signal confidence, and non-confidence, nervousness through the posture of the individual. Payne and Walker (1996) found that hand movements, facial expression, tone of voice and speed of delivery all contribute to how one person experiences another. Montgomery (1993) asserts that skilled competence is an integral part of communication in caring, and that this skilled competence leads to trust between patients and nurses.

The noun 'languaging' is the term chosen by Rosemary Parse (1981) to describe the communication of perceptions, beliefs and priorities through verbal and non-verbal means. It is "Sharing valued images through symbols of words, gestures, touch, gaze and posture" (p. 177). Language uncovers meanings of words; for example, when patients talk about what they mean, the communication of impressions, thoughts, and feelings changes the meanings giving them clarity and definition (Parse 1981). Interpersonal theorist, Hildegard Peplau's (1952/1988) understanding of communication remains valued to this day. Forchuck (1993), in referring to her work, observes that communication involved both verbal and non-verbal communication methods. Language is used for verbal communication, while sensitive and responsive connections, gestures, postures and patterns express non-verbal communication. For example, during the ear syringing procedure, I will ask the patient if she or he is experiencing any discomfort and the verbal response has a significant bearing on my decision whether to proceed or not. However, while the patient may have stated that there is no discomfort, she or he might be cringing and tense, non-verbally indicating a conflicting sensation.

While the conventional understanding of language is primarily seen as a vehicle of expression and a way of conveying meaning to others, Bjornsdottir (2001) argues that, as members of a culture, we not only learn a language as a tool to express out thoughts, but rather we learn different ways of speaking or different discourses. We need to be aware of a possible power imbalance when deciding whose understandings have most value, and be sensitive to how people's location as well as their social backgrounds could influence their understandings of what is important (Bjornsdottir, 2001). 
According to Devito, O'Rourke and O'Neil (2000), perception is the process by which an individual becomes aware of the many stimuli impinging on her or his senses. Messages that are taken in, and meanings given to those messages are influenced by how a person comprehends them. Perception is fundamental to the study of communication as it influences the way people are seen and the evaluations we make of them and their behaviour. In addition, Devito et al. contends that communication involves being polite to people and recognising that people of different cultures and genders experience politeness in diverse ways. Of importance in New Zealand, Bazely (1985) advises that it is not polite to practise the Maori language with a Maori patient unless the speaker is sure that the patient will understand what is being said. Bazley also contends that non-verbal communication is often misinterpreted and describes an example where a Pakeha wishing to communicate thoughtfully, looks directly at a Maori patient who regards such behaviour as showing a lack of respect and is rude. My own experience concurs with Bazley's assertion, when I have found that I need to retrace my metaphorical steps when passing on information or requiring information from Maori patients. In my experience, many people who identify as Maori appreciate direct eye contact, while others have looked away, and still others have said "yes" when I sensed that they meant "no". In these circumstances, a different approach is required that takes different ways of communicating into account.

When communicating with people, knowledge of the client group I am interacting with is critical. This is especially the case when working with people who need ear care as many have significant hearing loss due to age and or occupation (industrial hearing loss). Although I need to be competent in my communication skills, I must also be aware of the psychological needs of patients who have hearing loss.

Without effective communication, the risk to the patient is increased and informed consent is unable to be obtained. Further, Fox (2001) states that if the patient has not comprehended the consequences of treatment, or feels that the information was not provided in a way that was understandable to the patient, she or he has grounds for laying a complaint. 


\subsection{2 - Language as Power}

Nordgren and Fridlund (2001) argue that the relationship between carer and patient is one of power because of the medical knowledge of the carer and dependence of the patient. Language is an important factor in this interaction to equalise the balance of power. Although language is used to describe and communicate, it is also used as a vehicle of power. Technical language, whether it is computer technicians discussing Internet Technology (IT), vehicle mechanics discussing engines, or lawyers using legal terminology, alienates me in varying degrees from people who are familiar with those areas of practice.

When communicating with patients, Crawford, Nolan and Brown (1995) contend that the professional language of nurses has the potential to create power imbalance by disadvantaging patients who do not fully understand the peculiarities of the language. For instance, during the process of gaining consent for the ear syringing procedure I could use words such as "cerumen", "otitis externa", or "perforation of the tympanic membrane". However, I am aware that a significant number of patients in this practice would not understand what I was talking about. This incomprehension could place patients in a position where consent is given or withheld, without the full meaning of what I was said being understood.

Being aware of non-verbal communication strategies such as the posture I adopt when talking with patients, gestures, facial expressions and the tone of my voice all play a significant part in how people perceive my understanding of their problems. I am aware that when I take a patient into the consultation room to make a preliminary assessment of reason for the patient's visit and await the doctor, I will ask the patient to sit, but occasionally, I remain standing. Although this behaviour reflects my uncertainty in how far my contact with the patient should go, because after I leave, the patients will need to repeat themselves to the GP, my stance could indicate a power imbalance to patients.

Other factors that influence communication include the physical environment, such as room, temperature, seating, protective covering, and privacy. Time is also a factor, as if a patient or I am feeling rushed then the level of stress is increased. In my experience, if a patient is comfortable in the environment then he or she is more likely to understand what I tell them. This can lessen their stress and anxiety. 


\section{6 - Stress and anxiety}

\subsection{1 - Relationship between communication and stress}

Although I am mindful of my communication methods when disclosing the risks and benefits of a procedure, I have observed patients experiencing increased feelings of anxiety and stress when the possible negative consequences of a procedure such as ear syringing or immunisation are explained. These feelings can be expressed by patients holding their shoulders close to their ears, constantly shifting their position, replying to questions in mono-syllables, or clutching the kidney dish that collects the water and wax, tightly, for example.

The fear, anxiety and stress experienced by patients is described by many writers including Benner and Wrubel (1989), Bailey and Clarke (1989), Szeto and Yung (1999), Bay and Algase (1999), Mitchell (2000) and Norred (2000). Norred (2000) notes that heart rates might be altered by mental stress causing sympathovagal balance problems that could lead to coronary artery problems. According to Szeto and Yung, physiological changes such as increased cortisol levels, heart rate and blood pressure, and psychological changes such as increased anxiety are factors that affect the ability of patients to relax and cooperate with self-care and treatment options. Benner and Wrubel describe stress as the "disruption of meanings, understandings and smooth functioning, so that harm, loss or challenge is experienced, and sorrow, interpretation or new skill acquisition is required" (p. 60). Further, stress management strategies that deal only with altering emotional states by dampening, controlling or distracting patients attention to the stressful event, may help in the short term, but long term such strategies cultivate alienated attitudes toward expressing emotions.

Anxiety can have considerable effect on both the quality and intensity of pain experiences according to Niven (1994) who found that patients who were more anxious are more sensitive to pain. If, when syringing ears, the patient fears possible pain or discomfort, the anticipation could increase the level of pain or discomfort experienced. However, with effective communication and insight into the patient's feelings, nursing practice should be able to reduce this anxiety and accomplish the procedure with minimum distress for the patient. According to Fareed (1996), a factor in reducing anxiety and stress is the therapeutic effect of an environment that is informal, 
unthreatening and caring. In addition, patients also feel more comfortable with staff who are kind and helpful and where they feel that they can express their feelings and receive factual information.

Techniques I use for helping stressed patients include assuring a patient that I have time to go over any aspect of the procedure that he or she needs clarification of; that I am competent in my job; and that I have extensive experience in the procedure. Furthermore, I will make time to listen to patients and answer their questions and stop the process if the patient requests a halt. Mitchell (2000) contends that the level of control the patient has over the situation influences the degree of stress and anxiety a patient might experience. Likewise, when I tell a patient that he or she is coping well with the procedure this affirms the patient's feelings of being capable of self-care and confidence returns. If they are not managing a situation as well as they expected I use other means of encouraging their self-esteem, or shift the discussion away from the immediate event.

Because of my interest in patient safety and wellbeing, my research topic reflects the significant concern of my practice nurse colleagues and me, about peoples' perception when the possible risks of procedures such as ear syringing are explained to them. Reducing the stress, fear and anxiety experienced by many patients should improve her/his ability to relax, and reflect in an outcome where the patient states satisfaction that there was little discomfort and optimal hearing has returned. A patient who expresses the belief that her or his immediate need for clear ears has been met, also heightens my own professional and personal satisfaction.

\subsection{Conclusion}

This chapter examined the background to my inquiry into the exploration of language and nursing practice to reduce the stress and anxiety patients might experience in the context of ear sryinging. These emotions expressed by some people when requiring procedures undertaken by the PN such as syringing ears, immunisation, or cervical screening became the catalyst to explore how language and nursing practice could assist in relieving people of some of their anxiety and therefore enhance their wellbeing. 
The role of the PN is unique as she or he is employed by GPs and much of the work of the PN is by referral from the GP. This relationship brings its own stressors and conflicts and the PN needs to have a clear understanding of the legislation and codes of practice and that accountability resides with the PN.

Ways of expressing verbal and non-verbal communication raise issues in the nurse/patient and nurse/doctor relationship, demonstrating that effective communication between all persons decreases the risk of harm to the patient, nurse and GP and minimising the risk for procedures such as syringing ears. A description of the ear syringing procedure clearly demonstrates the need for competent and safe practice, and the requirement to have fully informed the patient of the risks, benefits and options before the event.

People express stress and anxiety in a variety of ways and nurses need to be aware of how their communication processes can reassure the patient and create beneficial outcome. Perhaps a comment about the title of practice nurse is a signal of discomfort. To find ways of improving communication and improving practice, I have used an Action Research methodology with a colleague, to reflect on language and nursing practice to disclose patterns of behaviour that require adjustments to sustain the belief of my coresearcher and myself that people deserve the best care we are able to give them. I discuss reflection and reflective practice including reflection-before-action (Greenwood, 1993), reflection-in-action and reflection-on-action (Schön, (1983) in the following chapter. 


\section{Chapter 3 - Reflection}

\section{1 - Introduction}

Reflection has been bringing meaning and value to both the professional and personal parts of my life. It enables what is behind the mirror image (Street, 1991), the shadows, the as yet, unknown, to become visible and give up its secrets. Critical reflection unafraidly explores, in context, what is visible, what is above, behind, underneath, beside, and inside the event being reflected upon, to uncover values and beliefs inherent in our practice and exposes them to our gaze for greater insight, understanding and integration into our 'self.' These revelations have the power to inspire, empower and liberate me to continue to strive to make and sustain positive changes to my practice and myself.

This chapter explores reflection, its philosophical underpinnings, and how I use this tool for analysing my practice. I discuss Street's (1991) assertion that critical reflection demonstrates the gap between what we think we know and what we do, in fact, know. The elements of reflection as described by Schön (1983) of reflection-on-action and reflection-in-action, as well as Greenwood's (1993) contention that reflection-beforeaction is equally important, are explored. I describe the values and limitations of reflection and how the insights gained from skilled critical reflection can make changes to practice. Throughout the chapter I provide examples from my practice as a PN and my research inquiry, and I argue that without the understandings and insights that reflective practice brings, changes and improvements to my practice and care of patients could not have been achieved to the degree that it has.

Because I refer to Taylor's (2000) work on reflective practice regularly, I provide a short history of her background. Beverley Taylor is the Professor of Nursing at the Southern Cross University in New South Wales, Australia. Taylor describes herself as being a thoughtful child and this thoughtfulness continued through her training as a nurse and midwife in the 1970s. While studying for a Master of Education in 1987 at Deakin University, Taylor discovered that reflection and reflective practice were intriguing concepts, and it was at this same University that she met Stephen Kemmis, John Smyth and Annette Street, whose work continues to be influential in her life (Taylor, 2000). I first became aware of Taylor's writing in 1996 when I read her book Being human: Ordinariness in nursing (1994) in which she discusses the human aspect of nursing. By 
this she means "nursing is a human relationship that becomes therapeutic by the humaness of interpersonal encounters" (p. 4). While patients trust and acknowledge the professional knowledge and skill nurses have, it is the human connection, when nurses transcend the professional crust and just be themselves that makes a difference to the nurse/patient contact. According to Taylor, nurses who value their own humaness enhance the relationship between nurse and patient.

\section{2 - Defining reflection}

According to the Collins English Dictionary (1986) reflection means "to ponder, think or meditate, to give long consideration or thought" (p. 713), while the Dictionary of Psychology (1985) describes reflection as a process of "introspection, or a rebounding, a casting back or returning to meditate on a past experience" (p. 624). Further, seventeenth century philosopher John Locke author of Human understanding in discussing his "simple ideas of sense" understood reflection to be "turning the mind inward to observe, and to contemplate the mind's actions, and to think, reason, believe and doubt (Hutchings, 1690/1952, p.128). According to Pierson (1998), nursing has several definitions of reflection, the essence of reflection remains an elusive idea.

\subsection{1 - Influence of John Dewey}

While philosophers such as Locke (1952) discussed reflection in relation to human understanding, one of the United States of America's foremost philosophers of last century, John Dewey (1933), was interested in how reflection could be used in everyday life. In addition to heading the pragmatic philosophical movement that applied the scientific method to all areas of human inquiry. He was also an educationalist and teacher who experimented with alternative teaching methods in a "Laboratory School". At this institution, he studied students' learning patterns, working to reveal which teaching methods achieved the best results. He is considered to be the first person to raise the concept of reflection and how it influences human cognition and thought. He argued that emphasis should be placed on the needs of students and less on formal subject matter (Hutchins \& Adler, 1963). According to Dewey, thinking can be synonymous with believing; believing that the sun will shine tomorrow, for instance, and he experienced it as a stream of consciousness, where there is always something in our minds to think about in the past, present, and future situations. However, for Dewey, this "stream of consciousness" method of thinking did not necessarily demand a resolution, 
whereas reflective thinking propels us to aim for a conclusion. Believing that only reflective thinking could lead to genuine knowledge, Dewey focused on the gap between thought and action.

According to Dewey (1933), reflective thought is more than random thoughts or ideas because it involves the consequences of these thoughts or ideas. Therefore, the process of reflection grows out of each thought or idea, supporting each other to a common end. It takes conscious and voluntary effort to place belief on a firm foundation of evidence and rationality. Open-mindedness, whole-heartedness and taking responsibility for the consequences of any action an individual might make, are attitudes emphasised by Dewey, who maintains that a combination of both sets of attitudes is utilised in clear thinking. In addition, he argues that a person's ability to think is affected by factors such as authority figures, for example teachers and parents, who encourage repetitive thinking patterns and a formula by which thinking should be undertaken. Dewey's experiments in the laboratory school supported his belief that teachers needed to understand how people learn before advocating how they should be taught.

In his book How we think, Dewey (1933) details the complex phases of reflection that include, being in a state of doubt, hesitation and mental difficulty where thinking originates, followed by the act of searching and inquiring that will resolve the doubt. In addition to this state of doubt, Dewey informs us that there are five different phases of reflective thinking. These five phases include suggestion, where the mind leaps forward to a possible solution; the intellectualisation of the difficulty of a problem that has been directly experienced; suggestions leading to a hypothesis; reasoning, and testing the hypothesis either by imagination or physical action. However, Dewey exhorts readers that these phases should not be seen as rules for reflection, but as tools for finding resolution for problems, and that by varying the sequence of the phases to accommodate different situations, solutions to problems could be found. The pattern of rambling thought and reflection process is constant, according to Dewey, and while this process recognises that my thinking is influenced by my beliefs about work, the nursing profession, family, and life in general, Dewey argues that there are times when a narrower, more concise and critical thinking and reflecting is necessary. 
As an illustration of what Dewey (1933) means and how it resonates with my thinking, I will explain some reflective perspectives as they relate to my research question that is "What do my co-researcher and I need to do to improve our communication and practice?" For example, during the data-gathering phase of my research, I reflected on my co-researcher's and my patient interactions, firstly at a superficial level. This degree of reflection provided me with an overall picture of the process that revealed that our language could be causing problems with communicating information to patients. Next, I reflected critically on our use of language to ascertain which parts of our verbal communication could be improved. Finally, I placed all my thoughts regarding the problem on the 'back-burner' of my mind, or what Heidegger (cited in Pierson, 1998) calls contemplative thinking. This kind of deep thinking takes time, and according to Pierson, "it is one of the greatest paradoxes of human existence, that we see clearly when we do not look; our thinking arises when we do not try to think" (p. 166). Being aware of this contemplative thinking and reflecting, and trusting the process has often led me to investigate possible solutions to problems I had initially thought were insurmountable. For example, struggling to find words to rephrase my writing, I leave it for a while and do something else. Later, and apparently from out of nowhere, a word or phrase comes to mind that fits my writing.

\subsection{2 - Influence of Donald Schön}

In addition to Dewey's (1933) studies on reflection to explore how people think and how it could be used in education, it was educational theorist Donald Schön (1983) whose continued interest in reflection demonstrated the role that reflection had in any action. Schön argued that the positivistic technical rationality of the applied sciences did not fit the reality and the complexity of problems in practice. In addition, he suggested that there is a professional artistic element and practical competence that has been overlooked when problem solving, and that the 'hard' knowledge of science and the 'soft' knowledge of artistry need to be combined as essential elements in professional practice. Schön understood that what practitioners thought they did in practice, was not necessarily what they did in reality. This point also noted by nurse researcher Street (1991), was emphasised for me when my co-researcher and I were listening to our audiotapes and realised that what we thought we were saying to the patient, and what we said in fact were not the same. 
According to Carr and Kemmis (1986) reflection is a dialectic process that looks both inwardly at the historical and social aspects inherent in a person, and outwardly to the existing situation through the process of action. Looking for a definition that allows for diversity in thinking as a basis of reflection, Taylor (2000) interprets reflection as a process of throwing back memories and thoughts and any other forms of attentive consideration, so that sense can be made of them and, if necessary, changes made. Taylor notes that while reflection entails thinking about an issue, a situation, or a moment in time, it is also a process that is both rational and intuitive, with the potential to create change. According to Street (1991), reflection begins with imaging. By this, she means that we need to have "an image of nursing practice that not only reconstructs the practice as it is experienced and expressed, but through imagination create the capacity to construct an image which contains the potentialities of nursing practice in the future" (p. 2). Taylor believes that reflection comes from sources such as life experience, art and religion, for example, while Friere (1972) points out that reflection does not begin with a search for answers but with a search for questions, and it is this search for questions that is essential for my reflective research inquiry. When listening to the audiotapes of the nurse/patient interactions, and reading transcripts, and again at meetings with my coresearcher, we searched for questions and possible answers to those questions, to be in a better position to suggest changes to the process of the procedure of ear syringing that would benefit patients.

Until a few years ago, my reflection of my practice usually only occurred after a critical incident where I frequently blamed myself for what had happened. I did not appreciate the need to examine the situation as a whole, or the role of other environmental or organisational aspects that contributed to the event. For me, reflecting on positive experiences was rare. Looking back, I can see now that my personal history and habit had at times deterred me from being as sensitive to variances and exploring the shadows of the complexities of interrelationships and interconnections and interbeliefs of nursing practice. This deeper insight and increasing understanding has only been possible after examining my background, my culture and my belief systems. My experiences reflect Taylor's (2000) and Street's (1991) contention that how we are raised and taught has a direct influence on how we practice our profession and our interactions with others. 
While reflecting on Street's (1991) writing, I experienced an unexpected sense of enlightenment. An "aha" moment. I realised and understood at an even deeper level, that while I had been practising reflection with what I thought was with some degree of skill and insight, it was probably more often at a technical, practical and objective level rather than at a subjective level. The aha experience effectively empowered me at a subjective level and enabled me from a conceptual position, to feel free to understand the need to use my imagination to look behind, around and inside a situation or circumstance. I envisage this process as one of asking questions about receiving an unexpected parcel. Who sent it and what did it hold? I begin by looking at what is presented to me, my first impressions, then I note the size, shape and weight and colour of the wrapping material of the package. I look all round the parcel to see who could have sent it and try to guess what is inside. Removing the wrapping piece by piece to discover what may be inside the parcel can be simultaneously exciting and scary but the anticipation of discovery encourages me to continue unwrapping the parcel. What I finally discover has the potential to change me as a person and change the way I interact with people.

In stating this notion, I maintain that the energy to look at situations with fresh vision is a cyclical or rhythmical, process. In my experience, while reflection can be encouraged and facilitated, there are many times when the process is simpler and more effective than at other times and retaining the awareness I discovered in my aha moment will be difficult. This is because I need the mental freedom and stillness of the environment to think more clearly, and factors such as work and family pressures affect the ability to think deeply.

According to Foster and Greenwood (1998) a burgeoning fascination with reflection has led to intense interest in the idea of how reflection and reflective practice could solve problems in professional practice. Most authors, in my experience, follow or extend Schön's (1983) two constituent parts of reflection-in-action and reflection-on-action, and in the following section I explore these parts of reflection.

\section{3 - Elements and levels of reflective practice}

According to Schön (1983), reflection-in-action usually occurs as consequence of an experience of surprise or puzzle and involves thinking about what a person is doing while he or she is doing it. In addition, Greenwood (1993) suggests that by critically analysing 
the situation the practitioner tries to make sense of the problem and the surrounding circumstances, then reflects on the insights and understandings gained in the process. For example, when I am dressing a person's wound I might find that it is unexpectedly displaying signs of infection. I reflect on possible causes for this occurrence and change my dressing plan to accommodate this new information.

Reflection-on-action observes aspects of practice following the action. After critically reviewing the action, the practitioner possesses a greater insight and understanding of what has occurred, and makes the necessary changes to his or her position and practice (Schön, 1983). While reflection-on-action, or, as Greenwood names it, "cognitive postmortem", can occur immediately following an event, or can be useful to look back at a later time, to gain further knowledge of the situation. For instance, the next time I dress the patient's wound, I reflect whether the wound is healing, the materials I used were appropriate, or if I needed to change the plan again. In addition, I might reflect on my care of this particular wound sometime later to see if there was anything I could have done differently. Taylor (2000) notes that while memory may fade it is still possible to make sense of practice events at a much later time.

A study involving trainee teachers undertaken by Goodman (1984) maintains that for the retrospective reflection process to be meaningful it requires depth, and to attain this depth, there are three levels of reflection. The first level focuses on what works; the techniques needed to reach the goal. The second level looks at the relationship between theory and practice. The third level includes critical reflections on both ethical and political concerns that include principles such as justice, equality and emancipation. Glaze (1998) argues that even expert nurses, who believed that they were reflective, were found to practice reflection at a superficial level. Glaze maintains that values, beliefs and knowledge that inform the reflective process are more significant in critical reflection than mechanical processes. According to Glaze, by practising critical reflection in a safe environment, and gaining confidence in the process, nurses can transform their practice.

Reflection-in-action and reflection-on-action are fundamental to Schön's (1983) reflective process, but Greenwood (1993) argues that by limiting reflection to two constituent parts undervalues the thought required before any action is taken. Greenwood contends that reflection-before-action is just as important. Action without prior thought, 
Greenwood asserts, can lead to errors in practice and the needless suffering of patients, families and practitioners. During my years as a nurse, I have experienced times where the outcome of my actions would have been different had I given more thought before undertaking an activity.

While I acknowledge that it is unrealistic to practice reflection at the deepest level all the time, experience with observation and participation has taught me that utilising all three elements, individually or in combination and in any given circumstance, generates knowledge I can use in my practice. For example, a patient is referred to me to have the ear syringing procedure. Reflecting before commencing the procedure means that I ensure that the patient understands the English language and that the patient is able to hear me so that my discussion of the contraindications, risks and options are understood. (Experience and reflection has shown me that to continue without making sure the patient is cognisant with what is happening or being told, can lead to difficulties further on) and that all the equipment is available and functioning.

During the procedure, this patient suddenly feels faint and nauseous. I would find myself thinking about this new situation at the same time as I am taking action to help the patient. While I have had experience with fainting patients, and syringing ears, I have not had the experience of this happening simultaneously. Reflecting-in-action I select or remix my responses from previous occasions to decide how to deal with the situation. Reflection-on-action is my retrospective contemplation of the incident and speculation of how I could have acted differently, or what other knowledge would have been helpful. According to Burns and Bulman (2000) contextual problems such as this require solutions that are appropriate to the situation rather than those that are general and context free.

However, being confident to examine and explore my behaviours and attitudes took courage, trust and time to become habitual. Many years ago, critical reflection taught me that by providing people with relevant and appropriate information on which to make a decision regarding care, I transferred power from me to the patient. The benefit of this transference of power was twofold. It liberated me from the shackles of fear and defensiveness that I had been experiencing, and it allowed people the freedom to make their own decisions without feeling coerced. In reflecting back on how I was practising, I 
now appreciate that my fearful, self-protective attitude arose from the feeling that I needed to be in control. I was afraid to give much of myself as a person because of the fear of exposure, the feeling that I would be putting myself at risk if I revealed some of myself. This belief vanished when I discovered that the opposite was true. People have said that they appreciated me giving something of myself as it made them feel that their illness of circumstances was less a weakness on their part and more something that many people, even health professionals experienced. The Dalai Lama (2001) expresses this concept as:

"The more honest you are, the more open, the less fear you will have, because there is no anxiety about being exposed or revealed to others.

So, I think that the more honest you are, the more self-confident you will be." (p. 110)

In my experience, power and the sense of power can be nebulous and contradictory, and the release of defensiveness and apprehension is liberating and empowering, and I experienced that by giving up power I gained power. McBain (2000) quotes a sixth century Chinese Taoist, who suggests that "Whoever gives weight to what is outside of him is inwardly clumsy" (p. 331). By placing emphasis on external factors such as what others' might be thinking or saying, rather than trusting my own reflective processes and judgement, I was unable to think clearly and responsibly. For example, during audiotaping the nurse/patient interactions for my research, my thinking often involved the external thoughts not strictly associated with the research, like "how am I going to transcribe this; how am I going to do this; is the patient going to be annoyed because I'm going to have to look at my cue card; how's this going to come out on tape; I wish the tape wasn't there." All these extraneous thoughts increased the clumsiness of my thinking processes. Changing my attitudes and behaviours through this understanding encouraged me to continue this emancipatory role in collaboration and participation with others, and with respect.

In addition to the elements of reflective practice described in the previous pages, Ghaye and Lillyman (2000) maintain that reflective practice embodies 12 principles. These are listed in Table 1 on the following page. 
1). Reflective practice is about you and your work.

2). Reflective practice is about learning from experience.

3). Reflective practice is valuing what we do and why we do it.

4). Reflective practice is about learning how to account positively for ourselves and our work.

5). Reflective practice does not separate practice from theory.

6). Reflective practice can help us make sense of our thoughts and actions.

7). Reflective practice generates locally owned knowledge.

8). The reflective conversation is at the heart of the process of reflecting-on-practice.

9). Reflection emphasises the link between values and actions.

10). Reflection can improve practice.

11). Reflective practitioners develop themselves and their work systematically and rigorously.

12). Reflection involves respecting and working with evidence. (p.xiii)

\section{Table 1 Ghave and Lillyman's (2000) 12 principles of reflective practice}

I agree with Ghaye and Lillyman (2000), who contend that while all change is not necessarily improvement, reflection is a way of achieving improvement in ourselves, our relationships and in our practice. In my work I use reflection to examine not only the workday as whole, but also any critical incidents that may happen during the day. These incidents may involve times where I feel that I have not performed as well as I expect of myself, such as a patient informing me that she hadn't felt heard during an interaction that happened some months earlier, to situations where something I did made a positive difference to a person's experience. Incidents, for example, where giving a hug to a lonely adolescent or elderly widow, observing signs of a previously unknown medical condition, or, following reflection, telephoning a patient whose well-health check, while at the time did not cause concern, now suggests that a follow-up appointment with the GP is warranted. While I was "just doing my job", it is only on reflection that these instances are revealed as generators of knowledge that informs future practice. 
Taylor's (2000) reflective practice includes Greenwood's (1993) reflection-before-action and Schön's (1983) reflection-in-action and reflection-on-action elements, as well as the Ghaye and Lilliman's (2000) 12 principles. In addition, Taylor proposes three main types of reflection that are categorised according to the kinds of knowledge involved and work interests they depict.

\section{4 - Types and categories of reflection}

The approach Taylor (2000) follows for her reflective practice embodies Habermas' (1972) critical social theory philosophy of empirical, interpretive, and critical paradigms. These paradigms include categories of technical, practical and emancipatory reflection. Taylor chooses these categories, because they explain human knowledge as cognitive interests, attitudes of social existence, reflection and the locus of learning. Cautioning reflective practitioners, Taylor asserts that we should be aware of classifying reflection in an attempt to fit situations where more than one type could be appropriate. Taylor contends that the types of reflection processes is irrelevant to the systematic exploration of everyday life events needed to reveal patterns, themes, teachings and values, and the changes to make. Although a description of Taylor's three main types of reflection might appear unnecessary and clumsy, I have addressed them in some detail to demonstrate how I use them in my research and practice.

\subsection{1 - Technical reflection}

The technical reflection process envisioned by Taylor (2000) allows the generation and validation of empirical knowledge so that nursing procedures are based on scientific evidence and critical thinking. While not excluding empathy and sensitive perception to help solve problems associated with practice, technical reflection embodies the nursing process of assessment, planning, implementation and evaluation. My co-researcher and I included technical reflection as it provided us with the background knowledge and skills as well as understanding and insight into our practice when syringing patient's ears.

Although technical reflection is useful in challenging rituals, traditions and unsubstantiated beliefs about what ought to be done in any given situation, it is less useful in practice situations where knowledge and understanding concerning nurse/patient relationship or communication needs to be generated. While technical reflection will not provide information about what it is like to work in environments 
where there are other people with whom clearly discerned communication is essential, practical reflection will fill this requirement (Taylor, 2000).

\subsection{2 - Practical reflection}

Practical reflection uses language as a means of making sense of human interaction and lived experience. By raising awareness of the wide range of communicative patterns and issues, Taylor (2000) contends that the creation of communicative knowledge through reflection presents the possibility for change and that a practical reflective process of experiencing, interpreting and learning encourages communicative clarity.

One of the questions this raised for my inquiry related to the interpretation of verbal and non-verbal communication patterns between patients and practitioners. For example, a patient who verbally denies any concern about having the ear syringing procedure done, sits hunched, on the edge of the chair with eyes squeezed shut. I could interpret the body language as someone who is fearful of the procedure and respond to this assumption, when in fact the patient might be anticipating the procedure with pleasure as the feeling of water swirling around in the ear is enjoyable for them. Another question for my inquiry raised the issue of power relationships in the use of verbal and non-verbal communication. What effect does my use of technical language that I hide behind to protect myself, have on the ability of patients to comprehend what is involved in the procedure of ear syringing?

However, practical communicative reflection, does not have the technical (instrumental) action to provide objective observations and analysis of work procedures and processes, and is incapable of examining critically the power of any forces within the workplace that constrain nurses' practice. According to Taylor (2000) the method to achieve transformation in practice is through emancipatory reflection and its elements of construction, deconstruction, confrontation and reconstruction.

\subsection{3 - Emancipatory reflection}

Emancipatory reflection by practitioners can reveal situations where employers, nurses and other staff members are constrained by historical, economic, social and political factors. These revelations could provide the knowledge for actions or changes that the practitioner could make to assist others to become empowered and transformed. 
According to Friere (1972) and Habermas (1972) critical theory has the potential to empower people to liberate themselves from oppressive forces of power relationships, and political, social and economic constraints that lead to subjugation.

The emancipatory reflective process includes construction, deconstruction, confrontation and reconstruction of any given situation that a practitioner or individual hopes to change (Taylor, 2000). Although nurses are familiar with issues relating to power and reification in the workplace, there are hegemonic attitudes inherent within the nurse/patient relationship that, without critical analysis, may go undetected. An example from my practice illustrates this point. Following an ear syringing procedure I reconstruct the interaction and reflect on how well it went. I note that the surgery was very busy and that other members of staff and patients interrupted us, and while the patient did not appear to be anxious, or troubled by the interruptions, this was his first experience of syringing. This patient's time was also limited as he had urgent appointments elsewhere. These issues became constraining factors to giving full and undivided attention to the patient and the task in hand. Following this examination of the incident, I deconstructed the interaction by analysing and critiquing the situation. I explored the conflicting demands of responding to the GP's requests, acting as receptionist when the receptionist went to lunch, and returning straying children to their caregiver in the waiting room, and how this affected my ability to adequately communicate with the patient. Focusing on my part of the event, I confront these issues, look at how I appeared to place more emphasis on responding to workplace demands and requests from my employer, the external political demands, than attending to the patient. I also note that while my upbringing, boarding school, nursing training, and nurses' homes disciplined me to follow orders and obey authority, I understood that I am inclined to expect patients to follow my instructions. As a consequence of this confrontation and in the light of new insights, I reconstructed the interaction by placing all these features of reflective exercise back in position with transformative strategies for managing change. Strategies such as negotiating with the receptionist to stay at the desk until I had completed the procedure, or, negotiating with the patient to return at a more convenient time could have been used. Changing my availability for my employer is more difficult, as is preventing patients coming in behind the curtain. 
Although recognition of factors constraining practice raises the question of how to effect change, by visualising different ways of acting, the possibilities of what could be achieved and ways in which action could be taken to accomplish those visions, creates an empowering and transforming opportunity for the practitioner to grasp. The practitioner embraces these new ideas and visions, and it is these attempts at making changes that becomes a political action.

The relevance this has for my research lies in the question of how much does the conflicting demands of working under these conditions affect communication with patients, the flow of communication, and the outcome of the whole experience of 'going to the doctor'.

\section{5 - Political constraints of the work environment}

The environment surrounding a particular practice can be unconducive to change, according to Taylor (2000). For example, in situations where colleagues or organisations are unsupportive of an individual's perceived need for change, the complex nature of nursing makes it difficult for reflective practice to create and maintain change and improvement. Taylor asserts that it is unhelpful for teachers of nurses to encourage nurses to attempt to reflect on their practice in situations where a practitioner, who is inexperienced in reflective practice, and in an unfavourable political climate, endeavours to make changes and improvements without full knowledge and understanding of an issue.

During the years of my professional life, it is only with reflecting on experiences that I have gained insight into the political constraints of my various work places. My enhanced self-understanding clarified for me, why management considered some of the changes I thought necessary to improve the standard of nursing care, and to reduce symptoms of burnout in staff, were not implemented or were considered irrelevant. The value of reflective practice lies in its ability to empower, liberate and enable a nurse to bring about effective change and improve nursing practice, and Taylor (2000) argues that its strengths and weaknesses can be experienced in every nurse/patient, nurse/colleague and nurse/employer relationship. A knowledge and understanding of these strengths and weaknesses of reflection can alleviate or prevent disillusionment for nurses, and harming either them or their patients. 


\section{6 - Values, strengths and weaknesses of reflection}

According to Burns and Bulamn (2000) reflection is not an easy process as it involves a gradual self-awareness, critical appraisal of the social world, and transformation. Street (1991) maintains that within the reflective processes, ideas evolve from the insights into practice and become organised into theory and tested in practice as the basis for further development and continuing radical action. Further, it is the cyclical, evolutionary process that is central to empowering research methodologies. Taylor (2000) suspects that while reflective practice is occasionally not taken seriously because it has become so familiar, reflection does provide a method where people are able to systematically find their way through issues experienced in practice to discover new insights and the potential for change and improvement. As a powerful educational tool, reflection enables practitioners to evaluate their work, explore ways to reduce the theory-practice gap, develop practice-based theories, and identify the unspoken knowledge that practitioners hold (Foster \& Greenwood, 1998). According to Street, critical reflection demonstrates to us the unacknowledged gap between what we think we do and what we do, in fact, do. It can be the fear of facing this problem that increases our reluctance to continue the reflective process.

This gap was brought startlingly to the attention of my co-researcher and myself when listening to the audiotaped interactions with patients we discovered that, what we thought we said, was not the same as what we had said. We thought that we had a patter that adequately covered the consent process when in fact, we found omissions. I define patter in this inquiry as the routine spiel that is repeated time after time to convey information that changes little, for example, the routine information regarding the contraindications to ear syringing. This gap will be discussed in Chapter 6 .

Discussing reflection with my co-researcher confirmed for me that reflection is most often limited to examining negative critical incidents, and the process of writing, journaling, seeking questions then answers, is not often considered. Reflecting in a systematic and regular manner is time consuming. While I espouse reflection and critical reflective practice, I find it difficult to be disciplined enough to keep any kind of regularity in my journaling and for the most part, reflection is carried out in my head. We agreed that this type of reflection, while useful in itself, might not go deep enough or be systematic enough for meaningful changes to be constructed and sustained. In 
addition, because memories can become unclear over time, it could become a problem when an action needs to be revisited.

Although Taylor (2000) cautions practitioners that the gap between raised awareness and change can be large and complex. One view suggests that attempting extensive changes that may not be successful can lead to disappointment and a sense of failure, while a second view suggests that confidence can be boosted with critical reflection that achieves small, but successful changes. Experience with success in small changes could lead to exploring other ways of making changes to larger problems. My experience has demonstrated that nurses need support to make changes, as unsupported attempts at change can lead to a decline in confidence and self-esteem that can be reflected in personal and professional behaviours in the workplace. This point has relevance to my inquiry because of the questions it raises. For example, how important was the reassurance and encouragement of my co-researcher and colleagues on the outcome of the inquiry? This will be discussed in Chapter 7.

Taylor (2000) argues that learning to value oneself and contemplative practice is a good beginning to reflective practice and the creation of change, while it may not solve all issues in practice or life, it is a useful tool in helping to face the dilemmas that life entails. In my opinion and personal experience, learning to value oneself is often difficult, as I, like many people, am self-critical and need other's opinions and insights to be able to examine situations clearly.

While I acknowledge that learning to value oneself and contemplative practice has a significant part to play in nursing practice, in my experience there is a danger that complex reflection without peer review or professional supervision especially for neophyte reflective practitioners could lead to a loss of confidence in their practice. For example, when I began journaling and reflecting, it was a very private and personal occupation. This was because a response from a colleague to a critical event I shared, was not as beneficial or benevolent as I wished at that time. As a consequence, I questioned my ability to practice and it took some considerable time to re-establish my confidence and to feel safe enough to be able to share my experiences with colleagues again. 
Taylor (2000) acknowledges that reflective practitioners need guidance to achieve their aim of improving practice and recommends utilising the skill and knowledge of a critical friend whom is experienced in reflective practice. Hanrahan (1998), found that at the beginning, reflection was difficult for her, and it was only following support from colleagues that she began to feel empowered enough to discuss her reflections and make decisions about her practice. Agreeing with Hanrahan, Taylor asserts that the quality of reflection is an important aspect of reflective practice. Taylor contends that if the practitioner is new to the process or feels so familiar with reflection that it is not carried out as critically as it could be, the outcome may not achieve the results expected. Reflection develops with experience and practice. Hanrahan, becoming confident in reflective practice, found that critical reflection was liberating as it empowered her to act on her own knowledge and not rely on the knowledge and attitudes of others.

Burns and Bulman (2000) contend that as there have not been many large studies done to evaluate the effectiveness of critical reflection as a learning strategy, it is questionable to continue a practice that we are not prepared to justify through evaluating its effectiveness and appropriateness. While I agree that we should think carefully about continuing a practice that that we do not have evidence for, I argue that for me, the ability to think and reflect critically is an ongoing educational process that with care and attention can improve and sustain my practice. This is born out in my research inquiry where reflection was used to describe a liberatory and emancipatory process for generating selfawareness and self-knowledge.

According to Glaze (1998) critical reflection requires practitioners to develop a critical element to their thinking. Reflecting critically and thinking critically about practice leads to the realisation that while the practitioner may be at the centre of her or his world, other people play a major part in how and why an individual acts in a certain way (Taylor, 2000). The steps of critical thinking as outlined by Bandman and Bandman (1995) are similar to the steps of Taylor's reflective process.

\subsection{Reflective critical thinking}

Definitions of critical thinking can range from the belief that reasoning is based on reflection and deciding what to do in context of the situation, to argumentation. Bandman and Bandman (1995) define critical thinking as the "rational examination of 
ideas inferences, assumptions, principles, arguments, conclusions, issues, statements, beliefs and actions" (p. 7). They describe four types of reasoning including deductive reasoning, inductive reasoning, informal reasoning, and practical reasoning. Deductive reasoning provides a source of knowledge that does not rely on sense experience; inductive reasoning shows that we have some evidence for our beliefs but it is inconclusive; informal reasoning is reasoning that we utilise in our everyday lives, and good and bad arguments are distinguished by practical reasoning. According to Bandman and Bandman, this practical reasoning allows practitioners to choose those arguments that result in credible beliefs and actions. I find that these definitions of the types of reasoning guide me to focus my thoughts on the issue or problem that I am concerned about. It is no use indulging in "fuzzy" thinking or blaming external influences when the issue is to do with me and my thought processes.

According to van Hooft, Gillam and Byrnes (1995), nurses, as professionals, need to be skillful reflective practitioners who contemplate deeply, individually and collectively, to understand their goals, and clients and peers' expectations in order to make informed responsible decisions. The ability for nurses to think critically is crucial to the health and well-being of patients. Nurses need to keep up-to-date with treatments, procedures, and health policy to be able to make up their own minds in any circumstances, and to act with ethically responsible judgement (van Hooft et al.). The nursing process elements of assessment, planning, implementation and evaluation are critical thinking activities and in any given situation, a nurse will identify a patient need by using the nurse's knowledge and experience of assessment. Discussing this assessed need with the patient, if possible, planning interventions and objectives are agreed on. Goals are set and strategies implemented to alleviate or modify the patient need. Finally, the whole process is evaluated by comparing the objectives set in the planning phase, with the known outcome. If these objectives have not been met, the nurse reviews each component of the situation to uncover the reasons why the outcome has not been met (Bernhard \& Walsh, 1995).

While I agree with Taylor (2000) that critical thinking is best suited for technical reflection, I find the process of critical thinking is part of all my reflection processes. When I have an aha moment I can use critical thinking strategies to explore the insights and gain a deeper understanding of my practice. According to van Hooft et al. (1995) 
important elements in critical thinking are: being aware of the differing perspectives of the people involved in an event, being self-aware, having an awareness of the points of view of others, and considering issues with sensitivity and empathy. Glaze (1998) suggests that the ability to become critically aware is more than simply examining an event to see what should be done differently, it has a political perspective that seeks out political ideologies and assumptions that need to be challenged. This awareness of contrasting perspectives is reflected in the complex work of nurses that requires a depth of knowledge that necessarily means that people outside nursing must rely on them to provide optimal care. Moreover, Glaze contends that this professional knowledge leads to a situation where those same people lack the understanding and expertise required to examine and evaluate nurses' performance. While van Hooft et al. (1995) affirm that governments set the laws governing health professionals, it is the nursing profession that employs professional organisations to uphold nurses' responsibility and accountability. Another avenue for maintaining standards of practice are nurses' use of professional supervision. In a secure environment, a skilled supervisor or counsellor assists a client to examine incidents in practice and to devise ways that problems might be resolved (Irvine, 1998).

Encouraging nurses to write reflective journals, Taylor (2000) argues that in order to make changes to their practice by reviewing and reflecting critically on incidents in practice situations, possible answers can be explored and improvements made. Even though reflective journaling might not be as critical as some would see as optimal, writing down my own thoughts of work and practice provides a means for examining problems and finding resolution. Hanrahan, (1998) who is an educationalist, describes how reflective journaling assisted her in her dialogue with colleagues and others when she was completing her Doctor of Philosophy Degree.

The issue of reflective journaling raises a question for my research. What effect did journaling for the inquiry have on the research, and how did our shared reflection influence our practice? Over the period of the research, I noted that my way of writing my reflective journal changed. Before beginning this research my practice had been to record incidents in practice $\mathrm{I}$ had problems with, or that had affected me in a personal way. I did not share my thoughts and reflections with anyone else for fear of ridicule or rejection of my concerns. Becoming conscious of the different elements, values, depths 
and ways of reflecting, and becoming confident in sharing my thoughts with my coresearcher, has had the effect of helping me clarify and express my thoughts, in writing and talking. It also provided me with a different perspective to explore practice issues. Although my co-researcher did not keep a journal or read about reflective practice, she reported that during the research process her reflections and our meetings brought about changes to her practice.

Nurses' practice should be informed by practitioner research, according to Ghaye and Lillyman (2000) as it supports, nourishes and enhances our professionalism and reinforces our sense of autonomy and professional and ethical responsibility. However, I believe that to allow a thoughtful analysis of ethical issues, I need to understand and appreciate whom I am as a person and as a nurse, a knowledge, and an understanding of my values and beliefs and what these mean to me as a nurse.

\section{8 - Reflective ethics}

As a person who is a nurse, I have values, and beliefs, goals, social roles and commitments, life experiences and personal moral rights. My early nursing experience of following deontological and utilitarian philosophies meant that I pursued familiar traditional rules and lores without thinking of the consequences to individuals (myself included) and society. Following the passing of the Nurses Act (1977) I became more aware of my accountability and responsible for my practice and I began to understand the need to gain a greater understanding of my role as a moral agent in the provision of health care.

According to Rogers and Niven (1996), it is no longer acceptable for nurses to abide by another profession's moral authority and they should challenge these authority structures. Critical reflection and analysis of processes that deny nurses moral authority could assist nurses in gaining a voice and empower them to speak out on behalf of their patients and themselves. Street (1995) challenges nurses to identify moral judgements that affect the way that they work and interact with patients and colleagues. Taking notice of our taken for granted values and reflecting on how they impact on our judgements and actions towards others, whose values are different, will enable us to become more sensitive to the consequences of our language and behaviour. For example, when listening to the 
audiotapes for this inquiry, I was disconcerted to find that I was more task-focused to begin with and that I was not clear when giving information.

Critical reflection enabled and empowered me to change my language and behaviour to benefit patients. However, experience has taught me that knowing what I need to do to empower and enable patients is not always easy in practice, and it is frustrating when organisational constraints work against a new way of being or responding.

In addition to these kinds of issues and in relation to my inquiry, I question whether my co-researcher and I really had consent from our patient participants to bring them into our reflective discussions. While I chose a colleague who worked in another town and would not be able to recognise any of my participants, and the participants were aware of the process of the research. Talking about them and their way of being in a research sense did not sit entirely comfortably with either of us. The feeling that we might inadvertently expose a participant, or not treat their information with due respect was always present. In addition, my use of journaling to assist my reflections and the reflections of people, such as my co-researcher, are not part of the usual documentation that patients can have access to, according to Hargreaves (1997), and patients are usually unaware of this process.

\section{9 - Conclusion}

Researchers and practitioners endeavouring to influence and inform their own practice, as well as the practice of others, and to create and maintain changes that benefit individuals, organisations and society, have used reflection in many ways. When nurses reflect on their practice they can make sense of what they do and use their imagination to raise their awareness of empowerment and liberation and emancipation to bring about change in their practice.

The cyclical process of reflection is a significant strength of reflective practice, as is the belief that change can be achieved by evolving insights and understandings from practice. Reflecting before action, in action and on action will help in creating change. An additional factor is that the results of these reflections can be organised into theory and tested in practice as a basis for further development. While critical reflection involves respecting and working with evidence like other categories and types of reflection it is 
liberating and empowering and teaches nurses to act on their own knowledge and not to rely on the knowledge and attitudes of others. I have discovered the reflection process can be long and arduous, as it takes time, effort and commitment to become expert reflective practitioners. Critical reflection has an important position in nursing and in my practice. It assists me in analysing the processes that deny me moral authority and gaining voice to empower me to speak out on behalf of people and myself. Reflection is transformational because it challenges me to examine my beliefs and values and the significance these have in my everyday practice.

The practice of reflection needs to be nurtured and supported to prevent not only neophyte practitioners from loosing confidence and self-esteem but also experienced practitioners to maintain their reflective skills. Throughout this inquiry I have experienced that continuing reflective practice, alone, and with my co-researcher, taught me to value myself, and that contemplative practice is a good place to begin reflective practice. In addition, while it may not solve all issues in practice or life, its is a useful resource in helping nurses to face the dilemmas that life brings.

Although reflection will remain an important tool for me to use to make improvements to my personal life and those with whom I interact, how I used reflection in my inquiry is still to be discussed. The next chapter, Chapter 4, explores the action research methodology I chose for my inquiry. 


\section{Chapter 4- Methodology}

\section{1 - Introduction}

The work of practice nurses (PNs) includes a large practical element such as giving vaccines, syringing ears, caring for wounds and taking cervical smears. Most PNs are employed by General Practitioners (GPs) in general practice and many nurses have their own consultation lists. However, in a significant number of practices, much of the work of the nurse is generated by referrals from the GP. In addition to nursing duties, some GPs require nurses to act as receptionists. In the surgery where I work, this dual function applies when the receptionist is away for lunch and other times when she is unavailable. In my experience, there are times when I can become so busy speeding from task to task that I tend to suppress my intuition that the care I am providing patients is less than it could be if I had more time to give to each person.

One reason I chose an action research methodology for my research inquiry was because I was looking for a method that would work in the general practice setting and answer my question, "What do my co-researcher and I need to do to improve our communication and practice?" Critical reflection was an essential part of this process to make changes to improve nursing practice, and this reflective action research inquiry goes some way to addressing the question with results being transferable to other patient encounters.

This chapter gives the reasons and purpose for choosing this methodology for my research inquiry, as well as a description of the design and data analysis of the research. I describe the history and evolution of action research starting with the critical social science philosophy of Habermas (1972) and the work of social psychologist Kurt Lewin (1946) who formulated the concept of action research in the United States of America (USA).

Reference is made of the parallel development of action research at the Tavistock Institute in Britain. This chapter also describes diverse typologies, definitions and approaches to action research, followed by examples of how these are used in nursing research and nursing practice. Finally, I explore the theoretical/conceptual framework for my research inquiry as well as methodological issues relating to data gathering. 


\subsection{1-Reasons for choosing action research}

Another important reason I chose action research is because it combines the upward spiraling cycles moving towards change with a depth of vision and clarity that other qualitative methodologies do not hold for me to the same extent (see Figure 2).

My reading of literature for this inquiry has demonstrated that there is an argument as to a precise definition of which action research approaches and typologies to use. However, I have put this debate aside in my research.

The fluidity of the process and possibilities for imagining improvements to patient care and nursing knowledge resonated with me. In addition, the possibility that action research creates for empowering and liberating both patients and nurses is an important political issue.

Despite action research's limitations such as the conceivable indistinctness of the outcomes (Zuber-Skerritt 1992), this study aims to empower and enable people by changing language and nursing practice. My inquiry is based on the work of educators Carr and Kemmis (1986) reflecting their belief, and that of Zuber-Skerritt (1992) who assert that emancipatory research is true action research.

Following much thought and reflection as to how best to illustrate my concept of action research and looking at the numerous pictures other authors have drawn of the cycles, the idea for the diagram in Figure 2 arose from the Atweh, Kemmis and Weeks (1998) concept. Atweh, Kemmis and Week's diagram shows a three dimensional, vertical downward spiral of cycles, while my concept follows the traditional upward focus of action research. In addition, the gradual incline my design emphasises that action research takes time and effort to achieve changes.

Although my drawing on the following page shows only three cycles of action research cycles, it does demonstrate the upward, onward and unlimited ability of the cycles to continue. Unlike most other drawings of action research I have observed, it demonstrates the depth and breadth of this kind of inquiry. 


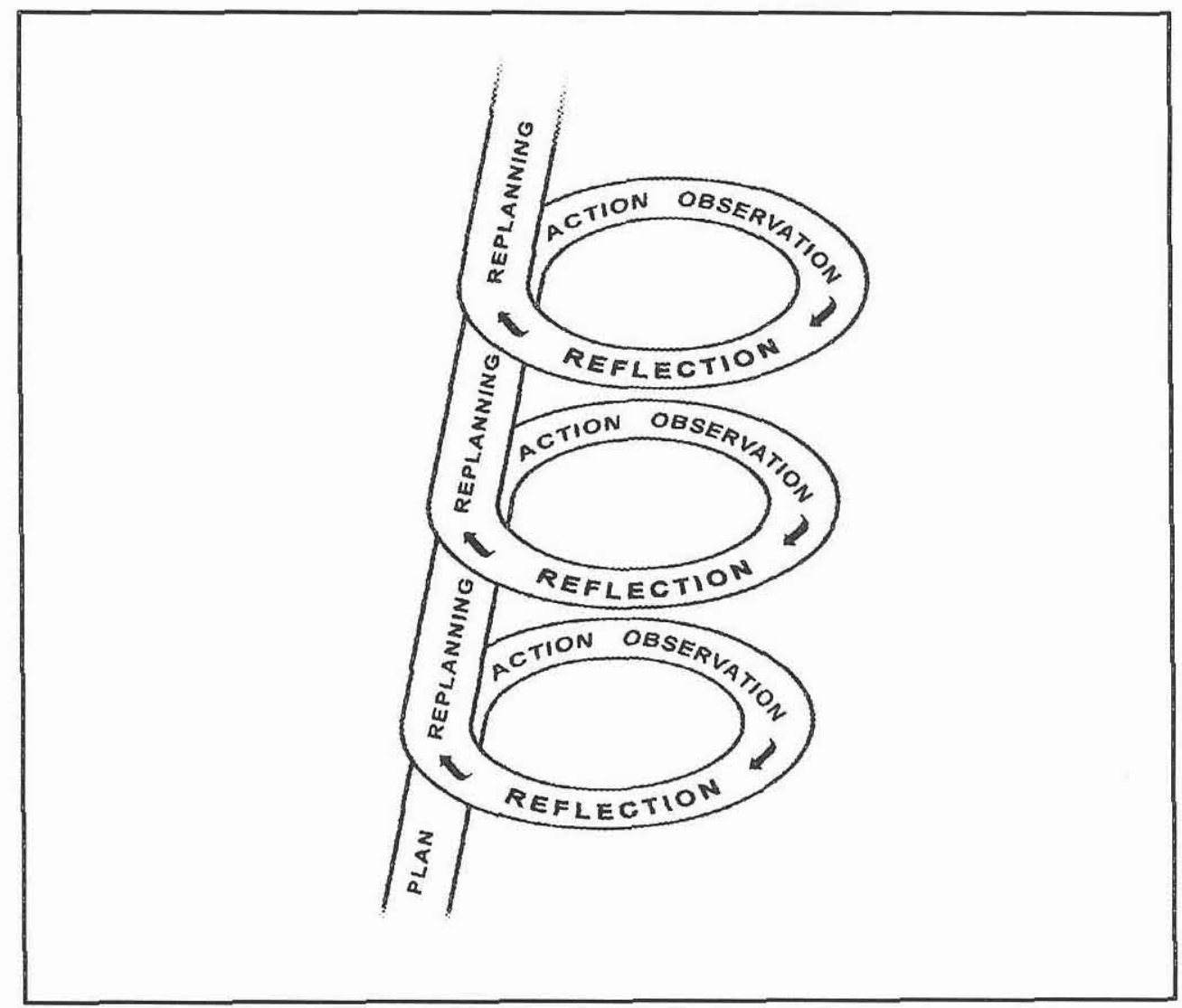

Figure 2. A self-reflective spiral in action research.

According to Holloway and Wheeler (1996) action research entails interventions on a small scale, that creates an effective and practical strategy for nurses to reflect critically on their practice. In my experience, critical reflection creates the potential to bring about desired change and/or refinement of nursing practice thereby enriching the care and environment of individuals or groups, whether they are patients or nurses. Even though action research is a challenging method, because change is occurring throughout the process, its mutual collaborative approach and freedom as to where the research can take place, allowed my colleague and I to undertake our interactions with patients in separate general practices. Reflecting critically on my own nursing practice and an in-depth knowledge of practice nursing led me to conclude that an action research inquiry was an fitting method for my study.

\section{2 - History and evolution of action research}

\subsection{1 - Critical social origins}

Action research is rooted in critical social theory and has a historical, realist ontology that, over time, is shaped by economic, cultural, ethnic and gender factors (Denzin \& 
Lincoln, 1994). Although grounded in critical social theory's subjectivist epistemology where knowledge comes from imposing meaning on the object, Crotty (1998) contends that action research differs from that doctrine by embodying Habermas's (1972) and Freire's (1972) critical social science philosophy. Critical social science is defined by Habermas as a social process that combines collaboration in the process of critique, with the political determination to act to overcome contradictions in the rationality and justice of social action and social institutions. Habermas and Freire believed that social conditions can distort a person's self-perception, and that reflection-on-praxis is a way of integrating theory and practice.

In keeping with Habermas' (1972) critical social science philosophy, action research becomes emancipatory by creating self-critical communities of people who participate and collaborate in all phases of the research process. According to Carr and Kemmis (1986) these communities are informed by their research into the relationship between circumstances and actions and the consequences of those actions, seeking ways to improve their situations. This view is supported by Kilgour and Fleming's (2000) action research study of a health visitor parenting programme for parents of pre-school children with behaviour problems. Although the study exposed that vulnerability, powerlessness, and hegemony (of parents and teachers) was experienced by both parents and children, expressions of empowerment and reflection were clearly expressed by women who felt powerful in their mothering role (Kilgour \& Flemming, 2000).

\subsection{2 - Kurt Lewin's influence}

Social psychologist Kurt Lewin (1946) coining the phrase "action research" developed the concept of cycles of self-reflective spirals of planning, fact-finding and execution, as a technique to improve industrial production after World War Two. Although Lewin was involved in helping social workers with their problems in practice, he was also concerned about the perceived political threat to democracy from communism. He asserted that action research could lead gradually to independence, equality and co-operation that empowered people to make changes to the policies of permanent exploitation. About the same time that Lewin was exploring theoretical and practical problems to gain deeper insight into the laws that govern social life in the USA, researchers at the Tavistock Institute for Human Relations, in England, were increasingly interested in how action research could be used to overcome problems between theory and practice. 
According to Holter and Schwartz-Barcott (1993), the work of Lewin, and the Tavistock Institute in the 1940's and 1950's, were the major forces behind the development of action research throughout the world. However, over time and in contrast to these early developments, researchers chose to emphasise group decision-making as a matter of principle rather than as a technique. By embodying democratic principles in research, participants were able to influence and/or determine the conditions of their own lives and work. For example, Swanson (1952) suggested that groups could collaborate to develop critiques of social conditions that sustained dependence, inequality or exploitation. In other words, the value of equal and collaborative discussions of the researchers and participants enabled those people who desired change to explore ideas that the group decided on. This group decision making process was perceived as more important in creating and maintaining political change than the action itself.

\subsection{3 - Expansion into education}

The evolution of action research continued in a number of areas, and according to Meyer (1993) it progressed from Lewin's functionalist approach through an interpretative tradition to where the current emphasis is placed on the practitioner as researcher. This is emphasised by Carr and Kemmis (1986) who helped develop action research as an especially useful tool in the classroom where educational research traditionally had been the preserve of researchers who designed curricula for schoolteachers to teach. Until the 1970's, according to Carr and Kemmis, there had been no mechanism for teachers to generate their own ideas for education.

Researchers became increasingly aware of the possible benefits of action research for reflecting on practice and creating changes that action research could bring. As a consequence of this awareness, researchers at Deakin University in Victoria, Australia, trialled action research to enable changes to the way in which school teachers and students communicated in the classroom (Carr \& Kemmis, 1986).

School teachers from the same school or different schools could collaboratively participate in the research programme and in their own learning process. Zuber-Skerritt (1992) note that curriculum development, professional development, school improvement programmes, systems planning and policy development also became targets for change using action research. 


\subsection{4 - Action research and nursing}

Humanistic sciences were perceived to be an alternative to the natural sciences that reflected nursing concerns in the past (Holter \& Schwartz-Barcott, 1993). Action research was seen as a valuable and viable method to address issues relating to nursing practice with Holter and Schwartz-Barcott noting that studies by nursing scholars date back to Lauri (1982), Smith (1986), Hunt (1987) and Webb (1989). Parmee (1996), Cowley and Billing (1999), and Mepham, Tripp, Gaines and Brunnock (2000) demonstrate more recent examples of how action research has influenced nursing practice in inquiries.

Parmee (1996) explored nurses' and patients' experiences of living and working with asthma using two parallel spirals of action research. One spiral explored the group members' experiences while the other spiral followed the group itself through the research process. The groups came to understand each other's perspectives and found areas to change. Cowley and Billings (1999) explored ways of implementing a new health visiting service. GPs in Britain had recently been empowered to purchase community nursing services and research was needed to identify the needs relevant to families. Cowley and Billing's study revealed that there were organisational constraints with the delivery of services that could be changed to improve the delivery of health care, and consequently, two new health visiting positions were established. Mepham, Tripp, Gaines and Brunnock's (2000) inquiry looked at procedures to improve cardiac care by introducing a telephone help-line to address the concerns of discharged patients, and their families. Using two spirals the cardiac team, not only explored the process of changes in practice, they also measured the outcomes of the results of those changes.

\section{3 - Action research}

\subsection{1 - Insight into action research}

For Carr and Kemmis (1986), action research expresses the reflection, enlightenment and political struggle accomplished by groups for the purpose of their own emancipation. Its two essential aims are strategic action that is taken to understand and improve practice, and the collaborative involvement of those who are in the group or organisation. Action research is undertaken by participants in social situations in order to improve the rationality and justices of their own practices. Carr and Kemmis maintain that action research is self-reflective inquiry that assists participants to understand their practice and 
the situation in which those practices are carried out. By thinking critically about their practice and discussing ideas and theories that form the basic tenet supporting best practice methods, people become enabled and empowered to make changes that benefit a group, organisation and/or themselves (Carr \& Kemmis, 1986).

Action researchers take a dialectical view of rationality and recognise that there are objective aspects of social situations that particular individuals are unable to do anything about at that time. At the same time, people's subjective understandings of situations can act as constraints on their actions. According to Carr and Kemmis (1986) action researchers perceive that these situations could be changed if they were better understood. For example, my objective understanding of my work place environment suggests that there are issues such as noise, lack of privacy, or where I carry out nursing care, are unchangeable. Simultaneously my present subjective understanding of the way that I deliver nursing care might also act as a constraint to care, as I might see my work as a series of tasks rather than meaningful interactions designed to assist people with health care. With a greater understanding and insight of both contradictions, new ways of working may become possible. For example, my employers could provide avenues for suggestions for improvements to the work place problems, and I might be encouraged to engage in types of reflection that will uncover different insights and understandings and ways of providing patient care.

As long as the group has a shared concern and acts collaboratively, Kemmis and McTaggart (1998) contend that the number of participant co-researchers could be many, or as few as one. Carr and Kemmis (1986) involved a teaching community working in the same or separate schools as participating co-researchers, the students, who would ultimately benefit from changes to the curriculum and improvements in teaching methods, were not involved as participating co-researchers. For my research I chose one PN colleague who works in a different surgery, as a co-researcher. The patients who consented to the ear syringing procedure as part of the research, were not involved any further in the reflection process or in the data analysis.

Further to its historical, realist ontology and subjective epistemology, Carr and Kemmis (1986) describe action research as expressing a constructivist epistemology that goes beyond critique to critical praxis where thought and action, or theory and practice, are 
understood as mutually constitutive. This means that neither thought nor action has ascendancy over the other. Crotty (1995) contends that truth and meaning come into being when we engage in the world, and meaning is constructed from what we learn and not just from the discovery. Action research is a collaborative inquiry where the researcher and the participants work together as co-researchers or research participants to develop knowledge by a process of active construction and reconstruction of theory and practice.

Although action research has clarity in its process of cycles, it can be approached from a number of different ways. Holter and Schwartz-Barcott (1993) describe three collaborative approaches - the technical collaborative approach, the mutual collaborative approach, and the enhancement approach, as well as the insider and outsider models of research. A further example of a collaborative approach is proposed by Tichen and Binnie (1993).

\section{4 - Approaches to action research}

\subsection{1 - Collaborative approaches}

The technical collaborative approach tests a particular intervention based on a prespecified theoretical framework. Reflecting Lewin's (1946) early work in action research, the technical collaborative approach applies existing theories in other settings. Armitage and Champney-Smith (1991) used this approach to introduce primary nursing into a ward, by involving a number of methods and pseudo-experimental forms of evaluation to implement and test the effectiveness of the interventions.

The mutual collaborative approach finds the researcher and practitioners coming together to identify potential issues and the causes of the problems, and then seeking ways of resolving them. As a consequence, the understandings of the problems and its causes find expression in the planned changes to practice. This mutual collaborative approach was chosen by Webb (1989) to describe the attempt by a researcher to work alongside nurses in a medical ward in order to evaluate their practice, with a view to making changes that would improve patient care.

The enhancement approach has two goals. Its first goal is to emphasise the increased closeness between the real problems encountered by practitioners in a specific setting, 
and the kind of theory used to explain and resolve those problems, as in the mutual collaborative approach. Its second goal is to help the practitioners raise their collective consciousness to shed light on the fundamental problems by raising questions about underlying assumptions and values. Practitioners are involved in reflecting critically on their practice and exploring the difference between what practitioners understand to be their underlying values and assumptions, and the unwritten laws that controlled their practice in reality. According to Holter and Schwartz-Barcott (1993), theory is generated by the reflective discussions between the practitioners and the researcher. For instance, in general practice, a researcher could be invited to assist nurses to resolve issues related to dividing their work between nursing and reception duties. Holter and SchwartzBarcott contend that action research can combine all three collaborative approaches or use only one or two.

For my research inquiry that looked at ways to improve communication and nursing practice in the context of ear syringing, my co-researcher and I embodied all three approaches. We formed a mutual collaborative partnership to undertake the study to make changes to practice in an effort to improve patient care. We used the technical collaborative approach to test the changes to our language and nursing practice, and the enhancement approach to emphasise the close relationship between the problem of time constraints that could lead to truncating the informed choice and consent process, and possible miscommunication between the nurse and the patient that may result in harm to the patient. The combination of these collaborative approaches enabled us to generate new knowledge and to make changes to our practice that benefited the patients as well as ourselves.

The variety of approaches is further confused by the issue of who undertakes the research project. A researcher may come in from outside the organisation, or from inside the organisation, or be a combination of outside researcher and inside practitioner who work together to explore practice issues. This concept has resulted in two action research models being documented as the 'outsider' model and the 'insider' model.

\subsection{2 - Outsider, insider models}

The outsider model is described by Holter and Schwartz-Barcott (1993), as a situation in which the researcher brings expertise in theory and research to the field of study (e.g. 
primary care nursing), or a particular perspective (e.g. social psychology). However the researcher has no local knowledge and returns to her/his place of work (e.g. university) at the end of the study. The action research inquiry by researchers Wadsworth and Epstein (1998) that sought to build dialogue between consumers and staff in acute mental health services would come into this category. However, according to Holter and SchwartzBarcott problems arise with this model if the researcher and participants have conflicting notions of where the research needs to be directed.

The insider model combines the roles of the practitioner (e.g. clinical leader with authority for initiating and managing change), the change-agent, and the researcher. While this model has advantages, it becomes problematic when the participant or change agent is also the researcher. Using an action research framework with an insider model, Mepham, Tripp, Gaines and Brunnock (2000) introduced a telephone cardiac help-line. This study responded to the need expressed by a number of patients who had been discharged from hospital who considered that they had insufficient knowledge to care for themselves adequately. The cardiac support nurses analysed the experiences of their patients who had been in hospital and designed the help-line to improve the care delivered to patients.

\subsection{3 - Double act model}

Tichen and Binnie (1993) have added a fourth approach that they developed, the collaborative group model that involves the researcher and participant in a 'double act'. This double act combines both an insider model and an outsider model that could overcome the difficulties of the insider/outsider models. This model differs from the group model described by Carr and Kemmis (1986) by facilitating collaborative groups of reflective practitioners, change agents and researchers, rather than groups of coresearchers from the same area of practice.

Tichen and Binnie (1993) describe their research process where the researcher and participant complement each other's positions in the research project. This double act occurred when the researcher (Tichen) and practitioner (Binnie) carried out the roles simultaneously as both were experts in their fields of practice using their knowledge to complement each other's places in the research project. At times both the practitioner (insider) and the researcher (outsider) roles are carried out simultaneously. 
The double act model has the advantage of generating knowledge for practitioners who need the assistance of an outside researcher. Although the inquiry that my co-researcher and I undertook was outside the experience of the patients, it was best suited to the insider model as we, as practitioners, were able to reflect critically and support each other with our new insights and understandings.

\section{5 - Action research typologies}

In addition to the insider/outsider models for conducting research, there are at least five different types of action research's reflection-on-praxis methodology described in the literature. These are: Participatory Action Research (PAR), Praxis Research, Generative Action Research, Action Learning and Action Science. Some other participatory research activities involving action are: Reflective Action Research, Participatory Research and Critically Reflexive Action Research. Each of these types of action research is employed for different research purposes according to the needs of the researchers and participants. In this next section I will present a brief overview of some of these different types of action research.

\subsection{1 - Participatory action research (PAR) and participatory research (PR)}

Participatory action research (PAR) is defined by its doctrine that people in the organisation or community on whose behalf the inquiry is being undertaken, actively participate with the researcher throughout the research process from the initial design to action, and the final presentation (Lindsey \& McGuinness, 1998; Rogers \& Palmer-Erb, 1994). Describing PAR as being directed at cultural change and improving a given situation, Street (1995) asserts that a group of committed nurses has more chance to make changes than a single person. While this definition closely resembles participatory research (PR), Wadsworth (1998) claims that its emphasis is on the liberation and empowerment of individuals by using the action research process.

\subsection{2 - PAR and action research}

Some researchers, such as Ellis and Kiely (2000), contend that there are definite distinguishing features between PAR and action research, such as the difference in emphasis that PAR places on awareness of social conditions and the liberation and empowerment of individuals and groups. As a consequence, in large organisations it can mean that power rests with the researchers and workers find it difficult to enable and 
empower themselves to open up opportunities for transformational change (Park, 1999; Wadsworth, 1998; Weil,1998).

Most types of action research require more than one person to achieve the aim of changing practices in groups or organisations, but there are times when the action research cycles might be used with effect in other situations such as one-on-one circumstances.

\subsection{3 - Praxis research}

Nursing often involves one-on-one interaction and therefore group participation is not relevant for this form of research. As a counsellor, Fahy (1996) found praxis research to be a useful approach to empower individual clients and to uncover knowledge that is embodied within the nurse-patient relationship. According to Fahy, critical action research, or praxis research, is described as an on-going spiral of practice, self-reflection, scholarly inquiry and theorising that leads to changed practice. Although praxis research generates knowledge for practitioners who work alone I see that its usefulness could be extended to areas of practice where practitioners want to make changes to their own situations or the way in which they practice. However, there are times when other issues become apparent within the research process that may impact on the participants or researchers but are not able to be addressed at the time, and an approach that took these issues into consideration is required.

\subsection{4 - Generative action research}

Generative action research is an approach described by Waterman, Webb and Williams (1995) that allows researchers to be attentive to the main focus of their studies, while at the same time being able to follow up different problems. For example, during the ear syringing procedure, a patient might express anxieties about family difficulties that in other action research processes are not accommodated at the time, but by pursuing the generative action philosophy, I would be able to address this issue during the consultation.

While generative action research allows nurses to attend to different problems raised within the research process, nurses need to continually review and renew their skills and knowledge to be able to provide the best care they can. However, there are many 
instances in general practice when nurses are unable to be released from work to attend education sessions that take place in another town and at a time that does not suit. Action learning is a method of action research that could address this educational issue for nurses.

\subsection{5 - Action learning}

Action learning is a process where nurses, supported by co-workers, meet to reflect on issues of practice. Action learning is a continuous process of learning and reflection with the intention of getting things done, and aims to encourage individual nurses to use reflection, by holding regular group meetings. Directed by an experienced facilitator, nurses attending these meetings challenge the person who is presenting a problem for discussion. Kirrane (2001) describes six stages of action learning from acknowledging that there is a problem to planning future action. The facilitator uses these stages to structure the reflective process during the action learning programme. Kirrane argues that by using reflection, individuals or groups can make changes. With the assistance of an experienced facilitator, peer review could be an avenue to explore action learning.

While PAR, praxis research, and generative action research seek to make changes and improvements to practice, attention also can be focused on the behaviours, attitudes, feelings and emotions of colleagues in the workplace. Action science is seen as a mechanism to change work-based and interpersonal behaviours.

\subsection{6 - Action science}

Agyris and Schön (1991) assert that action science explores people's feelings and emotional reactions in order to break down defensive mechanisms so that changes to organisational patterns, processes and defensive routines can be made. According to Kim (1999) action science includes Habermas' (1972) critical social theory and Bourdieu's (1990) theory of practice which asserts that the study of practice must include not only an understanding of habit, but also the accommodations and adaptations that are uncovered in practice situations. If another GP experiences difficulty in changing a PN's way of working, the feelings and reasons for the PN's resistance should be discussed with the PN. The GP would clarify the need for the request for change and perhaps point out that the particular regime the nurse is following is no longer necessary, to provide expert health care. 
Because my research is practice-based, the questions I asked reflected my nursing practice. An action research inquiry grounded on the work of Carr and Kemmis (1986) involving reflective cycles of planning, acting, observing, reflecting and replanning provided a formula that is simple to follow, made sense to me, and is a medium for ongoing reflective practice and change. My co-researcher and I adopted the technical, mutual collaborative and enhancement approaches, as they did not necessitate the inclusion of a group of patients, as each audiotaped interaction involved a different patient. Furthermore, action research allowed me to have one co-researcher with whom I had already developed a personal relationship and trust, rather than a group of, perhaps unknown, individuals.

\subsection{7 - My comparison of participatory and action research inquiries}

Comparing the different types of action research has been an interesting process for me as some researchers have used titles interchangeably, or made subtle changes to the definition of action research to fit their own inquiries. However, I have found that there are distinctions and I will describe them as I have observed them.

Participatory research is collaborative, mutually educative and acts on the results developed from the research questions. It strengthens partnerships by joint development of research agreements for the design, implementation, analysis and dissemination of results that could be applied locally or be transferred to other communities. According to Macaulay et al. (1999), although participatory research is a collaborative form of inquiry, emphasis is placed on participation leading to systematic planning and action rather than critical reflection. Whole communities participate in the inquiry, unlike action research that can have as few as one co-researcher. Researchers who are able to provide the necessary research skills can be sought from outside the organisation to work along-side members of staff (co-workers) who are seeking to improve their practice, management systems, or curricula, for example (Kemmis \& McTaggart, 1998; Zuber-Skerritt, 1992). This type of research uses the insider/outsider model.

While Street (1995) states that people involved in participatory research are commonly called participants, research participants or co-researchers, and Holter and SchwartzBarcott (1993) talk about researchers and actors, I have followed action researchers such 
as Carr and Kemmis (1986) and Kemmis and McTaggart (1998) and used the term "coresearcher" in my study. This is because the term co-researcher describes the collaborative and supportive relationship between my co-researcher and myself, and it denotes an equal partnership between researchers. However, throughout this chapter and in other contexts I have referred to others involved in action research as participants.

\subsection{8 - Making sense of this knowledge}

Knowledge of all these types of action research is valuable as they can be used to fit individual and unique nursing situations. Although action research, with its many interpretations and approaches often overlap, these overlays are beneficial when applying action research to the variety of situations encountered in nursing practice. Each type and model highlights different explorations and discoveries and the subsequent insights and understandings are reflected in the enhancement of nursing care and changes to practice. However, confusion concerning the roles of the researcher, co-researcher and participants, for example, as well as the balance of power, contribute to the criticisms and limitations of action research.

\subsection{9 - Limitations and criticisms of action research}

Researchers using action research need to be aware of potential problems to be able to discuss and validate clearly the outcomes of any study (Holter \& Schwartz-Barcott, 1993). As a supposedly collaborative process action research implies an equal relationship between researcher and participants. Street (1995) finds that problems with action research arise when the institutional constraints surrounding the project may be such that although changes are deemed necessary the means of introducing the changes may not be available. For example, PNs may see that changes need to be made to protect patients' privacy and confidentiality during the research process, however institutional constraints such as the availability of a private room, prevent this from being addressed. Meyer (1993) contends that time needs to be spent in reflection to resolve issues that may arise during the research process, such as participants not wishing to change, or wanting to discontinue the study because of personality differences. Further, Meyer found that while the intention was to offer an egalitarian relationship with participants, if the researcher comes from outside the context of the situation to be studied, that person could be seen to be in a more powerful position than the participants. In addition, there are times when participants are put at risk and become vulnerable or unco-operative due to 
the nature of the research, and Meyer questions where her loyalty should lie; with the vulnerable unco-operative participant or with the remainder of the team? However, this aspect was not an issue for this inquiry.

I disagree with Waterman, Webb and Williams (1995) who contend that action research contains features of the nursing process and does not take into account the many variables and shifts in ideas that happen in nursing research. I argue that while, at a technical level, action research has aspects of the nursing process, it does acknowledge that people are not rigid and isolated entities. It does recognise the variety of internal and external factors that influence people's health, as well as the interest of the research participants. While action research can mirror evaluation and audit processes, Mepham et al. (2000) contend that it goes further by seeking not only to reach the goal and solve the problem, it also generates new knowledge. The goal of the research originates with the participants, not the organisation. Meyer (1993) contends that action research is more than a strategy for professional development as it is the systematic inquiry and publication of its findings that differentiates action research from professional development. In addition to these contentions, Zuber-Skerritt (1992) acknowledge that time constraints are often a factor when determining when to terminate the study. Parmee (1996) for example, cites the need to complete her thesis as the reason to terminate her study into nurses and patients experiences of living and working with asthma. Timing of my inquiry will be discussed in the following chapter.

\subsubsection{0 - Limitations of consent in action research}

The issues of informed choice and consent described by Meyer (1993) revolve around the difficulty with action research's unknown outcomes, and it is difficult to give full informed consent when the process is developing as the future is an unknown factor. Because action research needs the participants to act together as co-researchers in the project, issues of confidentiality and anonymity arise if participants discuss the project with each other outside the research arena. This creates the potential to harm vulnerable individuals who may then wish to withdraw if they become distressed at what others have discussed.

While these are valid issues for some research inquiries, the question of informed choice and consent was not the same for my research inquiry. In addition to gaining a patient's 
consent, I needed to ensure that my co-researcher fully understood the aims of the research and what the study would mean for her and her employers. To do this I developed an information sheet that described the inquiry, the benefits of participation and the rights of the patients who became involved, and I also detailed how the results of the inquiry would be disseminated (see Appendix 4).

\subsubsection{1 - Limitations of ownership}

Parmee (1996) found that even though the project is often initiated by the researcher, the co-researcher/participant are also researchers, so the question of who 'owns' the work can be problematic. In a collaborative study according to Meyer (1993) the participants are supposed to own the findings that are returned to them by the researcher. Importantly, when I reflected on this assertion, in the design phase, I kept my coresearcher fully informed and involved in the decisions that enabled her to participate on an equal basis.

\subsubsection{2 - Considerations of my research limitations}

I gave considerable thought and reflection to this aspect of the research process, as I wanted to hold true to the equal collaborative partnership of the action research philosophy. My reflection and thinking resulted in acknowledging that $\mathrm{I}$, as the principal researcher still retained control of the process and that my research for my thesis belongs to me, although the practical section with patient interactions could not have been as effective without my co-researcher. Meyer argues that while collaborative approaches assume that research is done with and for people and not on people, in reality this might not be possible, and it could be argued that although my research includes a colleague as co-researcher, it also involved patients as participants. This involvement of perhaps vulnerable patients raised the issue of power, as co-researchers we would be able to influence patient participants. While I accept this possibility, I contend that this issue is the same for many research projects and not limited to action research, and patients in this research inquiry were provided with information to make a choice whether to take part or not.

Increasingly, action research has evolved to take into account the diversity of practice situations and approaches for reflecting critically on practice to create change. However, when I was formulating my proposal these differing approaches caused me significant 
confusion. My bewilderment adds weight to Holter and Schwartz-Barcott (1993) who contend that the variety of approaches, definitions, interpretations that are applied to action research has resulted in confusion for many researchers. My quandary continued when I noted that in the book Action research in practice (1998) edited by Bill Atweh, Stephen Kemmis and Patricia Weeks, the terms action research and participatory action research were interchangeably.

\section{6 - This reflective action research inquiry}

In general practice, it is not always possible or reasonable to pre-book patients requiring ear syringing, as many people are unaware that their ears are blocked with wax until the doctor or PN has examined them. Furthermore the nature of PN's' work means that they might be required for other tasks at short notice. I could have undertaken the study alone as Fahy (1996) demonstrated, but careful thought indicated that mutual collaboration with another PN would be needed to reduce the risk of reflection without change and to obtain greater validity and trustworthiness. I felt that I needed another person to challenge my practice and language as well as my interpretations of patient interactions. A nurse from another surgery, such as my co-researcher, who thinks differently to me and has contrasting working conditions, seemed to be an appropriate way of maintaining validity and trustworthiness.

An action research inquiry with its reflective spiral of cycles was chosen to find out, in the context of ear syringing, if there were any changes nurses could make to language and practice to reduce the anxiety and stress patients occasionally experience during this procedure. The fluid, open and responsive process of action research suited this particular inquiry as changes could be made throughout the process to take into account the diversity of individuals and circumstances when carrying out the procedure.

According to Atweh, Kemmis, and Weeks (1998), action research does not rely on following faithfully the steps of the cycles to be a success, but rather depends on whether the co-researchers or co-participants have a strong and authentic sense of development and evolution of their practices and the situation in which they carry out that practice.

During the initial planning of the research, my co-researcher and I had discussed with patients and others, how they would feel about being videotaped while having their ears 
syringed. Without exception, all clearly stated that they would not want to be filmed in this situation. Using audiotapes to gain information rather than videotapes was a wise choice in the circumstances. In addition to placing people at risk, the practicalities of the environment, and filming as we moved around the patient, would have been problematic. Because my intention was to test the effectiveness of one aspect of a nursing procedure, that is the on-going change in a PN's practice where reflection-in-practice originate, the idea of conducting a randomised control trial was discarded.

Throughout the period of this inquiry and writing up I have kept a journal specifically for this research process. While I do not describe my journaling here, I have used my thoughts and reflections from it as illustration in Chapter 7 Stream 2.

\subsection{1 - Choice of co-researcher}

Finding a nurse who shared a similar philosophical belief and whose commitment to continuing education and research was simple for me. Originally, my co-researcher and I met at committee meetings of the New Zealand College of Practice Nurses NZNO of which we are both members, and I grew to appreciate her astute and open mind. Further, while we both work part time, our employment situations had differences. I work in a small town with a large transient seasonal and tourist population and I am employed by one GP but share the working week with two other PNs. My co-researcher is employed by two GPs in a large town where few people who are not part of the practice population, visit the surgery, and her job is shared with one PN. In addition to these peculiarities, our workplaces are managed differently. In my co-researcher's surgery, and in addition to GP referrals, PN's have their own patient consultation lists that allows patients to see the PN without also consulting the GP unless the PN initiates that referral. In contrast, where I work, the vast majority of patients have a consultation with the GP prior to being referred to the PN.

In relation to my inquiry, patients at my co-researcher's practice requesting ear syringing need not first consult the GP, whereas in my workplace, patients must always have a consultation with the GP prior to the procedure. Our working environments for consultations for procedures such as ear syringing with patients differ as well. My coresearcher has the use of a private room, whereas I am required to carry out this type of task behind a curtain, meaning that anything private and confidential is unable to be 
discussed at the time. These distinctions and perspectives of practice created an increased potential for improvement and change as we had different experiences in the provision of patient care.

\subsection{2 - Ethics}

Prior to the research being undertaken, I had discussed with my co-researcher and employer, ethical issues that such a project might generate. Importantly, the issues of confidentiality, privacy and informed choice were addressed. We needed to be very clear about what the research was about and the context that the results would be used in and that patients had the choice to decline without altering the care they received. To assist in this aspect of the research, I provided written information sheets that explained the reason for the research, the manner in which it would be undertaken and how the results would be used to improve nursing practice and patient care (see Appendix 4). In addition, I was mindful of the requirement to provide potential participants with sufficient information that could be readily understood, and allowed time for them to address any issues that might arise for them. Patients and employers were given the opportunity to request a report of my findings if they wished. Furthermore, my co-researcher agreed that the research was not to be used for anything else than our own practices and undertook not to breach any patient's privacy or confidentiality.

Ethical approval gained from the Nelson Marlborough Ethics Committee for this study to be undertaken (see Appendix 2) addressed issues relating to the scientific basis and background for the inquiry. It included the specific aims of the research, the number and identification of participants, and recruitment of participants. The design of the research was explained and that data for this inquiry was to be collected over a three cycles. Furthermore, the risks and benefits of the research and the expected outcomes of the inquiry were detailed. In addition, the application addressed information and consent processes, confidentiality, the Treaty of Waitangi and budgetary issues. Importantly for this inquiry, the confidentiality and privacy of patients in two busy general practices was addressed, as it was not always be possible to protect the identity of participants from other members of the health care team.

My co-researcher and I work in different towns, however, assisting in the protection and confidentiality of participants, as we had no knowledge of each other's patients. No 
material that could personally identify participants would be used in any report of the study.

\subsection{3 - The research process}

For this inquiry, the action research process develops through self-reflective spirals of cycles with four phases. These phases include planning what action to take, implementing the action, monitoring or observing the action, and finally systematically reflecting and evaluating the action. This last phase includes planning the next cycle. Cycles are repeated for as many times as the collaborating researchers believe necessary to create learning and knowledge.

\subsection{4 - Study design}

In planning the inquiry as a whole, and before ethical approval had been given and we began gathering data, I was aware that, due to time constraints, the number of participant interactions would need to be limited. Therefore, my co-researcher, my supervisor and I decided that three cycles involving two participants for each co-researcher with a total of 12 participants, would provide ample data for analysis. The decision to have 12 people was influenced when consideration was given to the possibility that the number of patients requiring ear syringing and consenting to the inquiry process was an unknown factor and there was no set pattern of when people would come in. I planned to have three cycles consisting of two weeks to obtain the data, two weeks for transcription, meeting with co-researcher and planning the next cycle. My co-researcher and I discussed the number of patients who would be available, use of the audiotape machines, and the necessity of confidentiality and security of the tapes and transcripts. The transcriber signed a confidentiality form (see Appendix 5). We both had concerns that we would not be able to recruit enough people for our study.

\subsection{5 - Study settings}

The study was undertaken in typical General Practice settings, and in practices in different towns. My co-researcher, who is employed by two GPs, shares the working week with another PN, while I am employed by one GP and share the week with two other nurses. My co-researcher has the use of a room for procedures such as ear syringing, whereas in my situation, this procedure is carried out in a curtained off area. Readers could revisit the previous chapter if more detail of our working environment is 
required. Both my co-researcher and I base our practice for ear syringing on the guidelines developed by the Nelson Division of the New Zealand College of Practice Nurses (NZNO).

\subsection{6 - Recruitment of patients}

Patients were advised of the study by a notice in the waiting room and by personal communication with my co-researcher or myself. Furthermore, prior to the commencement of the interactions with patients requiring their ears to be syringed, my co-researcher and I discussed the study with them. We provided a detailed written and verbal explanation of the study, with opportunity to decline or withdraw at any time, without impacting on their health care. People who agreed to participate needed to sign formal consent forms (see Appendix 4). My co-researcher and I welcomed questions relating to the inquiry with the most common one related to the length of time that was necessary to take part in the research.

Those eligible for inclusion in the study were English-speaking people over the age of 18 years as this group of people were seen to be able to better understand the risks of the procedure and the need to give consent for the audiotaping as well as the research process. Younger children were excluded because often it is parents who decide for them insisting that the children "behave themselves" and submit to the procedure (personal experience, and personal communication with a child's mother, August, 2001).

\subsection{7 - Action research cycles and data gathering}

Unwittingly, by the process of writing the proposal for the inquiry and contemplating the study, my heightened awareness subtly influenced my interactions with patients. I found I was more mindful of my patter when explaining to patients the contraindications, risks and options of syringing, resulting in a more patient centred approach to imparting routine information.

Each of the three cycles my co-researcher and I carried out followed the same pattern of a planning, acting, monitoring/evaluating and replanning, with each phase including thoughts and changes we could make in the next cycle. The first cycle began with meeting with my co-researcher to discuss the inquiry and to explore each other's practices as we needed to be aware of possible constraints such as privacy or time, for 
example. The action phase of the first cycle included two ear-syringing procedures that looked at the process and procedure of ear syringing as it was practised prior to any changes being considered.

Following our co-researcher meetings each cycle continued in the same pattern but included any changes we thought necessary. We explored our verbal and nonverbal communication, thoughts and feelings, while carrying out the procedure to uncover attitudes, behaviours or beliefs that could be changed. Notes from patient's files were not used because of the risk of breaching the privacy and confidentially of individuals.

The degree of energy we needed to do this exploration and change process was draining physically and mentally. This meeting was also audiotaped for further reflection. Note was taken of any areas of concern such as our patter giving routine information, environmental concerns such as privacy, what we considered that the patient was feeling and what responses were made to requests for information, if any.

While reading the transcripts and listening to the tapes, we observed our communication patterns such as use of language, patter, rapport with patients, and listening and responding to patients. We explored how we informed patients of the contraindications, risks and side-effects of ear syringing as well as the options. The description of how we described these risks, and the reaction of patients was examined. We monitored our behaviours and the technique of ear syringing to see if we could make improvements. In addition to this process we continued our reflections before, during and following the procedure, and recalled our experiences.

\subsection{8 - Following the interactions}

Following the collection of the transcriptions, further reflecting was undertaken when my co-researcher and I met at her home to listen to the tapes of the first two ear syringing interactions. We reflected that what we heard and read caused us to think very critically about how we interacted with people and the words and patter we used and whether we assumed consent rather than gained consent for the procedure.

We wondered if the trust patients showed in us reflected their trust in the profession generally or was it because they knew us and were familiar with the surroundings. 


\subsection{9 - Method of data analysis}

We looked at the context of the procedure, observed both the researchers' and patients' verbal communication, and body language and placement. Our meetings uncovered and explored nuances and patterns that reflected the level of stress or anxiety experienced by patients and us. These themes were examined and any revelations discussed of creating change. Meetings were audiotaped, and transcribed verbatim followed by a new cycle incorporating the new planned changes. We analysed the data when doing the cycles, then further analysis as part of writing it up.

\subsubsection{0 - Difficulties experienced during the study}

Because of my lack of knowledge about research and transcribing issues I was unaware that the audiotape recorder I was using was unsuitable for the transcriber's machine. This led to many phone calls to businesses around town to ascertain the possibility of borrowing a micro or mini-dictaphone. Fortunately I was able to access a microdictaphone and also the transcriber discovered a transcribing machine that would take my larger tapes.

My plan to have phases of two weeks was not always possible, as we could not predict when patients would be available, when the transcripts would be ready, or when we could meet. My co-researcher and I experienced anxious times when we felt that we were running out of time to complete this part of the inquiry, and my co-researcher had the experience of three people declining for a variety of reasons, to take part. However, for the third cycle, my co-researcher was able to record her last two participants on the first working day following the meeting, where as, I had to wait for several days to obtain one person for the procedure.

Further problems arose after the first two taped interactions, when the transcriber, an experienced secretary and transcriber, found interpreting interactions of this nature difficult to understand and transcribe. At times, voices were similar or muffled, and often people talked over each other, and she felt unable to continue with her commitment. Fortunately, the receptionist at my place of work undertook the challenge and continued with the process of putting words on paper after her confidentiality consent form was signed (see Appendix 5). 


\subsubsection{1 - Trustworthiness}

The objective of our research was to learn from our in-depth reflections, understandings and insights of our experiences when interacting with patients. My co-researcher and I were very conscious of having a high level of collaborative critical reflection, being selfcritical and self-reflective. We utilised Minichiello, Greenwood, Sullivan and Axford's (1999) definition of construct validity that helped to ensure trustworthiness by being systematic in our reflection that revealed how our previous ideas and thinking had been altered by what we knew now. Ongoing reflection in our own time, feeding back to each other at our meetings and reflecting on our actions enhanced the trustworthiness of our research. In addition to sharing our findings with our peers and colleagues, other nurses could use our action research process to explore issues in their own nursing practice and to share the findings. When writing up the findings of our audiotaped meetings I constantly referred to the transcripts to ensure accurate reporting.

The length of time we were absorbed in our cycles and our attempts at understanding the basis and affects of our choices of change and actions to make changes, negated claims that action research is another name for the nursing process, quality assurance or management practices (Holian, 1999).

My co-researcher and I repeatedly listened to the audiotapes and read the transcripts and detected variations in our language and attentiveness and how these influenced people's responses, including our own. Our supportive reassurance of each other allowed us to challenge each other and ourselves during the meetings. Collaboration between us as coresearchers reflected our mutual respect and trust, and sharing the amount of work curtailed the possibility of misunderstandings or dilemmas affecting the research process.

Careful communication and our respect for each other meant that if any such problems did arise they became part of the action research (Minichiello et $\mathrm{al},$. 1999). It is intended that the findings of the inquiry will be published in the Practice Nurse journal and in PN newsletters as well as at meetings and education sessions for others to interpret.

\section{7 - Conclusion}

I chose action research for my inquiry as it demonstrated the ability to make changes to practice through the upward self-reflective spiral of cycles of planning, acting, reflecting 
and observing and further replanning provided the depth and vision that I felt that other qualitative research methods did not have. The influence of its critical social science beginnings resonated with my desire to explore collaboratively ways in which my practice as a PN could be changed to improve communication and patient care, using ear syringing as a procedure.

I found action research's typologies such as PAR, Praxis Research, Generative Research Action Learning and Action Science, as well as the different collaborative approaches confusing to begin with. However, exploring them confirmed my choice of basing this inquiry on the work of Carr and Kemmis (1986) who contend that action research does not rely on following faithfully the steps of the cycles. The clarity as well as the fluidity of the cycles meant that it could encompass other aspects of human interactions within the inquiry. For example, my co-researcher and I could discuss other matters of patient concern at the same time that we were audiotaping the interactions.

Ethical issues of most concern for my co-researcher and I included but were not limited to issues of informed consent, privacy and confidentiality. In the general practice setting in which this inquiry was undertaken, it was not always possible to protect the identity of participants from other members of the health care team. This was especially problematic for me as all my interactions took place behind a curtain. Some of the difficulties of gathering data were related to the when participants were available, quality of the recordings and timing the meetings to fit in with family life. While the criticisms and limitations of action research reflect the diversity of approaches and balance of power problems, I see it as a viable and positive form of research within nursing. The process of gathering the data across the three cycles is explained in Chapter 5. 


\section{Chapter 5 - Ear syringing across the three cycles}

\section{1 - Introduction}

The essential nature of action research means that the data and findings are intertwined. I found that separating them for discussion was difficult, and at times when, writing up this inquiry, I have needed to revisit sections for further explanation and understanding. To best capture the findings of this inquiry, I have separated them into three chapters, 5, 6 and 7. Each of these chapters has a unique focus in relation to the inquiry. Chapter 5 describes and discusses the action research process that involved two co-researchers and three cycles of planning, acting, observing and reflecting, then replanning a further cycle. I describe what we accomplished over the cycles, our observations of the interactions between us as researchers, and patients as participants, and planned changes for the next cycle. Although issues such as trust and patter and my desire to 'get the research right' are mentioned in this chapter, they will be discussed in full in Chapter 6. This chapter (Chapter 6) looks at issues relating to what I found about the research process, recruitment, consent to the process and procedure of ear syringing, trust, language, and research in the real world. Chapter 7 discusses the reflective process of the inquiry in two streams. One stream discusses the reflection process in relation to improving our communication and people's experience of ear syringing, and the other stream describes my own Master of Arts (Applied) journey of the research process.

To assist the reader identify data that I extracted from the audiotapes, I have displayed these in Italics.

\section{2 - What we accomplished in our research}

Over the period of the inquiry we accomplished changes and improvements to our language and communication, developed trust and confidence in reflective practice and in sharing our thoughts with each other. Although I agreed with my co-researcher who contended that "there's heaps we can change" the actual changes made were subtle, and focused on verbal communication. Our joint meetings highlighted the value of reflection and reflective practice as we continued to return to issues we had previously discussed. Importantly, these meetings revealed that we could learn from each other, and that our former ignorance was not something to feel mortified about, but that new learning was an important part of practice and life. 
Reflection with any depth is hard but I was surprised at the amount of effort required to look at, and explore the mirror image from all the perspectives that I have discussed earlier. Importantly, this inquiry affirmed the value of working with a colleague.

\subsection{1 - Changes}

My co-researcher and I focused on improving our language and communication with patients, and each cycle uncovered more insights and understandings. One of the most conspicuous findings of this research is that we continued to repeat our errors and omissions as we forgot some of our proposed changes for the following interaction. These recurring problems illustrated to us that it would take some time and repetition before our planned changes became an automatic part of our patter.

Noting that while her recollection of changes was intermittent, my co-researcher was able to include some changes into other areas of practice such as cervical smear taking, stating "This research has really made me think about how I work with other people". I agreed with her assessment, but I was surprised at the effort it took for me to keep focused on our changes whenever a patient, who was not part of the inquiry, needed their ears syringed. I found that I tended to relax, because what I was doing was not being recorded and not a part of the inquiry. I was conscious that at times, I reverted to previous language habits, although the fact that I was aware of what was happening probably prevented me from reverting completely.

Changes we did make to our patter related to acquiring a more comprehensive history prior to commencing the procedure. In addition to improving our verbal communication by using patient-friendly language, we pledged to pay greater attention to patients and their responses and not to drape them at the same time we were discussing consent in case they felt coerced. We made note of expressions we used and decided to include in our cue card such as "there are some situations where ear syringing is not recommended" rather than "there are contraindications to syringing". Nurse and situation specific cue cards would assist in recalling changes and could be altered to suit at any time. While we experienced problems recalling changes to our patter, by the third cycle our verbal language had changed. We were rephrasing our patter to take into account our plan to 
give a fuller assessment of the patient, checking whether the patient hears and understands the process of ear syringing, as well as our responses to patients.

Our inquiry portrayed the difficulty we experienced in changing long time habits and traditions, but it did reveal that we could have confidence in our process of transforming our language through the action research process. A research question for future exploration could relate to what nurses need to do to reduce the time to make the changes part of their patter.

The inquiry began with developing the information sheets and consent forms for our employers (see Appendix 1) and prospective participants (see Appendix 4). Once these were completed, my co-researcher and I began our first cycle.

\section{3 - The three cycles}

\subsection{1 - First cycle: Reconnaissance}

My co-researcher and I recruited two participants each to demonstrate how we currently carried out the process and procedure of ear syringing. Both of my participants were elderly men, while my co-researcher's participants were older women. After completing two interactions each, the audiotapes were transcribed and we arranged our first meeting. At this meeting we listened to the audiotapes, read each other's transcripts, observing areas of verbal and non-verbal communication and nursing practice we wanted to change, and then discussed these with each other. Following this critical reflection and discussion on our findings, changes for the next cycle were discussed and agreed between us. I recorded the meetings to allow me to further analyse them, as well as being able to return to them when writing up the inquiry. These meetings were held on Saturdays at my co-researcher's home to fit around family and work commitments.

The first meeting, held six weeks after we commenced the research, took us an exhausting mind and energy depleting two and one-half hours to complete. As the transcriber had sent my co-researcher's transcripts and recordings to me, she did not have the opportunity to assimilate the information they contained, so she needed to listen to all our recordings and read all the transcripts before we began our discussion. At this meeting we were looking and listening critically to the transcripts and recordings to capture an overall picture of how we went through the process and procedure as a whole. 
Our first observation was that our comments about what we found in the transcripts were similar, for example, we were disconcerted by the transcriber's mistakes in interpreting what we understood we had said. I noted that in my first interaction my nervousness resulted in my use of technical language such as 'auditory meatus' and 'contraindications'. As I believe that this form of language can place a barrier between the patient and the nurse, I was baffled that I would use it especially in this context where I was attempting to improve my communication. I was aware of my propensity to use this terminology in times of stress, and such language continued to occur intermittently throughout the inquiry. While my co-researcher did not have the same problem and continued to use everyday language, she speculated that the term 'contraindications' informed patients that there are conditions where syringing ears was not the preferred option. She decided to change her wording from asking about previous surgery the patient might have had, to include 'contraindications' in her next interaction. When explaining the level of the risk of perforation by syringing, my co-researcher reassured patients by likening it to "going across the road and getting run over by a car", and while I know I have frequently used phrases such as this before, I noted that none of my interactions reflected this.

We were disappointed with some of our communication with patients during the whole process and procedure because what we thought we had said or did, was not evident on the recordings or in the transcripts. For instance, our explanation during the consent process was not as clear as we thought, and the sequence we gave the information could be re-ordered more logically. To enable patients to understand what we were attempting to achieve, these areas were marked for change. As most issues surrounded the process, we concluded that we needed to discuss these before beginning the ear syringing and not part way through or at the end. For instance, we decided to inform patients how the procedure was carried out, and tell them to let us know if they wanted to stop at any stage. I commented that "we need to be prepared to stop and ask if the patient is okay, rather than expecting them to tell us". In other words, we needed to place more focus on patient understanding and comfort rather than concentrating on getting the procedure done. My co-researcher commented that, as the patient said that she felt funny while having her ears syringed, "we need to know more than that the patient 'felt funny', we should find out in what way did they feel funny so we could do something about it". Our 
post-procedure information was also an area that we identified we could improve. For example, letting patients know that "there still might be water in the ear canal and that it takes time to dry out, and that if hearing does not improve, then the patient should return to the doctor".

Although we were aware that we would find variations in our practice we were surprised that we omitted significant information during the consent process such as some important contraindications to syringing, options and side effects. We found gaps in our knowledge and instances of knowledge we once had, but now forgotten. For example, while I have traditionally mopped out the ears with paper tissues (tissues become soft when wet and cannot damage the drum or canal) so that most of any residual water is removed and the canal dries more quickly, my co-researcher was unaware of this practice. At the same ear care education session where I learnt about the use for paper tissues I also heard about the option of referral to the aural toilet nurse at the hospital. However, as my co-researcher did not live in this area at the time, she was not at the education session so was unaware of the availability of the aural toilet nurse. Other areas of memory lapses and knowledge gaps were discovered when my co-researcher needed to remind me that dizziness was a side-effect of syringing. Likewise, I needed to remind her that severe tinnitus is a contraindication to the ear syringing procedure. Over the period of data gathering, I continued to forget to mention dizziness, and my co-researcher forgot about tinnitus. Because tinnitus and options to syringing had been practice issues for me in the past, and concern about patient dizziness was the result of my coresearcher's experiences, I wondered if "we subconsciously had these issues in prominent places in our minds". My co-researcher thought that perhaps the reason she found patients were dizzy was "because I talked them into it". Although this was said as a joke, we really did begin to wonder to what extent our comments influenced patients' physiological responses. However, attempting to answer this question was outside our skill and knowledge. Our observations included that while we asked the patients questions throughout the process and procedure, the only question regarding ear syringing a patient made, was when my co-researcher's first patient asked "do you have a little tool that sucks?"

While we found things to criticise at this first meeting, we did commend each other on what we saw as each other's good points. My co-researcher projects a confident 
knowledgeable attitude that was obvious in the recordings when she discussed the risks of ear syringing openly and assuredly. I think that her way of being inspires patients' trust. Likewise, my co-researcher liked the way I discussed the contraindications and options to ear syringing as it let people know exactly what they were. However, my reticence in expressing criticism at this stage caused me to use the term "we" instead of "you" when I said "Do you think we are inclined to talk over people?" We finished this meeting exhausted but enthusiastic about beginning the next cycle that would include our changes of clearer communication of the contraindications and options, discussion thoughout the procedure and improved post-procedure information. We both had some misgivings about our competence to manage the changes we had planned.

We did not know at this stage what problems lay ahead of us, but being aware of my learning style and knowing my anxious brain could hinder my recall of our planned changes, I jotted them down on paper to have them available when I did my next interaction. To save time at the meetings and to listen, read and reflect on our interactions, we arranged to read each other's transcripts and listen to the recordings prior to our next meeting.

\subsection{2 - Second cycle}

It took 10 days before either my co-researcher or I could recruit our third patient each, to begin the second cycle. I was fortunate to complete my third and fourth interactions within a few days of each other, (one a forty-something man and an elderly woman). Because three people declined to take part in the inquiry, my co-researcher was not able to complete her fourth interaction until three weeks later. For this cycle my coresearcher's two patients included one man and one woman. Adding to the length of time of this cycle was the difficulty in arranging a meeting that took place after a further three weeks.

The plan to read the transcripts and listen to the recordings before meeting worked well, as we were able to observe and reflect in our own time and arrive at the meeting with ideas, suggestions and questions ready for discussion. The issues at this second meeting included verbal communication once more. We noted that as we were unused to researching and recording ourselves, nervousness was impacting on our ability to remember changes, with my co-researcher exclaiming, "I did that worse than the first 
time". My co-researcher felt that I had assimilated the changes better than she had, although I noted that I missed things that I would have normally included. For example, the risk of perforation was absent from my consent process patter. This surprised me, as it is an element of the consent process that I thought that I consistently remembered to say. My co-researcher was concerned that she forgot to inform patients of the options to ear syringing and the contraindication of tinnitus we had discussed at the meeting. However, we reassured each other once more and resolved to do better next time. My coresearcher commented "I liked your statement to patients 'are you happy for me to go ahead' because it is a good way of ensuring that we had consent" which validated and affirmed my patter. Another change we made was in the use of technical language. We would 'change the word 'contraindication' to 'situation' as it's a good everyday word that everyone could understand", according to my co-researcher. Thinking that I needed to be more explicit when telling patients that I thought that their ear drum was intact following the procedure, my co-researcher suggested that "rather than saying, that there is no sign of perforation you could say the canal is clear of wax and the drum appears intact, because it is more clear". Continued observation of our wording caused us to revisit and reflect on the difficulty of recalling our changes when carrying out the procedure. While my co-researcher was aware of my jotted notes, she felt that a more formal cue card would help both of us and we decided to individually compose a cue card that would suit our individual needs for the next cycle.

Many people are almost completely deaf when their ears are blocked with wax, and especially so if they are without their hearing aid. Observations of our practice uncovered assumptions that the patient had heard us and understood what we were saying. In addition, a significant number of people have had their ears syringed before, and we assumed that they had remembered the contraindications and risk associated with syringing. Once more, reflection on these issues raised our awareness of our communication shortcomings and our commitment to improve. Further critical listening and reading, revealed variations in the way we documented our interactions with patients following the procedure, and while we agreed that documentation was an important part of the process of any consultation, we did not reach a consensus on the amount of documentation we needed. 
The most significant changes we planned at this second meeting involved taking a more detailed ear history from the patient and to discuss the contraindications and risks associated with syringing more thoroughly during the consent process, making sure that the patient understood what we were saying. Additionally we would ask the patient how the experience was for them, and was there anything we could have done differently to make it better.

\subsection{3 - Third cycle}

For my co-researcher, this third cycle began on the first day back at work as two people, one woman and one man, consented to participate in the inquiry. It took me 10 days for someone (a young man) to require ear syringing, and a further five days for my second patient (an elderly woman) to be able to complete my last interaction. Four days later we met for our final meeting.

Observation of our performances once more reinforced the need for attention to our changes and how difficult it was to change our patter. Unfortunately, my co-researcher did not have her cue card with her at the time of her interactions so she found that she continued to omit some of the changes we had decided. Although I did have my cue card with my chosen words and phrases, I still forgot to inform patients about the risk of perforation until part way through the procedure. Having so much to think about and concentrate on I had placed the card on the bed where it was not easily readable, and even though I moved it, it still was difficult to read when working. Although these issues were disappointing our critical reflection informed us that we were making progress in changing our practice.

Only one of the 15 people we approached for the inquiry was under the age of 40 years, and he was aged 18 years, other participants were 40's and 70's. This age band reflected the practice populations of both surgeries, as well as the age many people become hard of hearing and experience wax problems.

While this was the last cycle for our inquiry, we planned to continue with our critical reflections to uncover other areas that we could improve on and to continue reinforcing the changes we had made already. 


\section{4 - Conclusion}

This chapter described how my co-researcher and I accomplished our changes to language and communication with patients and how my co-researcher and I went about our inquiry, beginning with the reconnaissance cycle that described how the patients were recruited for the inquiry, most of who were elderly people, and our communication with them before, during and after the procedure of ear syringing.

After the completion of two procedures each, in which we critically observed the way that we had routinely carried out the ear syringing procedure, my co-researcher and I met to critically look at our transcripts and critically listen to the recordings, reflecting on how we could make changes to improve our practice.

Finally we planned how we could implement our changes in the next cycle of acting observing, reflecting and replanning.

Over the three cycles, our verbal communication and listening, demonstrated that we could change our language and behaviour, to be more accessible to patients. We replaced technical words with everyday language, placed more emphasis on patient understanding, and continued to reflect on our practice. However, it took the three cycles to make changes to language and to listen to patients more effectively.

The following chapter (Chapter 6) explores the process of the research. I will discuss issues such as timing, consent, patter, ownership, and the observations my co-researcher and I made during the cycles. 
Chapter 6 - About the process of research and inquiry into communication and nursing practice

\section{1 - Introduction}

Following on from the discussion of the cycles of the inquiry, this second chapter of the finding and discussion chapters describes and discusses the research process. Timing of the inquiry, recruitment of patients and consent for the research process, as well as for the procedure, are discussed. Language, how I experienced research in the real world and the rigour of the research are also discussed. The issue of who owns the research is raised, as well as the use of patter when giving routine information to patients. Finally, I offer observations about the process of research of which I consider other researchers may need to be aware.

\section{2 - What I found about the research process}

Over the research period, I was thankful that I had taken Kemmis and McTaggart's (1998) and Parmee's (1996) advice and started small. Action research allows that there can be many co-researchers or as few as one, and as a beginning researcher I felt that the choice of limiting the number of co-researchers to one, worked well. The amount of data collected by more than one co-researcher would have been enormous and we would not have had time to reflect in such depth on the information and the changes we made. In addition, the possibility of personal and professional incompatibility could have had adverse consequences for the research, as well as our personal and professional relationships.

When planning this inquiry, I was very conscious of my co-researcher's and my part-time status and the opportunistic nature of ear syringing, so I allowed three months to complete all the cycles. Although I did not have a specified timeframe for each cycle I optimistically hoped to be able to complete the whole process of gathering data within six to eight weeks. However, it became obvious early on in the research process that my optimism was misplaced and that it could take the full three months. As if to prove that the research took more time than I had anticipated, my last cycle was not completed until the $14^{\text {th }}$ and final week. 
Reflection on the issue of timing and sequence of the process of the ear syringing procedure demonstrated to us that we needed to allow more time for patients to ask questions and discuss answers. We considered that it is better to spend time discussing issues with patients prior to the procedure rather than later when more serious problems might arise. If time is not allowed for listening, our responses may be the result of our assumption of what we thought the patient was going to say, rather than what he or she did say. Assumptions could lead to misinterpretation and therefore the practice process could be questioned.

Because the opportunistic nature of the inquiry meant that we recruited people as they presented for the procedure, my co-researcher found that the decision to create cue cards, made within the second cycle, did not have time to be acted upon. We had planned to prepare individual cue cards for the third cycle, and send copies to each other for comment before we began the cycle, my co-researcher had the opportunity of completing her last interaction before this could be achieved. In addition to this observation, I experimented with some of my own ideas I had following the meetings, such as using different words or asking questions differently depending on the responses from the patient. Not all of this was deliberate as some verbal changes happen in everyday practice anyway.

\subsection{1 - Recruitment of co-researcher and participants}

I had discussed my proposed inquiry with a colleague some months previously, so I needed only to revisit the subject with her to ascertain if she was still willing to be a coresearcher. I chose to approach this particular colleague because of the relationship we had built up through our participation on a committee. We met about four years ago when my co-researcher joined the committee of the New Zealand College of Practice Nurses NZNO, of which I am a member, and then she proceeded to become its chairperson. We worked on our Practice Nurse Accreditation process together and I respect and appreciate her enquiring mind and ability and willingness to challenge existing practice, search for answers and to make changes to her practice. Over a period of time (and several lunches) I felt that I had found someone I could trust and work with in my research. This feeling of kindred was important to me because I felt less guarded in sharing my thoughts and ideas with someone I knew. If we had not known each other as well as we did, I contend that the outcome of the inquiry would have been different. 
Familiarity, in our situation, did not lead to contempt and our relationship remained sound and supportive throughout the inquiry.

Recruiting patients for the inquiry was easier and, at the same time, as difficult as I had envisaged. When patients presented for the procedure, I found my increased visibility in the sense of standing out and drawing attention to myself, a new experience and contrary to my way of being. I was definitely outside my comfort zone. I felt that my inquiry, although important to me, had limited interest to patients, and by discussing my research with them, and asking that they consider participating, as well as reading the information sheet and signing a consent form, was an intrusion on their time and goodwill. Even though I had known the majority of my surgery's patients for a number of years and had developed a connection with them, it still surprised me that they responded immediately, with their willingness to participate. What I had thought was going to be problematic for me, was in fact, the opposite. My co-researcher denied any similar feelings although she was conscious of the extra time that patients needed to allow. Including the patients who declined, my co-researcher knew five of the six patients in her cycles.

While my co-researcher, in an attempt to get her second cycle completed, was initially disconcerted about the patients who declined, our critical reflection brought us to the conclusion that there is a strong degree of trust inherent in our nurse/patient relationships. We reasoned that this knowledge enabled and empowered people to consent or decline as they wished.

\section{3 - Trust}

My co-researcher and I observed that generally, patients didn't ask if there were risks to the procedure and we wondered if that meant that they trusted us to know what we were doing and were not going to cause them harm. I have always felt uncomfortable with this notion, because while I do not want to cause harm, I felt that the possibility of harm was increased if I did not obtain, or was not given, the information I needed to make clinical assessments about undertaking any procedure. For instance, if a patient withholds information relevant to the procedure, harm could result because I was not aware of the facts. The consequences of not being clear in our language or in the way information is conveyed could be crucial. 
Trust is defined by the Collins English Dictionary (1986) as "reliance on, and confidence in the truth, worth, reliability, etc. of a person or thing" (p. 929). For Sherman (1994), trust is "the ability to rely on someone without question and developed through honest and straightforward communication and requires confidence, dependability and credibility in the relationship (p. 54). Baier (cited in Peter \& Morgan, 2001) describes trust as "a reliance on another's goodwill not just dependable habits" (p. 5). According to Sherman, trust is an integral part of the nurse/patient relationship and without it neither person would feel any sense of personal involvement and the interaction would remain superficial. Sherman notes that it takes time to develop a sense of trust, and Pierson (1998) contends that trusting relationships tend to develop slowly and within an atmosphere of mutual respect and care. However, in general practice there are many instances where patient interactions are limited to a few minutes or seconds, and consequently, developing trust quickly in these circumstances is difficult and often unattainable. Watson (1985) in discussing "helping-trust" contends that "the patient who feels that the nurse really cares about and really sees the person's individual needs and concerns is likely to establish trust, faith and hope in the nursing care" (p. 25).

Each person experiences and demonstrates trust differently, so I use the tem "trust" with a degree of caution. I argue that the term gives rise to dichotomies of trustworthiness/untrustworthiness, right/wrong, black/white, and good/bad. It does not allow for the individuality of people's foibles and human ordinariness. For me, trust is better described as 'respectful knowing' that recognises individuals as human, each with our peculiar frailties and flaws. In recognition of respectful knowing, I strive not to place the burden of 'trust' on those who might not be able to live up to my perhaps unrealistic, expectations of them. I endeavour to value people for who they are and not for what I might hope they may be.

Nurses could be considered trustworthy because of their specialised knowledge and skill, and I imagine that this is what patients mean when they say that they 'trust' us. According to Nordgren and Fridlund (2001), patients trust nurses because they have confidence in their competence and feel that they have an opportunity to take part in the decisions making process. As long as this confidence lasted, patients did not feel the need to take the initiative in their care. 
As a profession, the NZNO Code of ethics (1995) states that fidelity is "being faithful in all commitments to clients so promoting trust as an integral component of the nurse-client relationship" (p. 11). The governing body of nurses is the Nursing Council of New Zealand, and that while not written into legislation, it "expects nurses and midwives to provide services of a certain standard, and to keep up to date in their area of practice" and to "maintain safe and acceptable standards of professional care" (Burgess, 1993, p. 60). Furthermore, Burgess explains that nurses are expected to conduct themselves at a standard above that of ordinary citizens. It is in this standard of behaviour and practice that patients should be able to trust nurses.

\subsection{1 - Trusting relationships}

This inquiry was carried out within the workplace and during working hours, so we needed the trust and consent for the inquiry from our employing GPs. The three GPs, by giving their consent freely, demonstrated this trust in our inquiry and us. Although we had discussed the inquiry with them, I provided them with information sheets explaining the action research inquiry and the benefits that could come from such a process. This information allowed employers to be confident that the purpose and rigour of our inquiry could be validated. All employers have shown interest in the process, even providing an audiotape unit for my co-researcher.

Over the time of the research, I observed that, apart from asking about putting oil in the ear prior to syringing, only one of the patients asked questions about alternatives to syringing. However my co-researcher pointed out that as we had explained what we were doing, perhaps they did not need further information. In addition, my co-researcher noted that, during the first cycle, while the younger of her two patients asked questions, the older patient did not. I suggested that it might reflect age differences, in the experience of my co-researcher and I, older people do not ask health-related questions as often as younger people do. My co-researcher added, "it might be because older people had experience of several ear syringing procedures and that they were comfortable with what was happening". However, I wondered, "if patients didn't ask questions about the procedure does that mean that they trusted what we were doing. Trusted us to know what we were doing". Patients have often told me that they trust me not to make a mistake and give the wrong injection, for example. My co-researcher expressed the thought that "people think that it's such a simple procedure that there aren't any contraindications or 
risks". Furthermore, "if we made a fuss about telling people about the side effects and contraindications, would they decide that what they thought was a simple procedure, is now a major operation and change their minds about having it done". My co-researcher added that she sometimes thought "knowledge is really great, and informing people, but don't you think that sometimes the more fuss that you make... Are these people going to then think 'well, this is not the simple procedure I thought it was going to be. This could be really major and I don't want it done". I replied "I thought that this is where patient choice came in, and that I don't think we need to be defensive or self-critical about it. Declining doesn't mean that our consent process or practice is inadequate or deficient, it means that people feel that the information gives them the opportunity of choosing the best option for them". However, I "wished they wouldn't be so trusting, as we are all fallible".

Listening to our own and each other's recordings of our interactions with patients had the potential to put our relationship at risk if we found areas of practice that we disagreed strongly with. As it was important that we had an understanding of how we would deal with any possible disharmony, we discussed this aspect of being co-researchers prior to beginning the research. Our knowledge of each other's education and practice helped us maintain clear communication channels, so that no significant issues arose.

Over the period of the cycles and meetings, our increasing confidence in each other allowed us to expose our practice and ourselves, and we gained support and reassurance from each other. We commended each other on points that we saw as admirable, skilful and knowledgeable in each other's practice or communication. For instance, my co researcher considered that my advice to patients "that there are contraindication such as previous surgery or perforated ear drums" was better than her "I just ask them if they had had any previous surgery." I found my co-researcher's inclusive communication and interaction with patients, superior to mine. For example, during the first cycle meeting I commented to my co-researcher "I think you communicate better than I do" when she interacted with a patient in a relaxed and informative way, and at the second cycle meeting, after my co-researcher had heard me detail the contraindications in the consent process, she said to me "you did that really well". However, we were quick to find problems with our own practice rather than with each other's, such as my co-researcher assertion that "I did that worse than last time", and I forgot to discuss the side effect of 
dizziness, with patients. Generally we remained more critical of our own practice and it took further critical reflection to gain insight and understanding of this aspect of trust. Our continued reassurance of each other reinforced the trust and confidence building throughout the process of the research.

\section{4 - Consent for research process}

In general practice, although many nursing tasks such as immunisation and ear syringing are the same, PN's often operate differently within a surgery. Much of what they do is dependent on their terms of employment. For example, my co-researcher has her own consultation list for such procedures, and refers to the doctor if she considers it necessary to do so, whereas I work in a surgery where the GP prefers to see patients prior to most nurse consultations including ear syringing.

With reference to the inquiry, this meant that discussing the research in confidence with patients and without the GP's knowledge was almost impossible. When I questioned patients about this, they denied any concerns relating to this aspect of my inquiry that perhaps is indicative of the faith people place in health professionals to maintain confidentiality.

While approaches to most people resulted in agreement to take part in this inquiry, during the second cycle my co-researcher was perturbed that three people declined. The first patient wanted to talk confidentially with my co-researcher without being recorded. The second patient, reading the form before my co-researcher discussed the research with him, stated that when he comes to the doctor or nurse he "expects them to know what they are doing ". Even though my co-researcher attempted to explain reflective practice with him, he informed her that she "just did things right" and he did not see the point in the inquiry. This comment reflects the trusting relationships referred to previously. The third person also given the information sheet prior to my co-researcher discussing the inquiry with him, looked interested but then changed his mind without giving a reason. My co-researcher felt that these people felt free to express their wish to decline, and my co-researcher continued with the procedure so "I just carried on as usual" with their care. This comment reflects the ethical imperative that those who decline to participate in the research should not be treated differently because of their decision. In addition, this issue has been addressed in the patient information sheet and in Chapter 4 (see p. 72). 
Although the sample was small, with three people declining to take part, it suggested that people were more likely to participate if the co-researchers were able to discuss the inquiry with them before reading the information sheet. Further, it demonstrates that the process of recruitment for this research, the patient information sheets and consent forms were valuable in allowing people to make an informed choice. It also raises the issue of when is the most appropriate time to give written information to prospective patients to read. This point was reinforced for me when I learned that research colleagues experienced difficulty with recruiting patients when a third party was needed to act as a go-between, leading to an increase in pressure of time for the researchers.

In addition to demonstrating that the consent process was working, it indicated to us that some people have little knowledge about the accountability and responsibility of nurses and that we needed to be aware that placed us at risk of exposing ourselves to harm if things go wrong. Of the second patient who declined, I observed "if you hadn't explained the risks of syringing to him and the pressure of water forced a hole in his ear drum, he could complain that he hadn't been given enough information to make a decision about syringing, and we have assumed that it is okay for us to proceed."

\subsection{1 - Assumed consent}

My co-researcher and I both realised that we took some factors of the consent process for granted. For example, during the first cycle, one of my patients informed me that $\mathrm{I}$ had syringed his ears previously. Assuming that he remembered our discussion from the previous encounter, I limited the consent process to asking him if he was happy for me to proceed with the syringing. Likewise, my co-researcher remarked that because some patients request an appointment for ear syringing, she assumes that they are content for her to carry it out, so she does not always go through the full process of informing the patient of contraindications.

Listening to our recordings and reading our transcripts revealed that we assumed we had conveyed information that perhaps we had not, and that sometimes it was difficult to know if a patient really understood what was said. We were aware that this changed after the first cycle. Our experience in this inquiry supports Burgess (1996) and Avenyard (2002) who contend that we need to be aware that, merely arriving at the surgery for ear 
syringing does not mean that the patient has consented to the procedure. If patients are unaware of contraindications, risks, options and side effects to any procedure, we cannot assume that by requesting a procedure they have sufficient information to make a choice about safe appropriate care

To support this contention I describe an incident from my practice. A patient was referred to me by a GP for ear syringing, and as I had carried out this procedure for this patient on previous occasions, I curbed the consent process to asking him if he was happy for me to proceed. Although he consented, when the GP who came to recheck his ears, informed him that syringing could perforate the eardrum, he appeared surprised and said that he did not know this. Looking back in his handwritten file notes of the earlier time I had syringed his ears (12 months previously), I found that I had discussed the whole consent process and informed him of the contraindications, risks and options of the procedure. While this experience did not happen during the research process, it does demonstrate that nurses cannot assume that because they have told people previously about the procedure and risks associated with it, that patients remember them.

Further corroboration comes from Dahl (2002) who describes an incident where she was about to administer a routine vaccination to a child she had not met before. Ascertaining that the child had had previous immunisations, she assumed that the mother was cognisant with the risks associated with immunisation as well as the benefits. It was the mother's obvious discomfort that alerted Dahl to the possibility that something was amiss, and further inquiry revealed that the mother had not been informed about the risks of immunisation.

\section{5 - Rigour and trustworthiness}

According to Kemmis (1998) the criterion for success in action research lies in the strong and authentic sense of development and evolution in the co-researcher's practices, our understandings of our practices and the situations in which we practice. For this inquiry rigour and trustworthiness is demonstrated through repeated and systematic critical reflection and self-reflection listening to the recordings and reading the transcripts. We were absorbed in our cycles and our attempts to understand the basis and effects of our choices for change. In addition, our joint collaborative meetings provided us with the 
sense of support, reassurance and confidence that we needed to critically explore our own and each other' practices and understandings.

When writing up this inquiry, revisiting the audiotapes as well as the transcripts, augmented my understanding of the necessity and obligation to ensure that what I was interpreting remained true to the interactions and our discussions. Initially I found that I wanted to change a word or sentence so that our verbatim comments were more grammatically correct, phrased better, and sentences completed. For example, during my second interaction I was asking my patient how long it was since he had his ears syringed. "I don't know if a long time ago- whether whoever did it for you...". However, any alterations to the content would have had the effect of changing or misrepresenting the meaning of what was expressed.

The trustworthiness of the research and 'getting it right' were extremely important to me, personally and professionally. In addition, I felt that if I were not true to the tapes and transcripts, I would be breaking the trust and confidence that continued to grow between my co-researcher and myself. Furthermore, accuracy in the writing up ensured that my co-researcher could be reassured that what I had discussed in our inquiry could be traced back to the tapes and transcripts, and checked if she wished. Revisiting the tapes and transcripts, my own integrity as well as the thought of my co-researcher reading my thesis kept me honest.

Repeated listening to the tapes and reading the transcripts of our first cycle, uncovered areas where the transcriber had left out complete sentences or they were misinterpreted, causing the transcriptions to become disjointed and misleading. For example, during the interaction with my second patient I was checking for contraindications to the ear syringing procedure. My question to the patient relating to perforated eardrums was transcribed as 'suppuration' and not 'perforation' as I had said. My co-researcher was taken-aback to discover one of her sentences transcribed as "I just get a little boat. I just dry it on the outer ear - that's rain" when she was about to use a cotton bud to dry the outer ear.

My co-researcher's response to these mistakes was reflected in her statement "I' $m$ amazed that anyone could write that when it doesn't make sense." However, despite 
these oddities the content and meaning of our interactions was clearly evident in the transcriptions and we learnt to ignore them. Glitches in the transcribing, while causing some consternation and then amusement, reinforced the value of listening concurrently to the tapes and reading the transcripts, and when we listened to the tapes we were able to correct the mistakes and confirm what we remembered saying. This collaboration illustrates once again the value of researching with a colleague.

\subsection{1 - Revisiting the audiotapes and transcripts}

Revisiting the tapes and transcripts at the time of writing up opened up unexplored areas of communication in the consent process. For example, we could have asked patients if they preferred a phrase such as "getting run over by a car, or hurting yourself by getting out of bed' to explain the level of risk as my co-researcher and I perceived it, or being given the information in a more factual and clinical manner. However, issues such as these could be addressed and reassessed in further cycles of critical reflection at any time in the future. The continuation of the critical reflective cycles of action research validates and affirms my belief that this type of inquiry clearly assists nurses in changing their practice and improving patient care.

\section{6 - Doing research in the real world}

My initial mental plan for this inquiry included looking at body language in communication as well as oral communication. I had envisaged that during our interactions we would have the time and concentration check for signs of tension, such as strained expressions, twitching, change in breathing patterns, shifting positions, and conversely holding very still. This did not feature to any great extent during the coresearcher discussions, as our focus tended to be on our oral language and the changes we were making. However, my co-researcher's first patient did show signs of tension especially in her comment "I am trying to concentrate on being a bit more relaxed".

Throughout the period of audiotaping the interactions and our meetings, I continued to be cautious in using the recorders. My nervousness about the technology and recording my own voice caused me some anxiety and I found that I needed to keep checking to make sure that I had pressed the correct buttons on the unit and that the tape had not run out. I also needed to change the type of unit I used to improve the clarity of recording. My coresearcher, however, was more adept than I, at using the machines and being recorded, 
and experienced few problems. She also helped me with recording our meetings when my anxiety about using two different audiotape recorders and different ways of using them, became a problem for me.

During the process and procedure of ear syringing we move around the patient or ask the patient to change position, to continue the procedure in the other ear. In addition, when examining a patient's ear, we necessarily need to be physically close to the patient and that closeness smothered our voices. This movement meant that it became a process of trial and error to find the ideal location to place the recorder to obtain as clear a recording as possible. While both my co-researcher and I experimented with positions of the unit, I shifted the position of my recorder from the sink bench to various positions on the couch. This caused interruptions to the interactions and continued to effect the quality of the recordings. In all the recordings there were muffled or unintelligible voices that were difficult for the transcriber to interpret.

After the first cycle, I needed to find another person to transcribe the interactions and that task was taken over by the receptionist at my workplace. In addition to being able to transcribe my interactions immediately following the event, I was able to help her decipher the mumbled sections of the recordings. Furthermore the receptionist had often overheard my patient consultations from behind the curtain, so she experienced less difficulty in deciphering my recordings, as she was familiar with my voice and my patter. However, my co-researcher did not have this opportunity, and she needed to wait until her transcribed copies and tapes were returned to her before checking for errors and omissions.

Due to the opportunistic nature of my study, it was not often possible to select an appointed time for these interactions to occur without interruption from other staff members as well as the GP. For instance, during my second interaction a child wandered in behind the curtain requesting a jellybean. In addition to this kind of interruption, I am required to take over receptionist duties when the receptionist needed to take her lunch break, and attend to the GP's requests to take blood samples or collect and test urine samples. Although interruptions are a normal part of general practice, it was a problem during audiotaping as I needed to switch the recorder off and on, and during my second interaction I missed a few words of interaction. Furthermore, interruptions affected the 
procedure by breaking the nurse/patient connection, as well as disturbing the process of data collection. I was more conscious of these interruptions than usual because of the research, and that the patient was waiting longer than either of us anticipated. I felt pressured to speed up, and I became even more self-conscious than usual about being overheard implementing changes to my practice. Fortunately, my co-researcher who has a separate and private room where these kinds of procedures are carried out, was called away only once by her GP during the research.

The transcripts uncovered other aspects of the consultation as well as the process procedure of ear syringing. My first patient had sutures from recent minor surgery and I asked him when they were due to be removed. One patient brought my co-researcher a mail-order hearing aid for her to demonstrate how it functioned, and the husband of one of my participants became a part of the interaction. In this last example, the patient checked her answers to my questions with her husband to refresh her memory and at the same time, he continued a conversation with me. The patient did not have her hearing aid in at the time so could not always clearly hear the questions, or her husband's replies.

\subsection{1 - Changing patter}

It was more difficult than either of us realised to change the familiar patter and to remember the new changes at the appropriate time. We found that some of the things we had marked for improvement in the second cycle had not been achieved, such as taking a more detailed history as well as the reason patients wanted their ears syringed, for example, although I commented that the reason for patients to request ear syringing becomes apparent when we examine their ears to explore the cause of their deafness of discomfort.

Revisiting this issue, we both observed that there are times when patients think that they have a wax problem when that is not the case, and it is then that further questions relating to ear history are asked. For example the deafness may be caused by blocked eustachian tubes as the result of a cold or influenza, and we can suggest a referral to the GP for further assessment if we need to. Post procedure, my co-researcher omitted asking if there were anything that she could have done differently that would improve her nursing practice. I noted that I was continuing to repeat patient comments and I am unsure if that is what I usually do or if it is the result of the situation. 
My co-researcher and I discussed the need to practice the new way of doing things, our patter, and I felt that we would become more comfortable with the changes with time and practice. I noted that while both of us asserted that we regularly checked patients' ears during the procedure, unless we stated it to the patient, it was not apparent from the tape.

I found that I needed to jot our changes down on paper so that I could remember them, and although this caused interruptions to my flow of patter, it meant that I was less likely to make errors and omissions. However, this did not always work, as over the period of the cycles we found that we consistently forgot our planned changes so the idea of a more formal cue card, clearly set out, was initiated for the third cycle.

Although we could use the ear syringing guidelines that are available in the form of a large folder to help us, we felt that a cue card that included our personalised changes that reflected our individual needs, would be a more efficient way of remembering and imparting information.

While we planned to write our own cue cards (see Figure 3 ) and send copies by e-mail to each other to check similarities and differences, this did not happen, as on the following Monday, my co-researcher had the opportunity to complete her final two interactions before we were organised.

This problem supports further my co-researcher's contention that making changes to practice can be difficult. Subsequent reflection on my part implied that if we had had more time, and increased the number of participants to four each per cycle, perhaps the problem of repeating our errors would not have been such an issue. I found that practising them in my own time and space was not particularly helpful as it seemed out of context and I had still had difficulty remembering the changes by the next interaction.

While these examples support our findings that repetition of new changes as well as time, are needed to cement changes into practice, issues such as these could be a problem for other PNs that could be addressed through education sessions and the regular PN newsletters. 


\section{CUE CARD}

1. Have you had your ears syringed before?

2. History.

3. There are some situations were syringing is not recommended.

4. Options.

5. Risk of perforation

6. Side effects.

7. Happy to proceed?

8. Let me know if you want to stop.

9. I will ask at the end of the procedure how you experienced the procedure.

10. The ear canal is clear of wax and the drum appears intact.

11. Is there anything you would like to change? E.g. position, draping, lighting, privacy, manner, language.

12. Was I clear about the information I gave you?

13. Would you have appreciated more or less information?

14. Are you happy with the outcome?

Figure 3. Cue card created by Elsa following second cycle.

\subsection{2 - Getting it right}

Because neither my co-researcher nor I had undertaken this type of research before, we were keen to get it right, however, I felt that as it was for my Master's of Arts (Applied) in Nursing degree I was responsible for 'getting it right', although I had no way of knowing what the rules were. For me, getting it right meant that there must be a correct way of conducting our meeting, that there were issues we were 'supposed' to see within the process of reflection and that if we didn't see these things then I was failing in some way. In other words, I was 'getting it wrong'.

While I was aware that the pattern I had in my mind didn't always fit with what was happening, it took me some considerable time and critical reflection to come to terms with what these meetings were really about, that is, honest reflection of our practice and initiating changes to improve nursing practice. In addition, even though my coresearcher reassured me that she was enjoying the process, it was not until the second meeting that I felt that I was not imposing on her goodwill and friendship. This insight allowed me to appreciate and encourage joint ownership of the research process. 


\subsection{3-Ownership of the research}

The issue of who owns this research did not cause me significant problems until I gained sufficient insight to understand some of the complexities of ownership. Raising the question of ownership of the research with my co-researcher at our second meeting, my co-researcher responded with an adamant denial that she had any claim to the research. "No, this is your research. You are doing all the hard work." While I agree that the research was for my Master's degree, it would not have been possible to complete it without her willingness to become involved as a co-researcher, and her trust in me and in the process of action research.

During the cycles I certainly felt that the research was a joint collaborative inquiry rather than mine alone, and over the course of the meetings my co-researcher's comments reflected her enthusiasm for the research and her part in obtaining information critically looking and reflecting and suggesting changes. Comments such as "we could try..." and "we might be better to..." indicated to me that her role in the research process was an equal collaborative one rather than subordinate. My co-researcher's comments support the action research's commitment to equal collaborative partnerships in the research process (Carr \& Kemmis, 1986).

\section{7 - Communication}

During an interaction with a patient, the relationship between the nurse and patient is crucial in how the interaction proceeds. To impart information and to make connections with people, it is imperative for us to interact with them in a way that is responsive to their needs and way of being.

For instance, in my first three interactions I found that patients were easy-going and casual in their manner and conversation and I responded to their mood in a similar way. However, my fourth participant was by nature a reserved woman and I took into account her way of being and that she appreciated reassurance and friendliness without intruding on her personal boundaries. This interaction included the presence of her husband and had the effect of subtly changing the atmosphere and I became more aware of my tenseness. I felt challenged in my professional capacity because of his questioning, and 
in addition, he said, "you would be more professional if you wore a white coat", which startled both my co-researcher and me as neither of us wears a uniform.

Of the people taking part (12 in total), only one patient was unknown to my coresearcher, while all my patients were familiar to me. The three patients who declined to take part in the inquiry were given the information sheet before my co-researcher was able to discuss the inquiry with them. This point was recognised as an important factor and it seemed to us that if we were able to make a personal connection and discuss the project prior to them reading the information sheet, gave them a feeling of connectedness that the allowed them to decide to take part. In addition, we acknowledged that we had made an assumption about our initial belief before reflection provided us with further insight.

Although only one patient asked my co-researcher a question about instruments for the procedure, in our experience, while few people ask questions about the procedure of ear syringing, most queries relate to the use of oil for softening the wax. For instance a patient asked my co-researcher about wax "Does it dissolve?" Other frequent questions relate to the size of the piece of wax that is removed or how wax gets in the ear in the first place and for what reason is it produced.

\subsection{1 - Process of verbal and non-verbal communication pertaining to ear syringing}

I felt that the patient who had been referred by the hearing-aid technician for ear syringing was a little nervous, although her stillness may have been accentuated because she had left her hearing-aid at home and she was conscious that I often repeated myself. However, when I asked her if I could have done anything differently that would have made it easier for her, she said "there's nothing I can think of". Perhaps the effort of trying to hear and understand what was being said was more of an issue, rather than nervousness. I did note that my other participants exhibited relaxed body language by their responsiveness and appearing at ease with the situation. The 18-year-old who had not had his ears syringed before displayed tension by his facial expression but not by his language. He responded casually to my queries about his work and the temperatures he was exposed to when spending time in the freezer, and described the clothes he was required to wear to keep warm. My co-researcher's comment "I think that you had a good rapport with this young man" pleased me, as I was endeavouring to put him at ease 
and wanted to make the experience as free from tension as I could. I contend that it is important to connect positively with young people to form a link to encourage trust and confidence so that they might feel more inclined to visit the doctor or nurse for other problems.

My co-researcher was conscious of her silence in her third interaction as it took much longer than she had anticipated and she felt that "I should have talked more, but I was squirting water in his ear all the time and it would have been hard for him to respond". As she was aware of the recorder her silence became an issue for her, "but I felt that I could make things more uncomfortable if I tried to force conversation". In addition, this patient's prominent position in local society contributed to her feelings of strain.

Although I found knowledge of the types, elements and principles of reflection interesting and illuminating, and they raised my awareness of the process, necessity and benefit of reflection, I do not think that they are meaningful in isolation. I concur with Taylor's (2000) contention that they are not meant to be mutually exclusive and that they might merge into one another. In addition, while a particular category might be better suited to one area of practice than another, it is the systematic exploration of everyday life that reveals patterns and values and changes to make.

\section{8 - Conclusion}

Observations made by my co-researcher and I revealed a number of issues in the ear syringing process and procedure. Because this was my co-researcher's and my first such research project, we were thankful that we had not opted for a greater number of participants as our part-time status and the opportunistic nature of ear syringing influenced the timing and recruitment of patients for the inquiry. In addition, we became aware that the most appropriate time to give prospective participants the information sheets was a relevant factor in gaining consent of participants after two people declined before my co-researcher was able to discuss the inquiry with them. A further person declined for other reasons.

The issue of trust and trusting relationships was discussed reflecting the importance of developing confidence between patients and nurses, co-researchers, and nurses and 
employers. We found that patients had confidence in our knowledge and expertise and that questions relating to the procedure were uncommon among our participants.

Rigour and trustworthiness was demonstrated through our repeated collaborative reflective and self-reflective critical observations and in the value of the changes we made to our language and communication with patients noting that some of our language or patter could influence patients' understanding of the contraindications and side effects of syringing.

During the writing up of this inquiry, revisiting the tapes and transcripts to re-examine our conversations with patients provided me with deeper insights and understandings about our communication processes as well as opening up unexplored areas to explore. Ownership of the research revealed that although my co-researcher denied any claim to the research, she became enthusiastic about the inquiry and was instrumental in seeking and suggesting changes and improvements to our practice.

Reflection on these issues and my own journey is discussed in the next chapter (7). 


\section{Chapter 7 - Reflecting on reflection}

\section{1 - Introduction}

This is the third chapter of findings and discussion of the inquiry, and to best present how reflection assisted my co-researcher and I, together and individually, I have separated this chapter into two streams. Stream 1 discusses the reflection used with the aim of improving people's experiences of ear syringing using an action research process. I discuss the process of reflection that we were undergoing and then the analysis of this process from literature. Stream 2 looks at my own reflection in relation to my Master of Arts (Applied) journey. Excerpts from my own journaling will be used to assist me in explaining and illustrating my thoughts and reflections throughout the inquiry and in writing up.

\section{2 - Stream 1}

\subsection{1 - Reflection on the process of the inquiry}

In choosing an action research methodology I needed to learn more about reflection than I had previously known and understood, and throughout the year I studied the different types, elements and principles of reflection. Although I had provided my co-researcher with literature to read, thinking that between both of us we would have the knowledge to explore the different elements of reflection, we found that we remained mostly oblivious to the distinctions during the interactions, and at the meetings between my co-researcher and myself. However, we became "alert to our practice" (Taylor, 2000, p. 117) and this alertness was reflected in the changes we made and plans for the next cycle. For instance, we became alert to our language, our forgetfulness and our assumptions. In addition, we placed trust in the process of reflection and each other.

I was reluctant to raise the issue of exploring our practice using different elements with my co-researcher because I felt that I did not have the confidence, knowledge or skill at that time to advise on the different kinds of reflection and how we could use them in our interactions. In addition, I felt that we had enough communication issues to keep our minds occupied in remembering changes and questioning ourselves about our practice. While I was disappointed about my lack of confidence in this aspect of the inquiry, future research could focus on other elements of reflective practice such as emancipatory 
reflection or technical reflection to provide a more rounded change and improvement process.

At the beginning of the research, I had not formulated any ideas about which element, if any, of reflective practice we would focus on as I thought that the three elements of reflection, technical, practical and emancipatory, would be more clearly separated. Although I found that the distinctions were not always clear, the majority of our critical observations and reflections involved mostly practical reflection and making changes to our verbal communication and patter. During the second cycle we unknowingly included emancipatory reflection when discussing coercion and power during the consent process, and it was emancipatory reflection that empowered us to continue to explore our practice given the constraints such as interruptions to the interactions, privacy, and time. I found that forms of reflection merge into one another, and that this whole research process was emancipatory. We challenged our routine practices and previous ideas and routines, learned more about our practice and the basis for our beliefs, and developed a trusting relationship. While 'transformation' is perhaps too strong a word, we did change our practice to improve communication with patients.

Over the course of the cycles, our reflections revealed that we could change our terminology and sequence of imparting information to improve our communication with patients when discussing the risks and contraindications of ear syringing. We realised that the way that we expressed ourselves could make a difference to how much the patients understood the information when making a decision about ear syringing.

A question for future research could look at areas such as assuming that all women patients feel at ease while undressing for a cervical smear behind a curtain in the consulting room while the nurse is also present in the room. Or exploring when the most appropriate time to give patients with chest pain information regarding the taking of ECG's.

\subsection{2 - Reflection on meetings, audiotapes and transcripts}

To begin with, my co-researcher and I found that revealing our work with someone else in this way was uncomfortable and challenging, because everything we said during the interactions was there to be read in the transcripts, heard on the recordings and 
interpreted by another person. There was no editing or changing anything to make our words or interactions with the patients different. Listening to the audiotaped meetings revealed that our reflective sessions flowed forwards and backwards, often repeating phrases such as my co-researcher's comment "ear syringing is a simple procedure" or use of language. I found on listening to our recorded meetings that we often restated, almost word for word, what we had discussed at the beginning of the meeting. We did not remark that we had already discussed an issue, we discussed it again, coming up with the same answers.

Observing that she often talked over patients who were speaking, my co-researcher ascertained that she could improve her listening skills by allowing more time for the patient to reply to her questions. Her impression of her conversations with patients is that "I have a spiel that I need to say, and I forget that the patient needs time to respond". I replied that "I had experienced the same phenomenon but I improved when I realised, that for me, it was a confidence issue, but it also depended on what was going on at the time, like where I was needed next or what else is going on in the surgery and me. I don't think that beating ourselves up about what are minor and correctable inadequacies is helpful and that critical reflection to make improvements was more important". It was what the spiel or patter contained that concerned us.

\subsection{3 - Reflection on patter}

Reflecting critically on this kind of communication strategy became more important over the period of the inquiry, as I had previously regarded patter as an efficient but negative way of acquainting people with facts. There are times, such as during the influenza vaccination period before winter when I give these injections many times a day, I am aware that sometimes the patient, as a person, becomes 'lost' in the process and providing patients with enough information to gain consent can become the overriding factor. (Although patients have been amused when I have raised my eyes to the ceiling and counted on my fingers to make sure that I have remembered every appropriate contraindication of a procedure).

Procedures such as ear syringing or immunisations are no different so patter has the potential to transform the consent process into an 'end to a means' rather, than a 'means to an end'. To begin with, I thought that our changes would open a way of 
communicating that would remove the need for patter, however, both my co-researcher and I continued to use it to trigger recall with expressions such as "there are contraindications to this procedure" and "one of the side effects of syringing is that you might become dizzy". Following the second meeting we decided to use a cue card to help our recall. This cue card could be amended to suit the individual nurse's needs, and be helpful in other procedures such as smear taking or ECG's.

While I had initially thought patter would be a problem, it became an integral part of our communication strategy and I found that it was not the 'bogey' I thought it was going to be as it became a vital tool in assisting my memory. In addition, although it takes time to trust the process, when delivered with sensitivity, patter can impart knowledge to the patients in concise and frank language understandable to all.

\subsection{4 - Reflection on trust}

When listening to the first audiotaped meeting between my co-researcher and myself I noted that I appeared uncomfortable. I remember feeling a degree of reluctance in revealing myself to my co-researcher who I assumed would find my thoughts and ideas unusual. Increasing trust between my co-researcher and myself occurred over the time of the research and meetings, however we remained more critical of ourselves than of each other. This could be the result of not having enough time to create the sense of trust needed, or the language, to critique each other's practice. As we became more comfortable with each other over the period of the inquiry, our trust in each other increased, as did the faith that our relationship would hold, when we gently challenged each other.

It took time to learn to have certainty in the process of reflection in association with action research, as we wondered if we would find much to change. However, as each cycle brought more understandings and insights we began to look more critically at how we worked and learnt to trust our reflective instincts, and to be more assertive in our critique. For example, my co-researcher commented that "I think that you could change your wording from contraindications to situations as you did previously".

Further reflection occurred while I was writing the thesis reports on the research. I found that I could look at the provision of informed choice and consent process in a different 
way, and although this is something I had known, it took deep critical reflection to articulate it. While the patient might trust me to know what I am doing and not to cause them harm, I also needed to have knowledge of their relevant history, so a joint decision could be made. There appears to be two aspects of this thought that reflect professional and personal accountability. One is about caring for the patient and not causing harm, and the other is about caring for myself and not causing harm. One of the underlying values in the NZNO Code of Ethics (1995) is 'non-maleficence', meaning the prevention of harm, while another value is 'beneficence', which is "performing actions that are seen as worthwhile and good" (p. 12).

To create a partnership between the nurse and patient and to promote safe care, both parties are important in the interaction and need to trust each other, and provide enough information to be able to arrive at a conclusion that benefits both patients and nurses. This could be an issue for discussion at PN's peer review sessions.

\subsection{5 - Reflection on practice nurse education}

While my co-researcher commented "I think that taped interactions would be useful for peer review so that what we said to patients could be reviewed by other nurses", clinical assessment tools and processes are not readily available for PN's. For example, I know from written feedback from the cervical screening programme that while I am competent in my technique, I am less sure about some of the conditions of the cervix that I observe. In cases such as this, my practice is to ask the woman if she would object to a GP, who might be a male, providing us with a second opinion. So far this option has never been declined, and in addition, my assessment of the cervix has been critiqued.

Meeting with supportive colleagues for critical reflection is one answer to the problem of assessing practice, however, as Taylor (2000) points out, nurses need to be able to feel safe and have the self-esteem and confidence necessary to examine their practice and a willingness to make changes.

This inquiry has demonstrated a way where, in a safe and supportive environment, changes to nursing practice can be made. Further to peer review or critical reflection groups, PN's also have regular education sessions as discussed earlier. Although, 
experience has demonstrated that many nurses are reluctant to ask questions in front of a large group in case they appear "silly".

In my experience, it is during group education sessions where nurses have face-to-face discussion with experts that these small facets of practice arise. While it would be helpful for new PN's to have access to this kind of information, due to the number of education sessions that can be included in the time available, it is not practical to have the same education subjects each year.

Although literature is helpful, it also takes time and commitment to read and absorb the information.

\section{3 - What the findings meant in relation to the literature}

The findings of this research support Carr and Kemmis's (1986) description that action research goes beyond critique to critical praxis. By thinking critically about our practice, my co-researcher and I gained insight and understanding of the constraints of our practice that empowered us to challenge our practice with critical reflection and make changes to improve our communication with patients. This, in turn, empowered and enabled patients to think about their knowledge and standard of care. However, I disagree with Carr and Kemmis contention that in action research neither thought nor action takes ascendancy over the other. Both my co-researcher and I found that thinking and reflecting about our practice and how we could seek answers to questions we had not yet formulated as suggested by Freire (1972) in Chapter 3, was the major part of the process. Although we had many work and family commitments to attend to, thinking about our research did not start and stop with the interactions. This accords with Taylor's (2000) contention that reflection is a process that is both rational and intuitive.

\subsection{1 - Reflection before, in and on action}

Although not at the same depth or intensity, I found that we thought and reflected on our research in a continuous cycle of Greenwood's (1993) reflection-before-action, and Schön's (1983) reflection-in-action and reflection-on-action. My co-researcher would come to the meeting with new insights and questions for further exploration, such as in the second meeting, her concerns about the way that information given to patients could deter them from having the procedure done, and I raised issues relating to power, 
coercion and consent. While these issues were thought about and reflected on beforeaction, they were also addressed in-action and on-action, and explored and reflected critically at our meetings. I found that I reflected most critically when I was writing up my journal, as it was at this time that I was able to sit quietly and look at the interactions and meetings as a whole and at a greater depth.

On analysis, I found that we reflected in an eclectic fashion combining types and elements and principles. For example, at our first meeting we listened to the tapes and read the transcripts using Schön's (1983) reflection-on-action before deciding on what changes we wanted to make for the next cycle. This pre-planning utilised Greenwood's (1993) element of reflection-before-action. Schön's reflection-in-action was found in our personal informal reflections when we checked with the patients of progress and how they were experiencing the procedure, and afterwards, reflection-on-action was when we continued our informal reflection, read the transcripts and listened to the audiotapes.

While Schön's (1983) and Greenwood's (1993) elements of reflection were reasonably simple to observe, Taylor's (2000) types were more difficult to see or observe in practice as they often merged or intermingled with each other. For instance, technical reflection involved our discussion on the use of paper tissues for drying ears after the procedure, as well as the differences between types of instruments we used. In addition, we critiqued the Nelson Division of the College of Practice Nurses NZNO Guidelines (2001) finding things we could change or improve. Exploring our language and the lived experiences of our participants and ourselves, became part of our practical reflection. Emancipatory reflection was found in discussions where the constraints of our practice were examined and the idea that by improving the communication between the patient and nurse both could be empowered.

\subsection{2 - Formal versus informal reflection}

All forms of reflective practice are valuable and are often interwoven into nursing practice, with formal or informal methods used to learning to reflect. According to Burns and Bulman (2000) reflection is a process of reviewing practice so that we can describe, analyse, evaluate our practice in order to learn. One advantage of being a reflective practitioner is that it provides a way of learning to articulate insights into what happens in practice situations. 
Formal reflection allows for beginner practitioners to follow a prescribed course of action so that the practitioner is able see how reflection is carried out, and how it can influence practice. Reid (2000) suggests that gaining the support and expertise of a skilled mentor is one way of learning to reflect formally. In this situation a practitioner and mentor meet to discuss issues of practice and ways of gaining insight and learning from them. Another method of formal reflection involves the skills of clinical supervision. According to Gillings (2000) clinical supervision can be seen to be the formal and legitimate process for practitioners to engage in reflection. Informal reflection is a process where the practitioner reflects on practice usually in isolation through journaling. Taylor (2000) suggests that art, poetry and music can assist in the reflective process.

Although my co-researcher and I have different methods for reflection, both of us reflect informally. However, this inquiry has given us insight into how a more formal approach to reflection, such as we experienced in our meetings and in this inquiry, provides the challenges and support needed to critically explore issues of practice. During this inquiry and in the writing up, I found that both shared and private reflection assisted me in resolving problems and issuing challenges for me to learn from. From my experience of reflection, nurses who are beginning reflective practice would need to learn more about the process and ways of reflection to gain the full benefit. Following set questions and giving answers without insight into 'self' as well as practice situations could cause frustration and boredom of the practitioner, without gaining the benefits of reflection and changing practice. Therefore, I contend that reflective practitioners include both private and shared sessions with a skilled practitioner such as a mentor or supervisor, so that insights and understandings of practice are both challenged and supported. In addition, nurses should be aware that effective critical reflection, whether it is before, in, or on, practice, while more difficult than it appears, is worth the time spent as this inquiry has shown by improvements my co-researcher and I made to our practice and patient care.

\subsection{3 - Reflection on Taylor's (2000) work}

Although Taylor's (2000) work is about reflective practice, what I feel is understated in Taylor's work is the issue of trust. I was unable to find any reference by to trust by Taylor, at all. Trust became an ongoing theme in this research, trust between nurse and patient, nurse and employer, and especially in relation to the research, trust between co- 
researchers. The personal relationship between reflective practitioners is not emphasised by Taylor, however reflection on, and observation of the experience my co-researcher and I revealed that in our research, personal relationships were very important to the outcome of our meetings. I recall an experience about trust explored in Chapter 3 (see p. 39) in which I note that following sharing a critical incident with a colleague, the negative feedback had the effect of me deciding not to share critical incidents with colleagues in the future. It took me some time before I felt secure enough to relate negative experiences and to have my practice affirmed and supported.

\subsection{4 - Reflection on my practice, communication and consent}

Although we were more critical of our own practice than of each other's work we chose to highlight the positive aspects of our practice and research rather than the less favourable. Reflection is not only about looking at the negative aspects of practice, but can used to explore which positive aspects of practice to restate. This did not mean that we ignored poor practice, it meant that we recognised that patterns of communication required changing. More importantly our acceptance of these weaknesses allowed us to support and reassure each other to encourage further improvements.

Future research could explore whether working with one congenial co-researcher offers similar findings, or whether a larger group of nurses with a greater diversity of characteristics and personalities would find it more difficult to remain coalesced as a group.

The importance of communication in the consent process was reinforced when my coresearcher reflected that some patients might change their minds about having their ears syringed when the risks of what they have perceived as a simple procedure, are explained

complicating factor in the consent process arises when the patient does not understand what is said on her or his behalf. Our ctions disclosed that when people are hard of hearing, we ence for assent and failed to follow-up our questions of how they procedure.

rom patients before undertaking any procedure, is crucial, I argue required. There are times when patients insist that their ears are to them. In addition, a is hard of hearing and observations and refle sometimes took their si] were feeling during the

While gaining consent that our consent is also 
blocked with wax, when there is no evidence of blockage, indicating another cause for deafness, or, the wax is so hard that applications of oil to soften the wax before syringing is warranted. In these instances both my co-researcher and I decline to syringe and advise the patient regarding further care or options.

Over the research process, we were aware that how the patient presented influenced our interactions. In addition, our own personalities, and stressors such as interruptions and work pressures, shaped our language and the way we informed patients. When patients wanted to continue chatting, the possibility of losing track of the consent process was greater, leading to increased likelihood of truncating the consent process, which begs the question of whether in that case consent could be said to be gained. We both recognised the possibility of making the assumption that while the GP might have referred the patient for ear syringing, or that because the patient had made the appointment for the procedure, that they had made an informed choice. However, these reflective cycles have clearly demonstrated to us that not all patients are aware of the risks and contraindications and side-effects of the procedure before having it done.

Patients' assumptions that the procedure was safe, with little or no risk raised further issues in communication. Our assumptions that we had consent to continue included asking a patient if "everything was okay" and not following up the patients' reaction or non-reaction. However, patients who need their ears syringed are often elderly and hard of hearing, and when the hearing aids are removed, and if an ear is being syringed at the same time, the patient can be very deaf. Our experience and reflections supports Avenyard's (2002) contention that compliance by silence does not always constitute consent. Reflection continued throughout the inquiry and for me it continues still, either in my head or journaling. Taylor (2000) asserts that when writing or typing our reflections not to 'cut and paste' or edit, just do it, which is what I do.

\section{4 - Stream 2}

\subsection{1 - Reflection on my learning about the research process}

It was when writing my journal following our first meeting that I experienced an unexpected sense of enlightenment, my aha moment (Street, 1991), where, at a deeper, more meaningful level I realised I had not fully integrated the complexities of reflection. In the most part, my reflection processes were limited to objective, practical and technical 
levels. I needed to use my imagination and mirror images to look at what is behind the image as well as what is obvious. Despite thinking that this was how I practiced reflection, the depth and peripheral vision required was often absent. This lack of depth was also apparent in our recorded meetings. Even following my aha moment I found it difficult to move out from what was familiar to both my co-researcher and I, and to look critically at the research process in a different way.

While I had some understanding of reflection and reflective practice before undertaking the research, I found that from a theoretical perspective, learning about Ghaye and Lilliman's (2000) principles of reflection detailed in Chapter 3 (see p. 33), placed a framework around my thoughts and practice before undertaking this research. These principles embody Locke's (1690/1952) definition of reflection of turning the mind inward to observe and to contemplate the mind's actions, to think, reason, believe and doubt, as well as Dewey's (1933) stream of consciousness, and capture Schön's (1983) reflection-in-action and reflection-on-action, and Greenwood's (1993) reflection-beforeaction. When I revisited the principles of reflection, I noted that they involved critical thinking as well as Taylor's (2000) types of reflection. For example in principle 1: "Reflective practice is about you and your work"(p. 33). This is followed by learning from experience, valuing what we do and why we do it, accountability, closing the gap between theory and practice, making sense of our thoughts and actions, generating knowledge, reflective conversations, linking values and actions, improving practice, systematically developing practice, and respecting and working with evidence.

When reflecting on our meetings and what I wrote in my journal, it was often in the reflective process of further writing that more insights and understandings emerged. I included this new knowledge in my subsequent interactions with patients as well as discussing them with my co-researcher during the meetings. For example, following the second cycle meeting, I wrote "just had a thought; I will try explaining what I will say before beginning the procedure. I wonder how that would work? Would it cause patients to expect problems? Would they appreciate it? It seems to me, that to expect people to think of things that they would have liked to change (unless they were big issues) after the procedure could be as much of a problem as at the beginning. I will try 'I will ask you at the end of the this procedure if there is anything you would like to change that would make it better for you, for instance, the words I use, privacy, or 
anything about my practice that you would like me to change for you.' Reflecting on what I have written, I will need to change the wording, but this is essentially what I want to say". I tried this change of sequence in my final two interactions and patients said that they appreciated being asked. At the following meeting, my co-researcher commented that "letting the patients know the type of things we are looking for before the procedure was a good idea as patients might not want to show their ignorance if they don't understand our questions at the end."

Reflecting on my discomfort about being taped and placing myself in the visible and exposed position of researcher, my personal critical reflection suggested that I used these terms as a subconscious shield to protect myself, rather than as an act of power over the patient. While I was disappointed that my tentative attempts to raise issues of power and coercion such as draping the patient and discussing consent at the same time, were not reflected on, and discussed more substantially, we did decide not to continue this practice.

Early on in the process of analysis, I realised that I had been trying to impose data on my preliminary headings and not the other way around. This imposition is not what I intended but it was what was happening. I needed headings to help me with interpreting the data, but I began looking for my own sense of what I thought should be there, without embodying Street's (1999) imagining, and my own interpretation of mirroring, that is, looking over, under, behind, and to the side of any given situation to see and understand what is revealed. During the time of writing up the research I became more adept at this skill.

\section{5 - Conclusion}

Chapter 7, separated into two streams, looked back on the process of reflection and its importance to the outcome of the inquiry. Initially, my co-researcher and I found opening ourselves up to each other uncomfortable but with time and reassurance our confidence grew and we began to enjoy our meetings. This confidence resulted from a growing trust between us, and we discussed how other PNs could be involved in the process of critical reflection through meeting supportive colleagues at peer review. While my co-researcher and I use informal reflection processes, formal reflection 
facilitated by a mentor or a professional supervisor could be helpful to beginner and experienced practitioners.

In relation to the literature, we found that Carr and Kemmis's (1986) description of action research does go beyond critique to critical praxis. The insight and understanding we gained from thinking critically about our practice enabled us to feel empowered, and by making improvements and changes to our practice, empowered others. Contrary to Carr and Kemmis' contention that neither thought nor action takes ascendancy over the other, my co-researcher and I found that thinking about our research did not start nor stop with the interactions. This supports Taylor's (2000) claim that the reflection process is both rational and intuitive.

We included Greenwood's (1993) reflection-before-action, as well as Schön's (1983) reflection-in-action and reflection-on-action in each of the cycles and at the meetings. I used Taylor's (2000) work throughout this inquiry, however I found that while the issue of trust was an important aspect of this inquiry, it was understated in her work. Trust in relationships also became apparent, as people were able to accept or decline to participate in the inquiry if they chose.

My own learning about the process of the inquiry, found that reflecting at the time of writing in my journal, was a significant part of my reflective process and I gained unexpected insight into my process of reflection. This insight has been and important aspect of my Masters Degree.

This chapter was the last of three chapters that reported and discussed the research. Through Chapters 5, 6 and 7, I demonstrated that the critical reflective process within action research continued to be an important strategy in seeking answers to questions of changing our practice to benefit patients. Attention given to the reflection and self reflection in a collaborative partnership built on trust has the potential to create and hold change in any area of practice. 


\section{Chapter 8 - Conclusion}

\section{1 - Introduction}

This action research inquiry began its life as an idea to improve practice and enhance nursing care, and it finished by becoming an important and enlightening aspect to the professional life of my co-researcher and myself. What originated as an exercise to complete my Master of Arts (Applied) in Nursing became an intrinsic part of my practice. This chapter describes the conclusions I came to in relation to how my coresearcher and I improved our communication pertaining to ear syringing using action research with reflection. In this chapter, I describe the conclusions and recommendations to nursing practice, such changes to the ear syringing process and the time that changing practice takes. I look at the conclusions and recommendations for nurses' use of reflection, and whether the number of co-researchers was enough. Conclusions about formal and informal reflections are made, as well as recommendations for practice nursing. I make some conclusions and recommendations regarding action research and nursing, followed by general considerations I found impacted on the inquiry. The limitations of the study as I found them, are described. Finally I talk about my journey and acknowledge inspirational authors such as Dewey (1933), Schön (1983) and Taylor (2000), and the work of my co-researcher, as well as those patients who had their ears syringed.

\section{2 - Conclusions and recommendations for nursing practice}

The conclusions and recommendations of this study are about assessment, language and information that my co-researcher and I found that we needed to change to improve nursing practice and patient care. Although my co-researcher and I were enthusiastic about improving our practice and patient care, we recognised that as this was our first formal research project, our focus was narrow. This insight has implications for future research and nursing practice.

\subsection{1 - Changes to the ear syringing process}

In this study, changes to the ear syringing process included checking that people could hear what we were saying to ensure that they understood what was involved in the ear syringing procedure. This aspect was important during the consent process, because if 
the patient did not hear or understand the information, could lead to the assumption that consent had been gained. This, in turn, could lead to errors being made.

One communication recommendation I suggest, is that when patients arrive to have their ears syringed, practice nurses (PN's) place more emphasis on making a full assessment that includes patients' ability to hear and understand the information that the PN is passing on to them. Deafness could create a barrier between the nurse and patient with the result that an informed decision about syringing is not possible. A further recommendation is to ensure that patients are aware of the process and procedure of ear syringing, so that they have the knowledge to inform the nurse if something is different to what they had been led to expect. A nurse-specific cue card (see Figure 3, p. 103) could become an integral part of the ear syringing procedure. It would be instrumental in ensuring that nurses covered areas of their practice that they were unsure of, or needed reminding about.

Changes made to language and terminology assisted patients to better understand that there were times when the proposed treatment was not the best option for the patient. Recommendations surrounding verbal language involve ascertaining if the patient understands what is being said and to adjust the words to suit each individual. However, nurses should be aware that sometimes patients respond in the manner they think that the professional expects, and not necessarily how the patient is feeling. Language surrounding simple procedures can still be complex, and terminology that includes technical words, such as "contraindications" or "tympanic membrane" the nurse might be familiar with, may be unknown to the patient, and need to be changed to fit the situation. Clear communication between patient and nurse is essential in preventing mishaps, and errors, and, when delivered in a patient sensitive way, patter is a useful form of communication to convey information, as well as assisting recall of routine information.

\subsection{3 - Changes take time}

Change is often difficult to integrate into a way of being without thinking, and an important conclusion of this inquiry is that it took my co-researcher and I time to make and cement changes to practice. Even though my co-researcher and I had three cycles with six patients each, we still had difficulty in consolidating the changes and felt that we 
needed to continue monitoring our practice. Further cycles would have been helpful in this regard before moving on to other changes we may have wished to make.

\subsection{4 - Other areas that could look at nursing practice}

Additional areas that could perhaps look at nursing practice are cervical screening, immunisation, and other procedures that have the potential to cause patients stress and anxiety. For example, before taking a cervical smear, do nurses assume that because they are women, that the patient would not have problems with the nurse being in the room while the patient is undressing? When doing an electrocardiogram on a patient experiencing chest pain, when is the most appropriate time to explain the process?

Further to these considerations, when nurses are busy or are interrupted, it becomes difficult to remember all the issues that we need to discuss with patients. A cue card could be useful to support nurses' recall of points that patients need to be aware of in relation to their treatment. The notion of a cue card to aid memory recall has additional implications for practice situations, such as advising women about cervical screening and mammography, including programme details, for example.

\section{3 - Conclusions and recommendations for nurses' use of reflection}

This research demonstrates the important role of private and shared reflection. Reflecting in private, such as when writing in a journal, opens the way for more in-depth reflection and allows time for what is in the back of our minds to come to the fore. Shared reflection with supportive others is equally important, as it is this aspect of reflective practice that creates further understandings and challenges to practice.

\subsection{1 - One co-researcher was enough}

In my opinion, sharing the research with one co-researcher colleague was more manageable for beginner researchers such as my co-researcher and I, than if we had included more co-researchers or participants.

For this study, I found that reflecting critically with one co-researcher was enough for us to accumulate data for analysis. More co-researchers would have increased the amount of data we collected which would not have had time to be fully explored within the time 
frame available. In addition, gaining trust within a diverse group would have been more difficult to attain, and relationships might have also been put at risk.

Sharing our reflections with each other as co-researchers, followed by critical examination of our changes, brought into focus for me the importance of choosing a coresearcher with whom I had already developed a comfortable relationship. Over the period of the research our trust in each other was an important factor. Trust was enhanced and nurtured between my co-researcher and I throughout the process of listening to each other's audiotaped interactions, reading each other's transcripts, sharing our thoughts and reflections, and putting forward our ideas for the following cycle.

Being more critical of our own practices we initially found areas of our own practice and communication we could change. However, once trust was established, we were not afraid to bring issues to each other's attention. For example, my co-researcher suggested I change some of my language, and I pointed out that she continued to talk over people. While we both acknowledged areas where we could improve our own practice, we constantly supported and reassured each other. This reassurance and approval of good practice was important in keeping our relationship and the research on course, and although it could potentially have degenerated into a mutual 'back patting' exercise, the opposite was true for us.

\subsection{2 - Formal and informal reflection}

My co-researcher and I used both formal and informal reflection in this action research inquiry. At the three collaborative meetings we reflected critically, challenging, reassuring and supporting each other throughout. We found that practicing reflection takes courage and confidence, therefore, I suggest that in addition to journaling and other forms of reflection, practitioners, whether neophyte or experienced, need to have times where they are able to share their reflections with other like-minded nurses, in addition to journaling and other reflective practices.

While my co-researcher and I found that reflecting verbally at our meetings helped us devised our changes, it was our continued thinking and reflecting we did during the time of the research process that gave great satisfaction and uncovered new ways of looking at 
things. It was this kind of reflective process that kept our minds open to looking at a deeper level for ways of improving our communication and interactions with patients.

Although I reflected in our meetings and wrote notes, it was often in the process of revisiting the writing that further reflections on our research emerged. The reflective process did raise the issue of how, when, and where we reflect, and I argue that in my experience, many nurses do not know enough about critical reflection to be able to reflect effectively to make changes to practice. In addition, even though I considered that I used reflection in journaling, it was often at a level that, while it brought understandings it could have been at a deeper level to gain the most beneficial effect. To encourage nurses to become more knowledgeable about reflection, involving the skill of mentors or professional supervisors could be helpful. These meeting could be in groups or singly or a mixture of both, depending on the needs of the nurse at the time.

Gaining insight and understanding of our practice with reflection and self-reflection were crucial elements in this action research inquiry. It was action research's cycles of planning acting, observing, reflecting and replanning that put in place a framework (see Figure 2, p. 46) from which we could explore ourselves, as well as our practice. The insights and understandings we gained gave us the confidence to challenge each other, and our own thinking, in order to make changes. Without the understandings and insights attained through reflection, our changes, if any, might have remained an evaluative strategy such as the nursing process.

\subsection{3 - Recommendations for practice nursing}

Recommendations for practice nursing include using reflection to explore and challenge long-held beliefs and routines, and to have trust in the process of desired change. Some of this reflection might indicate that nurses could become more patient focused and look at the needs of the patient, rather than procedure focused where the action of the procedure takes precedence. In addition, continued examination and critical reflection of practice and procedure guidelines, has the potential to improve nursing practice and patient care, by challenging what is written and to make the improvements needed to change practice. 


\section{4-Conclusion and recommendations regarding action research and nursing}

\subsection{1 - Methodology for nursing}

Action research is an appropriate methodology for reflecting on, and making changes to nursing practice. Its collaborative approach to research sharing equally with coresearchers who, in this study, were practice nurse colleagues, is one of its strengths, as we understood our shared experiences during our meetings.

My co-researcher and I found that action research was a manageable process that, while it could be seen as prescriptive, when interacting with patients, its fluidity did allow for empathy and recognition of wider issues. It allowed us to explore in safety, together and in our own space, ways in which we could think about and influence changes to our practice without excluding other facets of human interactions. For instance, action research allows nurses to accommodate peoples' individuality. Nurses are aware that anxieties and concerns unrelated to the current procedure could impinge on patients' ability to understand and make choices. Action research worked for us, and our improved communication benefited patients by enabling them to understand and have knowledge of the contraindications, risks, options and side effects of the ear syringing procedure. It allowed them, in partnership with the nurse, to make choices about their care. However, without the willingness of the patients to participate, this action research inquiry could not have taken place.

I can unreservedly recommend an action research methodology for a research inquiry of this nature. While cycles have a clarity and sense of purpose in seeking changes and improvements to practice, it is not limited to the technical aspects of practice. For my coresearcher and me, it provided a sense of achievement and affirmation, and trust in each other and the process of research that we might not have received in another methodology.

\subsection{2 - Number of participants and cycles}

For our study, the number of participants and cycles were enough to obtain a significant amount of information that we were able to explore and reflect on. At the beginning, my co-researcher and I thought that there would not be much to change, however, there was more than we could give full consideration to in this instance. 
The nature of action research means that it involves action and reflections before, in and on the action so that new insights and understandings can be explored and changes made. While we continued to uncover areas of practice and terminology we could improve on, I would have liked to have had the time to look in more detail at the body language of patients that might indicate stress responses. In addition, this research raises question of how long it would take for us to automatically include our changed language and communication and patterns, and to identify what influences the uptake of planned change.

Recruiting a co-researcher was not an issue for me, however I would have had more difficulty in sharing my thoughts and ideas to someone I had not had the opportunity to build a relationship with beforehand. Knowing my co-researcher as a person and as a nurse created an atmosphere where we were able to continue developing our trust in each other that influenced the outcome of the inquiry. Without her astute mind and willingness to critically reflect on her practice this action research inquiry would not have been possible.

The task of recruiting patients to participate in the inquiry demonstrated that we were more likely to obtain the consent of people if we had the opportunity of discussing the inquiry prior to the person reading the information sheet. However, my co-researcher and I feel that if the information sheet were revised and refined, and became more responsive to patients' needs then perhaps the number of patients declining to take part would be reduced. While I was surprised at how willing patients were to participate in the inquiry I have come to accept that this willingness portrays the degree of trust patients have in our care of them, and I acknowledge and appreciate their unreservedly given consent for the inquiry.

\subsection{3 - Continuing cycles}

Action research allows the cycles to continue for as long as deemed necessary by the coresearchers. In this study, my co-researcher and I could have continued to explore our practice and make changes to benefit patients. 


\subsection{4 - General considerations}

Because of the opportunistic nature of the inquiry, recruiting people within a time frame had the potential to become a problem. We found that, of the three patients who declined to participate, two had been asked to read the information sheet prior to the nurse discussing the inquiry with them. I conclude that this initial personal discussion by coresearchers affirmed the relationship and the sense of trust allowing people to understand the inquiry fully. Although we were initially disconcerted about people declining in what we thought was a well thought out and planned strategy to help people. The fact that people declined indicated that the consent process was working. While the timing of the cycles for this project allowed for three months, the nature of general practice meant that we were unable to plan in advance to have people requiring their ears to be syringed at a nominated date or time. If more people had been recruited, we would not have been able to complete our three cycles in the time allowed, thus limiting the amount of data we could collect.

In addition to the trust between my co-researcher and myself, participants showed that they trusted us not to cause them harm. Further, we needed to trust them to communicate openly with us so that the information we gave them was adequate, understandable and appropriate to the circumstances. Without trust from our employers, expressed by their consent for the inquiry to be undertaken at work, the trust of patients who participated, as well as those who declined, and between my co-researcher and myself the outcome of this inquiry could have been much different. I conclude from this aspect of the research that building trusting relationships is imperative to communication, and that clear communication is essential to quality research.

The joint co researcher meetings with transcription of the audiotaped interactions as well as the audiotapes, ensured that we could not deviate from what the patients or we, had said. In addition, when I was writing up the research, I was fully aware of the need to be completely honest and not to write something because it might sound better to another person. The trusting relationship between my co-researcher and I had the effect of ensuring trustworthiness of my analysis of the information revealed in the tapes and our meetings as each of us had the opportunity to check each other's accounts of what was said. Furthermore, my co-researcher would know if I had made errors or omissions in 
our research, and as I value her friendship and her judgement, I took some considerable pain to reflect our findings accurately.

\section{5 - Limitations of this study}

Although my confidence in the action research process improved over time, one limitation of this research was my own anxiety. I felt I needed to get it right even though I was unsure what 'right' entailed. Confidence in any field of endeavour enhances the outcome, and I contend that if I had been more comfortable and experienced in research, our reflections and time allocation could have been put to more efficient use. As neophyte researchers, everything we undertook was new, and for me, nerve-wracking. I am unsure at this stage how I could have managed this better at that time and place, except that I could have had more practise with the different audiotape units.

The wordiness of the information sheet and consent forms for prospective participating patients might be able to be refined and printed on a single page instead of three. In addition, we found that it was more difficult to change our familiar and comfortable patter than we initially thought, as well as cementing our changes into practice, and one of our principal difficulties was remembering changes to our language and terminology. This led to our previous errors and omissions being repeated, and the decision to write cue cards to assist our recall of our changes was a significant step forward. However, while I was able to develop my cue card in time for my final interactions, my coresearcher did not. She completed her final interactions before she could do this, resulting in some of the errors and omissions being repeated. A conclusion on this aspect of our inquiry suggests that in future planned changes needs to be in place before the next cycle begins.

Another limitation is related to the interruptions of my interactions. These contributed to forgetfulness of my place in my patter, as well as breaking the concentration of the participant and me. The problems with finding a suitable place for the audiotape to record the interactions, muffled voices when examining ears, and indecipherable words and comments, all contributed to the research's limitations. Furthermore, people talking over each other increased the difficulty in obtaining a clear recording. In addition, my co-researcher and I had planned to explore non-verbal behaviours such as body position 
and facial expressions, however we were unable to do this to the extent that we wished in this inquiry.

I conclude that my co-researcher and I wanted to do too much in a short time frame. In my opinion, for a study such as this, the number of patient interactions per cycle should be increased to four. This number would still be manageable and the resulting establishment of the patter would allow researchers more opportunity to explore avenues for improvement. However, depending on the circumstances, the time frame might need to be extended. While my co-researcher and I as neophyte researchers felt comfortable with each other and the reflective research process, it would be interesting to find out if different outcomes and findings would result from a larger research group.

\section{6 - Celebration of the inquiry and its people}

This inquiry has been a major challenge for me. Throughout this journey, reflection on all its levels has played a significant part in the outcome. The work of Dewey (1933), Schön (1983), Greenwood (1993), and Taylor (2000) was inspirational and thought provoking. I appreciated Dewey's thought processes, Schön's work about reflecting inaction and on-action, as well as Greenwood's reflection-before-action. However, without Taylor's work that provided clear explanations of the types and elements of reflection and gave examples of how it changes practice, this work would have been more difficult. In addition to acknowledging these authors, my co-researcher's enthusiasm, encouragement and trust in the inquiry was instrumental in achieving changes to our practice that has benefited patients. Finally, this inquiry would not have been undertaken if we had not had the gift of consent from the people who consented to be participants. Their part in the inquiry has benefited others in the future who come to us for ear syringing.

Different ways of reflecting and gaining insights to practice have been the greatest discovery in this inquiry, along with learning to trust my colleague and the process of research. While some of my initial concepts have yet to be realised, my co-researcher and I have found a process in our interpretation of action research that will be available and beneficial for future studies of our practice. The concepts and suggestions for change to the process of ear syringing have already found an outlet in the form of cue cards and revision of the Practice Nurse guidelines on ear syringing. 


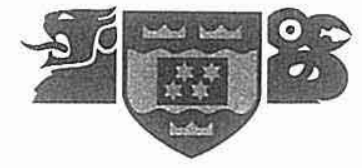

\section{Employers' Agreement to do the Study}

This study, which forms the basis of my thesis, is being undertaken to complete a Master of Arts (Applied) degree in Nursing from Victoria University of Wellington. My supervisor is lecturer Kathy Nelson from the Graduate School of Nursing and Midwifery at Victoria University of Wellington.

Title of Study: Explore Language and Nursing Practice to Reduce Stress and Anxiety in the Context of Ear Syringing.

Aims of the Study: From a critical social science paradigm using action research methodology, this qualitative study aims to explore ways to make the ear syringing process and procedure a less stressful experience, enrich patient care and improve outcomes for both patient and nurse.

History of Action Research: Originally designed by Kurt Lewin in the 1940's to increase productivity in industry, action research was redefined by Carr and Kemmis in the 1980's to develop school curricula, enrich professional development and foster school improvement programmes. Action Research methodology has been chosen for this study as it has been demonstrated by nurse researchers to be a useful tool in implementing changes that improve patient care by refining nursing practice. Action Research involves a series of cycles of four phases; a planning phase, an action phase, a monitoring phase and an evaluation phase. While the number of cycles will be contingent on the amount of time available for the study, 3 cycles are planned.

Selection of Participants: Participants will be selected from English speaking adults over the age of 18 years of age requiring ear syringing, who have no contraindications to ear syringing and who agree to participate. Participants will be able to withdraw from the study at any time without affecting their treatment at the time, or in the future. Each cycle will require 2 participants for each co-researcher (a total of six participants with each cycle, making 12 participants in all).

Location of Study: Because the inquiry is practice based, the coresearchers plan to carry out the study in the normal working environment within the nurses' working day.

Time Span for the Study: The data collection phase of the study will be undertaken from July 2002 to October 2002. The full report is due next year. 
What Happens During the Study: The complete process and procedure of ear syringing will be audio taped. The co-researchers will meet to reflect on the nurse/patient interactions to reveal language usage relating to stress and anxiety associated with the procedure. Meetings between co-researchers will be audio taped and transcribed by an experienced transcriber.

Confidentiality: While co-researchers will not have knowledge of each other's patients, measures will be put in place to ensure that participants remain unidentifiable. No material that could personally identify participants will be used in any reports on this study, and consent and confidentiality forms will be signed by the co-researcher and transcriber. Transcripts and the results of the study will be stored in a sealed envelope locked in a filing cabinet in the surgery until the successful completion of the thesis, then incinerated.

Results of the Study: Employers, participants and co-researcher will be notified personally or letter, when results become available about May 2003.

Benefits, Risks and Safety: The outcome of this inquiry should advance patient/nurse communication leading to enhanced care. General Practitioner employers will appreciate that nurses are using best practice methods when carrying out procedures such as ear syringing. Factors relating to the reduction of stress and anxiety will be transferable to other procedures such as cervical screening, immunisation, venepuncture or electrocardiogram recording for example. Although the study does not carry any foreseeable risk to participants, the study will only proceed once full ethical approval is given and you are notified of this approval.

There will be no extra cost to participants, however, the usual practice consultation charges will apply.

Practice Nurses Elsa Lally (Tudor Family Practice, Motueka) and Diane Auld (Drs Low and Dawson, Nelson) are co-researching this study, with the research being written up by Elsa.

I consent to Practice Nurse Elsa Lally/Diane Auld undertaking this study.

\section{Signed:}


10 June 2002

Mrs E Lally

22 Tudor Street

MOTUEKA

Dear Ms Lally

\section{AN ACTION RESEARCH PROJECT TO EXPLORE LANGUAGE AND NURSING PRACTICE TO REDUCE STRESS AND ANXIETY IN THE CONTEXT OF EAR SYRINGING (Ref. 02/04/007)}

At is meeting on 4 June the Committee received your letter of 23 May 2002 and that of Ms Nelson dated 27th May 2002.

The Committee agreed that any concerns it may have had regarding your research have been met by the responses and unreservedly confirms its earlier approval.

We wish you well in your research and look forward to your report in due course.

Yours faithfully

Cathy Knight (Mrs)

Secretary 


\author{
NIILSON DIVISION \\ OF THE NZ COLLBGB OIY PIRACTICE NUIRSES NZNO
}

\title{
PRACTICE NURSE GUIDELINES 8. EAR SYRINGING
}

\section{OBJECTIVES}

To clear the ear canal of wax.

\section{CONTRA-INDICATIONS}

- Previous injury from or aversion to ear syringing

- Previous or current history of middle ear disease or wet infected ear

- Previous history of ear surgery

- Previous or current history of vertigo

- Otitis Externa (acute or chronic)

- Perforation of tympanic membrane

- Presence of grommets

- Mastoid cavity

- Dermatitis involving scalp or ear

\section{PROCEDURE}

1. Have the client sit at a height that is suitable for the nurse to perform the procedure.

2. Examine the client's ears with an otoscope. Ascertain shape and direction of ear canal. Ensure eardrum is intact.

3. Take relevant history from the client, eg, asking

Have you had any previous ear problems? eg. Perforations, surgery, injury, infection.

Have you sore or painful ears at present?

Have you ever had your ears syringed before? Did you experience side effects? Identify any contra-indication as listed above. If in doubt, seek advice from Doctor or don't syringe.

4. Explain the procedure to the client including possible side effects ie.

- residual water may cause a 'popping' feeling but will disappear in an hour or so a feeling of giddyness or dizzyness during the procedure. Inform the nurse if this occurs

- perforation of the ear drum may occur but this is a rare complication and usually heals spontaneously. Surgical repair is usually successful if required.

The procedure should not be painful - if pain or undue discomfort occurs, inform the nurse immediately.

5. Fill jug with warm water at body temperature $\left(37-38^{\circ} \mathrm{C}\right)$. 
Drape client \& ask to hold receptacle firmly in place under the ear. Run water through tubing until it comes out at body temperature.

Gently pull pinna up \& back for aduits, and down and back for children to open \& straighten the canal.

introduce nozzle of ear syringe into canal for $3 \mathrm{~mm}$ \& direct steady flow of water towards posterior wall, slightly upwards \& backwards.

Water then flows along the roof of the canal \& over the drum, from above down. Water exits the canal along the floor, taking wax \& debris with it.

6. Examine the ear canal periodically during the procedure for effectiveness.

7. If the wax is not removed satisfactorily after a reasonable amount of time, a further appointment should be offered after the client has used some oil or a wax softener for a few days.

8. Drain excess water from the ear by tilting the head towards the affected side.

9. Examine the ear canal with an otoscope.

\section{POST EAR SYRINGE}

1. Explain that residual water may remain in the canal for a short while \& may cause a 'popping' feeling or the client may still feel slightly deaf.

This will disappear in an hour or so.

2. Advise the client not to put anything in the ear.

3. Advise the client to phone the surgery if they have any concerns.

4. Clean equipment used \& sterilise tip of ear syringe (autociave).

5. Document procedure in the clients notes including informed consent given, \& outcome.

\section{REFERENCES}

New Zealand Medical Journal, "When not to syringe an ear" 3 Nov 1998

NZNO Memorandum, Nicola Bush \& Laura Cronin, NZNO Legal Advisors, 17 April 1998

Nelson City Medical Care, "Protocol: Ear Syringing" 12/Feb 2000

Dinsdale Medical Centre, "Aural Lavage Protocol" 18/4/00

ENDORSED BY: J. Cleland

DATE: $30 / 05 / 2001$

Ear Nose Throat Specialist, Nelson 


\section{VICTORIA UNIVERSITY OF WELLINGTON \\ Appendix 4 Te Whare Wananga o te Upokoo te Ika a Maui}

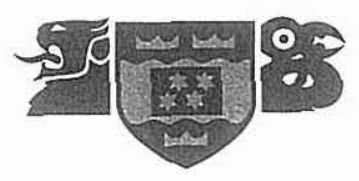

\section{Information Sheet for Participants.}

\section{Project Title.}

\section{Explore Language and Nursing Practice to Reduce Stress and Anxiety in the Context of Ear Syringing.}

You are invited to take part in the study that seeks to explore the language used by patients and nurses, and to examine nursing practice to reduce the stress and anxiety demonstrated by people during the process and procedure of ear syringing. Time will be set aside for you to read this information before you make a decision on whether to take part or not. You have the right to decline to participate without affecting the standard of care or treatment.

Who is the Researcher? Practice Nurse Elsa Lally is the principal researcher in this study with Practice Nurse Diane Auld as co-researcher.

This study, which forms the basis of Elsa's thesis, is being undertaken to complete a Master of Arts (Applied) degree in nursing from Victoria University of Wellington. Elsa's research supervisor is Kathy Nelson, lecturer, from the School of Nursing and Midwifery at Victoria University of Wellington.

What are the Aims of the Study? This study aims to explore ways to make the ear syringing process and procedure a less stressful experience, enrich patient care and improve outcomes for both patient and nurse.

How will People be Chosen? The Practice Nurse researcher will invite English speaking people over the age of 18 years who need their ears syringed and, after reading the information sheet, agree to participate. The number of participants will be 12 .

Where will the Study be Held? The study will be undertaken at the surgery during working hours.

How Long Will the Study Take? The study will be undertaken from July 2002 to October 2002 and will be written up as a thesis due for submission in 2003. 


\section{What Would Being in the Study Mean?}

1) Signing a consent form.

2) During the procedure of ear syringing your conversations with the nurse will be audio taped and after the procedure the nurse will ask you some questions about your experience of the procedure.

The information from our conversations and from questions asked after the procedure will be studied by Elsa and Diane to see if any improvements can be made to the way we practice. Our meetings will be audio taped and then typed up by a transcriber. Any differences to the way nurses work and communicate with patients will explored further so that any changes made to nursing practice will be designed to help people alleviate their stress and anxiety. The tapes and notes will be kept in a sealed envelope locked in a filing cabinet in the surgery until the successful completion of the thesis and then incinerated.

Benefits, Risks and Safety: Ultimately People will benefit from the study through improved communication and nurses' raised awareness and skill to recognise signs of stress or anxiety in a patient, and know what helps to relieve symptoms. This knowledge will be benefit patients needing other procedures such as vaccination, cervical screening and taking blood samples for example.

There may be some inconvenience to you because of the extra time needed to read the information sheet and sign the consent form, however, it is important that these procedures be completed before taking part in the study so your involvement is based on informed choice. There are no foreseeable risks to you by participating in this study apart from the normal risks associated with the procedure.

Participation: Your participation is entirely voluntary (your choice). You do not have to take part in this study, and if you choose not to take part you will receive the usual treatment/care. If you choose to withdraw during the study, your tape will be destroyed and another participant will take your place. Participation in this study will be stopped should any unintended consequences of the procedure appear, or if the nurse and/or doctor consider that it is not in your best interests to continue. Participation in the study is free, but the usual consultation costs will apply.

Will my GP be told I am in the study? Elsa and Diane will not tell the doctor but as he or she often refers people for ear syringing it may not always be possible to protect your identity from the doctor or other members of the health care team.

What will happen at the end of the study? After the study is completed, the results will be available for other health professionals to read and to adapt their practice if necessary.

Where can I get more information about the study? Ask the Elsa or Diane. 
What if I have any concerns about my rights as a participant in the study? If you have any concerns about your rights as a participant in this study you may wish to contact a Health and Disability advocate, telephone 0800-377-766.

Confidentiality: No material that could personally identify you will be used in any reports on this study. Transcripts and the results of the study will be stored in a sealed envelope in a locked filing cabinet in the surgery until the successful completion of the thesis, then incinerated.

Results of the Study: Although there will be a delay until the thesis is published, you will be able to discuss the results of this study by contacting Elsa Lally. The results will also be published in the College of Practice Nurses newsletters and journals and in discussions with other nurses. Thesis will be available in the library of the Graduate School of Nursing and Midwifery, Victoria University of Wellington.

Statement of Approval: This study has received ethical approval from the NelsonMarlborough Ethics Committee. Please feel free to contact the researcher if you have any questions about this study. 


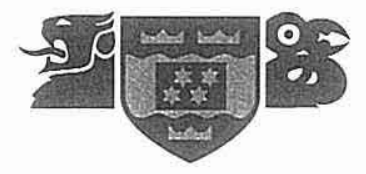

\section{Consent Form}

I have read and I understand the information sheet dated for volunteers taking part in the study designed to relieve the stress and anxiety experienced during the ear syringing procedure. I have been given the opportunity to discuss this study and I am satisfied with the answers I have been given. I understand that taking part in Elsa and Diane's study is voluntary (my choice) and I may withdraw from the study at any time without affecting my future health care. I understand that my participation in this study is confidential with the understanding that it may not be possible for the doctor to be unaware if he refers me. I understand that no material that could identify me will be used in any reports on this study.

I know whom to contact if I have any questions about the study.

I wish to receive a copy of the results. Yes/No

hereby consent to take part in this study.

Date:

Signature:

Project explained by:

Project role:

Signature:

Date:

Address for copy:

Tudor Family Practice

22 Tudor Street

Motueka. 


\section{Transcriber Confidentiality Form}

I (Transcriber) agree that the information I am about to transcribe involving interaction with patients as data collection for Elsa Lally's Action Research project exploring language and nursing practice to reduce stress and anxiety in the context of ear syringing is strictly confidential. Patients' names mentioned within the interactions will be replaced with pseudonyms, for example 'patient 1', patient $2^{\prime}$

At all times the research information (tapes and transcripts) will be inaccessible to other persons. The researcher has assured me that she will debrief me following each interaction to address any issues that transcribing the interaction arise for me.

I agree to the conditions of transcribing for Elsa Lally's research and understand that the research is a requirement for the completion of a Master of Arts (Applied) in Nursing which is being supervised by Kathy Nelson, Lecturer, School of Nursing and Midwifery, Victoria University of Wellington.

Date

(TRANSCRIBER)

Date

(RESEARCHER) 


\section{References}

Agyris, C. \& Schön, D. (1991). Participatory action research and participatory action science compared. In W.F. Whyte (Ed.). Participatory Action Research. (pp. 85-96). London: Sage.

Armitage, P., Champney-Smith, J., \& Andrews, K. (1991). Primary nursing and the role of the nurse preceptor in changing long-term mental health care: An evaluation. Journal of Advanced Nursing, 16, 413-422.

Atweh, B., Kemmis, S., \& Weeks, P. (Eds.). (1998). Action research: Partnerships for social justice in education. London: Routledge.

Avenyard, H. (2002). The requirement for informed consent prior to nursing care procedures. Journal of Advanced Nursing, 37(3), 243-249.

Bailey, R., \& Clarke, M. (1989). Stress and coping in nursing. London: Chapman and Hall.

Bandman, E.L., \& Bandman, B. (1995). Critical thinking in nursing ( $2^{\text {nd }}$ ed.). East Norwalk: Appleton \& Lange.

Bay, E., \& Algase, D. (1999). Fear and anxiety: A simultaneous concept analysis. Nursing Diagnosis, 10(3), 103-111.

Bazley, M. (1985). Maori health: A real need for understanding. The New Zealand Nursing Journal, January: 5-8.

Benner, P., \& Wrubel, J. (1989). The primacy of caring: Stress and coping in health and illness. Menlo Park: Addison-Wesley Publishing Company.

Bernhard, L., \& Walsh, M. (1995). Leadership: The key to the professionalisation of nursing $\left(3^{\text {rd }}\right.$ ed.). St Louis: Mosby.

Bjornsdottir, K. (2001). Language, research and nursing practice. Journal of Advanced Nursing, 33(2), 150-158.

Blake, P., Matthews, R., \& Hornibrook, J. (1998). When not to syringe and ear. New Zealand Medical Journal. November, 422-424.

Boutain, D. (1999). Critical language \& discourse study: Their transformative relevance for critical inquiry. Advances in Nursing Science. 21(3), 1-8.

Burgess, M. (1996). A Guide to the Law for Nurses and Midwives ( $2^{\text {nd }}$ ed.). Auckland: Addison Wesley Longman.

Burns, S., \& Bulman, C. (Eds.). (2000). Reflective practice in nursing: The growth of the processional practitioner. ( ${ }^{\text {nd }}$ ed.). London: Blackwell Science Ltd. 
Carr, W., \& Kemmis, S. (1986). Becoming critical: Knowledge and action research. Geelon: Deakin University Press.

Crawford, P., Nolan, P., \& Brown, B. (1995). Linguistic entrapment: medico-nursing biographies as fictions. Journal of advanced Nursing. 22, 1141-1148.

Christensen, J. (1995). Nursing partnership: A model for nursing practice. Wellington: Daphne Brasell Associates Press.

Cowley, S., \& Billings, J. (1999). Implementing new health visiting services through action research: an analysis of process. Journal of Advanced Nursing, 30(4), 965-974.

Crotty, M. (1998). The foundations of social research: Meaning and perspective in the research process. St Leonards: Allen \& Unwin Pty.Ltd.

Dahl, J. (2002, November). Confidence gained. Practice Nurse Newsletter, 3, 7.

Dalai Lama. (2001). The essence of happiness: A guideline for living. Sidney: Hodder.

Dawbin, A. (2001). Competency-based practising certificates. The Practice Nurse, 1(2) 11.

Denzin, N., \& Lincoln, Y. (1994). Handbook of qualitative research. Thousand Oaks: Sage Publications.

Devito, J., O'Rourke, S., \& O'Neil, L. (2000). (New Zealand Edition). Human communication. Auckland: Pearson Education NZ. Ltd.

Dewey, J. (1933). How we think. Chicago: Regnery

Docherty, B. (1996). Nursing in General Practice: A New Zealand Perspective. Christchurch: Barbara Docherty.

Ellis, J.H.M. Kiely, \& J.A. (2000) The promise of action inquiry in tackling organisational problems in real time. Action Research International, Paper 5 Retrieved June 6, 2002 from http://www.scu.edu.au/schools/gem/ar/ari/p-jellis00.html.

Fahy, K. (1996). Praxis methodology: Action research without a group. Contemporary Nurse, 5(2), 54-58.

Fareed, A. (1996). The experience of reassurance: Patients' perspective. Journal of Advanced Nursing, 23, 272-279.

Forchuk, B. (1993). Hiledgard E. Peplau. Interpersonal nursing theory. Newbury Park: Sage Publications.

Foster, H., \& Greenwood, J. (1998). Reflection: A challenging innovation for nurses. Contemporary Nurse, 7(4), 165-172. 
Fox, A. (2001). Nurse-led ear care: Training needs and the latest techniques. Professional Nurse, 17(4), 256-258.

Freire, P. (1972). Pedagogy of the oppressed. England: Penguin Books.

Ghaye, T., \& Lillyman, S. (2000). Reflection: Principles and practice for healthcare professionals. Dinton, Wiltshire: Mark Allen Publishing Ltd.

Gillings, B. (2000). Clinical supervision and reflective practice. In S. Burns \& C. Bulman. (Eds.). Reflective practice in nursing: the growth of the professional practitioner $\left(2^{\text {nd }}\right.$ ed.). (pp. 106-123). London: Blackwell Science Ltd.

Glaze, J. (1998). Reflection and expert nursing knowledge. In C. Johns \& D. Freshwater (Eds.), Transforming nursing through reflective practice. (pp. 151-160). Oxford: Blackwell Science.

Goodman, J. (1984). Reflection and teacher education: a case study and theoretical analysis. Interchange, 15, 192-195.

Greenwood, J. (1993). Reflective practice: A critique of the work of Argyris and Schön. Journal of Advanced Nursing, 19, 1183-1187.

Habermas, J. (1972). Knowledge and human interests. London: Heinemann.

Habiba, M. (2000). Examining consent within the patient-doctor relationship. Journal of Medical Ethics, 26, 183-187.

Hampton, J. (2001). The people's choice. Plastic Surgical Nursing, 21(1), 45-47.

Hanrahan, M. (1998). Academic growth through action research: A doctoral student's narrative. In B. Atweh, K. Kemmis, \& P. Weeks. (Eds.), Action research: Partnerships for social justice in education. (pp. 302-328). London: Routledge.

Hargreaves,J. (1997). Using patients: exploring the ethical dimension of reflective practice in nurse education. Journal of Advanced Nursing, 25, 223-228.

Holloway, I., \& Wheeler, W. (1996). Qualitative research for nurses. London: Blackwell Science.

Holter, I., Schwartz-Barcott, D. (1993). Action research: What is it? How has it been used and how can it be used in nursing. Journal of Advanced Nursing, 18, 298-304.

Holihan, R. (1999). Doing action research in my own organisation: ethical dilemmas, hopes and triumphs. Action Research International, Paper 3. Available on-line:

http://www.scu.edu.au/schools/gcm/ar/ari/p-rholian99.html.

Hutchins, R., \& Adler, M. (Ed.). (1963). Gateway to the great books: 10 philosophical essays. Chicago: William Benton, Publisher. 
Irvine, H. (1998). Professional supervision for registered nurses and midwives. Winston (Churchill Memorial Trust rep.). Wellington: Winston Churchill Memorial Trust Board.

Johnstone, M-J. (2000). Informed consent and the betrayal of patient's rights. Australian Nursing Journal, 8(2), 40-41.

Kemmis, S., \& McTaggart, R. (1998). The action research planner ( $3^{\text {rd }}$ ed.). Geelong: Deakin University Press.

Kilgour, C., \& Fleming, V. (2000). An action research inquiry into a health visitor parenting programme for parents of pre-school children with behaviour problems. Journal of Advanced Nursing, 32(3), 683-688.

Kim, H. (1999). Critical reflective inquiry for knowledge development in Nursing practice. Journal of Advanced Nursing. 29(5), 1205-1212.

Kirrane, C. (2001). Using action learning in reflective practice. Contemporary Nurse, 16(5), 1102-1105.

Lewin, K. (1946). Action research \& minority problems. Journal of Social Issues, 2, 3436.

Lindsey, E., \& McGuinness, L. (1998). Significant elements of community involvement in participatory action research. Journal of Advanced Nursing, 28(5), 11061114.

Locke, J. (1952/1690). Concerning human understanding. In R. Hutchins (ed.), Chicago: William Benton. (pp. 83-395).

Macaulay, E., Commanda, L., Freeman,W., Gibson, N., McCabe, M., Robbins, C., \& Twohig, P. (1999). Participatory research maximises community and lay involvement. British Medical Journal, 31, 774-778.

McBain, S. (2000). The mastership game. London: Harper Collins.

Meyer, J. (1993). New paradigm research in practice: the trials and tribulations of action research. Journal of Advanced Nursing, 18, 1066-1072.

Mepham, S., Tripp, C., Ganes, E., \& Brunnock, E. (2000). Using action research to improve cardiac care. Professional Nurse, 15(11), 719-722.

Minichiello, V., Sullivan, G., Greenwood, K., \& Axford, R. (1999). Handbook for research methods in health sciences. Sydney: Addison Wesley Longman, Australia Pty.

Ministry of Accident Insurance, (1992). Accident rehabilitation and compensation insurance act. Wellington: Author.

Ministry of Health, (2002). Immunisation handbook 2002. Wellington: Author. 
Mitchell, M. (2000). Nursing intervention for pre-operative anxiety. Nursing Standard, May 31-June 6, 40-45.

Montgomery, C. (1993). Healing through communication: The practice of caring. Newbury Park: Sage Publications.

Nelson Division of the New Zealand College of Practice Nurses NZNO. (2002). Guidelines for practice nurses. Nelson: Author.

New Zealand Nurses Organisation. (2001). College of Practice Nurses NZNO Job Description. Wellington: Author.

New Zealand Nurses Organisation. (1995). Code of ethics. Wellington: Author.

New Zealand Nurses Organisation. (2001). Practice nurse standards. Wellington: Author.

New Zealand Nurses Organisation. (2001). Standards for nursing practice. Wellington: Author.

Niven, N. (1994). Health psychology: An introduction for nurses and other health professionals. ( $2^{\text {nd }}$ ed.). Edinburgh: Churchill Livingstone.

Nordgren, S. \& Fridlund, B. (2001). Patients' perceptions of self-determination as expressed in the context of care. Journal of Advanced Nursing, 35(1), 117-125.

Norred, C. (2000). Minimising pre-operative anxiety with alternative caring-healing therapies. Association of Operating Room Nurses, 72(9), 838-843.

Nursing Council of New Zealand. (1995). Code of conduct for nurses and midwives. Wellington: Author.

O'Brien, M. (2002). Mastering your risk. Cognitive Institute. Milton, Australia: Cognitive Institute.

Otago Division of the New Zealand College of Practice Nurses NZNO. (1998). Telephone guidelines. Dunedin: Author.

Park, P. (1999). People, knowledge and change in participatory action research. Management Learning, 30(2), 177-187.

Parmee, R. (1996). Living and working with asthma: A dynamic interplay. Nursing and Midwifery. Wellington: Victoria University of Wellington.

Parse, R. (1981). Man-living-health: A theory of nursing. New York: Wiley.

Payne, S., \& Walker, J. (1996). Psychology for nurses and caring professionals. Buckingham, UK: Open University Press. 
Peplau, H. (1952/1988). Interpersonal relations in nursing. London: MacMillan Education Ltd.

Peter, E., \& Morgan, K. (2001). Explorations of a trust approach for nursing ethics. Nursing Inquiry, 8, 3-10.

Pierson, W. (1998). Reflection and nursing education. Journal of Advanced Nursing, 27, 165-170.

Price, J. (1997). Risk management: A survey of ear syringing claims. Practice Nursing, July, 10-13.

Reid, B. (2000). The role of the mentor to aid reflective practice. In S. Burns \& C. Bulman. (Eds.). Reflective practice in nursing: The growth of the professional practitioner ( $2^{\text {nd }}$ ed.). (pp. 79-105). London: Blackwell Science Ltd.

Rogers, J., \& Niven, E. (1996). Ethics: a guide for New Zealand nurses. Auckland: Addison Wesley Longman.

Rogers, S. \& Palmer-Erb, V. (1994). Participatory action research: Implications for research and evaluation in psychiatric rehabilitation. Psychosocial Rehabilitation Journal, 18(2), 3-12.

Schön, D. (1983). The reflective practitioner. New York: Basic Books.

Sherman, K. (1994). Communication and image in nursing. New York: Delmar Publishers Inc.

Street, A. (1991). From image to action: Reflection in nursing practice. Geelong: Deakin University Press.

Street, A. (1995). Nursing replay: Researching nursing culture together. Melbourne: Churchill Livingstone.

Swanson, G., Newcomb, T., \& Hartley, E. (1952). Group decisions \& social change. New York: Holt.

Szeto, C. \& Yung, P. (1999). Introducing a music programme to reduce pre-operative anxiety. British Journal of Theatre Nursing, 9 (10), 455-458.

Taylor, B. (2000). Reflective practice: A guide for nurses and midwives. St Leonards: Allen \& Unwin.

Taylor, B. (1994). Being human: Ordinariness in nursing. Melbourne: Churchill Livingstone.

The Health \& Disability Commissioner, (1996). Code of health and disability services consumers' rights. Wellington: Government Printing Office. 
Titchen, A., \& Binnie, A. (1993). Research partnerships: Collaborative action research in Nursing. Journal of Advanced Nursing, 18, 858-865.

Turner, D. (2002). When is a practice nurse not a practice nurse? The Practice Nurse. 2(2), 1.

van Hooft, S., Gillam, L., \& Byrnes, M. (1995). Facts and values: An introduction to critical thinking for nurses. Sydney: Maclennan \& Petty.

Wadsworth, Y. (1998). What is participatory action research? Action Research International, paper 2. Retrieved September 19, 2002 from http://www.scu.edu.au/schools/sawd/ari/ari-wadsworth.html.

Wadsworth, Y., \& Epstein, M. (1998). Building in dialogue between consumers \& staff in acute mental health services. Systematic Practice and Action Research, 11(4), 354379.

Waterman, H., Webb, C., \& Williams, A. (1995). Parallels \& contradictions in the theory and practice of action research \& nursing. Journal of Advanced Nursing, 22, 779784.

Watson, J. (1985). Nursing: The philosophy and science of caring. Bolder: University Press of Colorado.

Webb, C. (1998). Action research: Philosophy, methods and personal experience. Journal of Advanced Nursing, 14, 403-410.

Weil, S. (1998). Rhetorics and realities in public service organisations: Systemic practice and organisational learning as Critically Reflexive Action Research (CRAR). Systemic Practice and Action Research, 11(11), 37-62.

Willis, E., Congdon, J., \& Litt, J. (1998, June). Working Relationship between Practice Nurses and General Practitioners in Australia: A critical analysis. Paper presented to the $9^{\text {th }}$ annual international Critical and Feminist Perspectives in Nursing conference, Adelaide.

Zuber-Skerritt, O. (1992). Action research in higher education: Examples and reflections. London: Kogan Page Limited. 